\title{
Job Polarization, Skill Mismatch and the Great Recession
}

\author{
Riccardo Zago $^{1}$
}

February 2020, WP 755

\begin{abstract}
This paper shows that job polarization has a persistent negative effect on employment opportunities, labor mobility and skill-to-job match quality for mid/low-skilled workers, in particular during downturns. I introduce a model generating an endogenous mapping between skills and jobs, that I estimate to match solely occupational dynamics during the Great Recession, a major episode of polarization in the US economy. Yet, this is sufficient for the model to replicate well the reallocation patterns of all workers on the job ladder and the mismatch dynamics observed in the data. Comparison with the planner solution reveals that $1 / 4$ of mismatches is efficient and attenuates polarization and unemployment over the cycle.
\end{abstract}

Keywords: Job Polarization, Business Cycle, Job Quality, Skill Demand.

JEL classification: E24, E32, J21; J24; J62, O33.

\footnotetext{
${ }^{1}$ Directorate of microeconomic and structural analysis. riccardo.zago@,banque-france.fr.

I thank Zsofia Barany, Sergei Guriev, Etienne Wasmer for their support and advice. I also thank David Autor, Jess Benhabib, Richard Blundell, Tito Boeri, Thomas Chaney, Nicolas Coeurdacier, Assia Elgouacem, Priscilla Fialho, Stéphane Guibaud, Jean-Olivier Hairault, Marcel Jansen, Pawel Krolikowski, Guido Menzio, Claudio Michelacci, Rachel Ngai, Cecilia Garcia-Penalosa, Tommaso Porzio, Fabien Postel-Vinay, Xavier Ragot, JeanMarc Robin, Anna Salomons, Jeff Smith, Joanne Tan, Gianluca Violante, Francesco Zanetti and seminar participants at Sciences-Po, New York University, Paris School of Economics, Collège de France, ECB/CEPR Labour Market Workshop, SOLE 2016 Annual Meeting, the ZEW 2016 International Conference on Occupations, Skills and the Labor Market for helpful comments and suggestions. All errors remain mine.
}

Working Papers reflect the opinions of the authors and do not necessarily express the views of the Banque de France. This document is available on publications.banque-france.fr/en 


\section{NON-TECHNICAL SUMMARY}

Job polarization is a well-known feature of the U.S. labor market: routine jobs have been disappearing in the long-run and job destruction is mostly concentrated in routine occupations during downturns. Yet, little is known about the effects of job polarization on the reallocation of skills across jobs and on the demand for skills across jobs. In other words, we do not know much about how skill-heterogeneous agents use the job ladder when the market polarizes, what job opportunities they have, and which skills employers are looking for in this context. This paper aims to fill the gap in the literature.

By exploiting a quantitative model replicating the long and short-run dynamics of job polarization in the US from 2005 onwards, this paper shows that this phenomenon and the business cycle interact and have heterogeneous effects on high and low-skilled workers, on their labor mobility and employability, and on the quality of skill-to-job matches formed on the labor market. In fact, the model gives avidence that the disappearance of routine jobs during the Great Recession (GR) triggered large movements from the top to the bottom of the job ladder. Workers -despite their education and experience- moved down the ladder and accepted lower paying and lower qualifying jobs. However, the dynamics of mismatch between skills and occupations is very different across workers. For example, high-skilled workers tend to move down the ladder -mostly from abstract to routine job- only during the downturn, but they climb up the ladder again once the economy recovers. In other words, they use the job ladder in a procyclical fashion, and their mobility and skill-to-job match quality is only temporarily compromised. This is not true for low-skilled workers. In fact they move down the ladder -from routine to manual jobs- but they do not climb it up afterwards. This happens because the downturn permanently destroys routine occupations, thus reducing dramatically the job opportunities of these workers. At the same time, their low level of skills prevent them to upgrade to top jobs in the next expansion. Consequently, also their labor mobility is permanently compromised. These downgrades generate wage-losses over the life cycle that are small and temporary for high-skilled workers, but large and extremely persistent for low-skilled workers. In fact, high-skilled workers benefit from wage compression when moving down the ladder such that their wage-loss results bounded. Conversely, the more a low-skilled workers move down the ladder the larger the wage-loss will be. Altogether these results shed light on inequality in labor mobility, job opportunities and wages in the context of job polarization.

The paper also shows how a social planner would optimally manage the allocation of skills both in the long-run and over the cycle in the context of job polarization. In the long-run, the efficient allocation of skills would be such that no skill-to-job mismatch occurs and polarization accelerates. In fact, it would be efficient for the economy to relocate workers from the shrinking and low-productivity routine market to other markets as fast as possible. However, during downturns, the interaction between polarization and the business cycle generates huge welfare losses due to routine job destruction and higher and more persistent unemployment. In this case, the social planner would operate to protect more routine workers and would tolerate some skill mismatch if helpful to keep more routine jobs alive. 
Employment Mismatch Dynamics during the Great Recession in the US

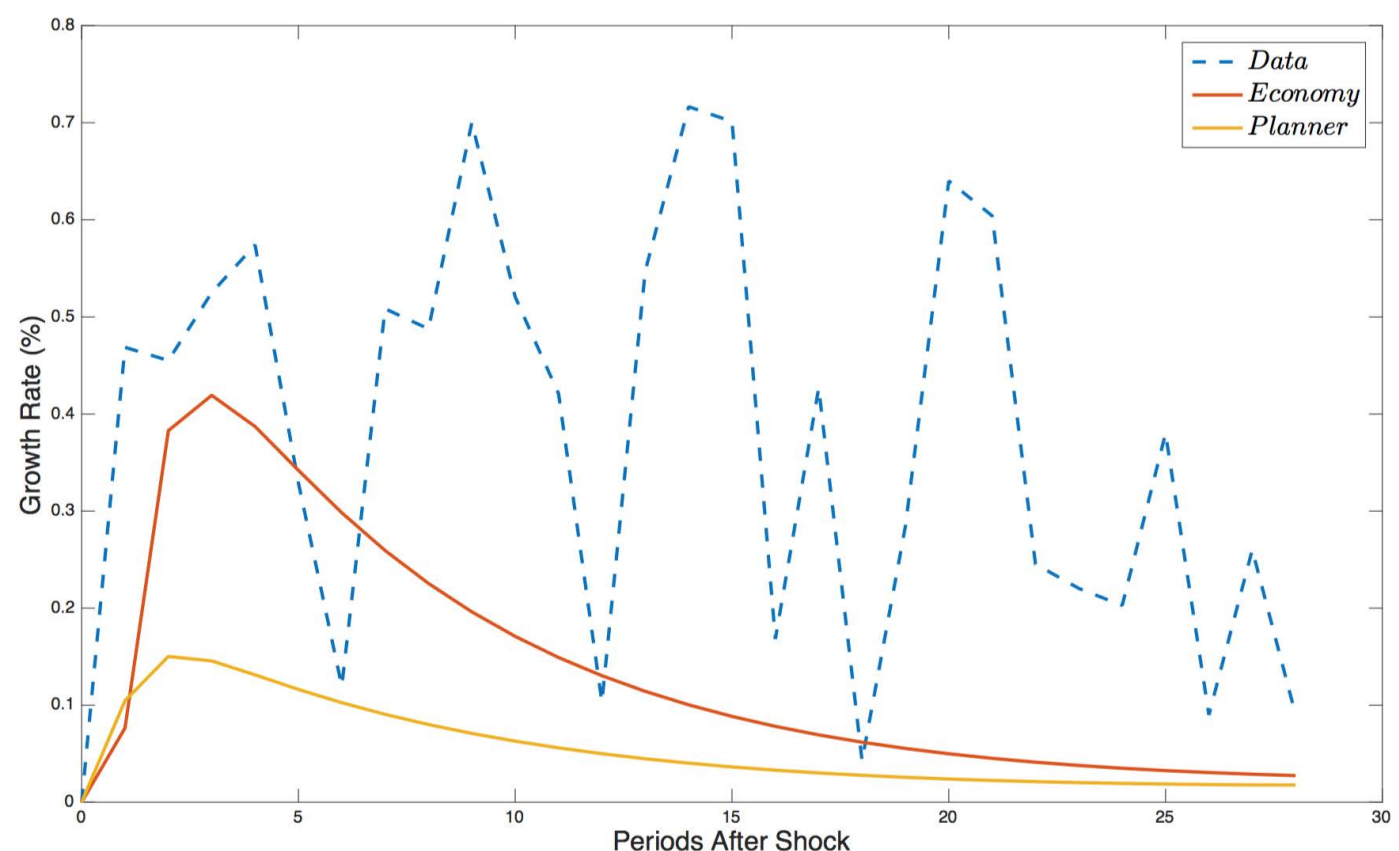

Note: This figure plots the growth rate of employment mismatch -i.e. the employment rate of workers not matched to the job most in line with their skills- from the beginning of the Great Recession (2008Q1) onward in the US labor market. The time series in red is for transitional dynamics under the market solution. The time series in yellow is for transitional dynamics under the social planner solution. The time-series in dashed blue is from the data.

\section{Polarisation du marché du travail, mauvaise allocation des compétences et Grande Récession}

\section{RÉSUMÉ}

Cet article montre que la polarisation du marché du travail a un effet négatif persistant sur les opportunités d' emploi, la mobilité de la main-d'œuvre et la qualité de l'allocation des compétences aux emplois pour les travailleurs moyennement ou peu qualifiées, en particulier en période de crise économique. J'introduis un modèle générant une correspondance endogène entre les compétences et les emplois, que j'estime pour reproduire uniquement la dynamique de l'emploi pendant la Grande Récession, un épisode majeur de polarisation dans l'économie américaine. Cela suffit pour que le modèle reproduise bien les motifs de répartition de tous les travailleurs sur l'échelle de l'emploi et la dynamique de mismatch observée dans les données. La comparaison avec la solution du planificateur central révèle qu'un quart du mismatch est efficace et atténue la polarisation et le chômage au cours du business cycle.

Mots-clés: Polarisation de l'emploi, cycle économique, qualité de l'emploi, demande de compétences.

Les Documents de travail reflètent les idées personnelles de leurs auteurs et n'expriment pas nécessairement la position de la Banque de France. Ils sont disponibles sur publications.banque-france.fr 


\section{Introduction}

Job polarization is a well-known feature of the U.S. labor market: routine jobs have been disappearing in the long-run and job destruction is mostly concentrated in routine occupations during downturns. Yet, little is known about the effects of job polarization on the reallocation of skills across jobs and on the demand for skills across jobs. In other words, we do not know much about how skill-heterogeneous agents use the job ladder when the market polarizes, what job opportunities they have, and which skills employers are looking for in this context. These questions are fundamental for a deeper comprehension of this phenomenon, particularly in light of the dynamics of the U.S labor market during the Great Recession (GR). De facto, this was a major episode of polarization in which the occupational structure permanently shifted towards non-routine jobs. However, at the same time, the labor market also experienced a fall in labor mobility, and abnormal movements of workers from the top to the bottom of the job ladder along with a decay of skill-to-job match quality. In fact, workers -despite their education and previous experience- moved down the vertical ranking of occupations and ended up in jobs for which they were overqualified and paid less than their potential (I refer to this concept as skill mismatch). Given this evidence, this paper contributes to the literature first by showing that the disappearance of routine jobs and the change in the skill-demand across jobs explain well longer unemployment spells and sluggish labor mobility of workers from the mid/low-range of the skill distribution. Second, it shows that job polarization accounts well for the rise of skill-to-job mismatch, with dynamics and costs from mismatch varying a lot over the skill distribution. Finally, it also demonstrates that not all mismatches are inefficient in this context. For example, having some overqualified employees in the disappearing routine sector helps routine employers to keep those jobs alive.

To do so, I propose a search-and-matching model with skill-heterogeneous agents and three types of jobs differing in technology and (endogenous) skill-requirements. Under this set-up, the model generates an endogenous mapping between jobs and skills such that I can track workers and their allocation of skills across occupations over time, and know whether they have better job opportunities given their skill-level. The model predicts long-run polarization under a routine biased technical change (RBTC) trend, and "cyclical polarization" when the economy is hit by a transitory aggregate shock. Hence, I estimate the structural parameters of the model to match solely occupational dynamics for periods around the GR, and show that this estimation procedure is sufficient to explain well the different reallocation patterns of high-skilled and low-skilled workers on the job ladder and the skill-to-job mismatch dynamics observed in the data. 
In particular, the model predicts that $1 \mathrm{pp}$ decline in routine employment leads to a rise in skill mismatch by $0.18 \mathrm{pp}$ (0.31pp in the data). Over the cycle, skill mismatches widen, are mostly concentrated in the economic recovery and are explained by movements from the top to the bottom of the ladder, i.e. workers move down the vertical ranking of jobs from high to low productivity occupations. Such movements are due to the shift of the occupational structure, changes in workers' job opportunities and adjustments in the skillrequirements across jobs. Yet, the use of the ladder differs a lot across skill-groups during the downturn. In fact, when the economy is hit by a negative transitory shock and the labor market polarizes, high-skilled workers are mismatched only temporarily to lower-paying jobs, i.e. they typically move from abstract to routine (clerical) jobs in bad times, but they climb up the ladder when the economy goes back to its expansion path. On the contrary, the bulk of low-skilled workers are mismatched permanently or remain unemployed for longer since their mobility is constraint by their skill-level and their employment opportunities are critically reduced due to job polarization. In fact, these workers typically move from routine to manual jobs in bad times, but they stay there afterward since routine occupations are not rebuild when the economy expands again. Consistently with the data, the model shows that the wage loss from mismatch is decreasing in skills and is bounded for high-skilled workers due to their higher return to skills, higher mobility and broader job opportunities.

If a social planner had to take action during the downturn, the cyclical features of job polarization would be dramatically attenuated and skill mismatch reduced. In fact, the planner would do anything possible to keep routine jobs alive in order to preserve the welfare of routine workers, which have the biggest weight in the welfare function, and protect them from unemployment and mismatch. This is possible by reducing the size of other segments of the labor market and by bringing more overqualified and productive workers into the routine market. This mechanism allows routine employers to better cope with the negative shock through a more productive work-force such that massive job destruction is avoided. Therefore, $1 / 4$ of skill mismatch results to be efficient under the social planner.

To conclude the theoretical part, I show that the implied changes in skills demand across occupations, the scarcity of higher skills in the economy and labor market frictions endogenously generates a fall of aggregate matching efficiency. Thus, the model is able to rationalize $38 \%$ of the shift-out of the Beveridge curve in the post-recession era, a feature not much exploited in quantitative frameworks.

In the second part of the paper, I validate the aggregate predictions of the model within local labor markets. In particular, I exploit individual and State-level data and show that the way high and low-skilled workers use the job ladder within local markets is qualitatively similar to what observed in the aggregate. Moreover, I show that the probability of being 
mismatched peaks during the local economic recovery and is higher if the local market has experienced faster polarization during the recession, i.e. if it has destroyed more routine jobs relative to others. The result is in line with the theory: for local markets that experienced $1 \mathrm{pp}$ increase in polarization during the recession, high-skilled workers are 3pp more likely to temporarily downgrade into routine jobs while low-skilled workers are 2pp more likely to permanently downgrade into manual jobs in the upcoming recovery. Such dynamics are mostly explained by women and younger cohorts.

Thereafter, I map the theoretical ranking of skills with individuals' educational attainments and I show what type of education matters the most and during which cyclical phase for unemployed individuals to find a job. The analysis suggests a rise of skill-requirements in abstract and routine jobs in bad times and an increase of the median skill-level within occupation. For example, during recession periods, a Master $/ \mathrm{PhD}$ degree gives $12 \%$ more chances to get an abstract job than a bachelor degree and $20 \%$ more than a high school diploma, while the difference attenuates once the recession is over. On the contrary, individuals with some college or a vocational degree have almost $6 \%$ more chances to get a routine job than individuals with only a high school diploma, but transition probabilities never go back to pre-recession levels for the routine market. This corroborates the idea that the effects of the recession in the abstract market are only temporary, while very persistent in the routine market. Finally, I analyze skill returns, occupational and skill premia and show that the data and the model are close in their predictions: the more skilled an individual is, the more bounded his wage loss will be when moving down the ladder.

These results altogether shed light on the role of skills in a world in which technological change and the business cycle are so rapidly reshaping both the occupational ladder and the demand for skills across jobs. At the same time, they reveal the key role of labor market frictions and asymmetric occupational dynamics in explaining the reallocation patterns of skills and the process of skill-to-job mismatch in the economy. Therefore, under this angle, the paper has relevant policy implications concerning firms' incentives to change workforce skill composition, training programs subsidization, welfare implications for optimal allocation of skills, efficiency, and labor mobility. It is not a case that, in recent years, these have become major topics in the U.S political agenda as in many other developed countries.

Related Literature - This work builds on three strands of literature. The first one is on job polarization, which documents the long-run falling of employment and wages in jobs with a high content of routine tasks (among the many, see Acemoglu (2002), Autor, Katz, and Kearney (2006), Goos and Manning (2007) and Acemoglu and Autor (2011)). In this literature, this phenomenon is mostly explained by technological change: new and cheaper 
technologies allows substitution of man-work with machines in performing routine tasks (see Autor, Levy, and Murnane (2002), Autor (2007), Autor et al. (2010) and Autor and Dorn (2013)) thus causing the long-run decline of routine employment. The model of this paper relies on technical change to generate long-run polarization, but it completely abstracts from the second source of polarization usually cited in the literature: international trade. In fact, trade and offshoring allow respectively to substitute home routine productions with imports and to move routine activities in countries with lower labor costs (see Autor, Dorn, and Hanson (2013) and Autor, Dorn, and Hanson (2015)) so to trigger the decline of home routine employment. Yet, job polarization has also a short-run counterpart (see the left-panel of Figure 1 for the GR): as explained in Jaimovich and Siu (2012), it accelerates in recessions and leads to jobless recoveries. In fact, during downturns, the bulk of job-destruction occurs in the routine market but, differently from other occupations, routine employment never goes back to pre-recession levels. The model of this paper internalizes this cyclical feature of job polarization by introducing a temporary aggregate shock to the economy that diffuses unevenly across segments of the labor market.

The second strand of literature is on the cyclical reallocation of workers on the job ladder. McLaughlin and Bils (2001), Carrillo-Tudela and Visschers (2013) and Haltiwanger, Hyatt, and McEntarfer (2015) show that workers tend to move to higher-paying occupations during expansions and lower-paying occupations during recessions and that efficiency in labor factor allocation is procyclical. The same fact is observed when considering a job ladder with occupations vertically ranked by productivity and skill-requirements. As documented in Davis and von Wachter (2011), Jarosch (2014), Huckfeldt (2016) and Krolikowski (2017), workers losing their jobs during a recession move down the vertical ranking of occupations (see the right-panel of Figure 1, which displays the marginal probability to move down the ladder -after displacement- for cyclical phases around the GR). This is usually explained with human capital devaluation: when a worker is displaced, he experiences a deterioration of skills so that he no longer qualifies for his previous job and must search for new opportunities down the ladder. This mechanism affects individual career paths and salary dynamics since the wage loss from moving down the ladder is very persistent over time and has a strong negative impact on the life-cycle. However, in these papers, there is no skill-to-job match quality deterioration because of human capital devaluation and direct search. In other words, there is no overqualified worker in lower qualifying and lower-paying jobs, and the allocation of skills is always efficient. The model of my paper takes into account changes in skill demand across jobs and assumes also the existence of a vertical ranking of occupations, but do not consider any skill-loss after an unemployment shock. Instead, it allows workers to diversify their job-search across different segments of the labor market while maintaining 
Fig. 1. Job Polarization, Vertical Downgrading and the Great Recession
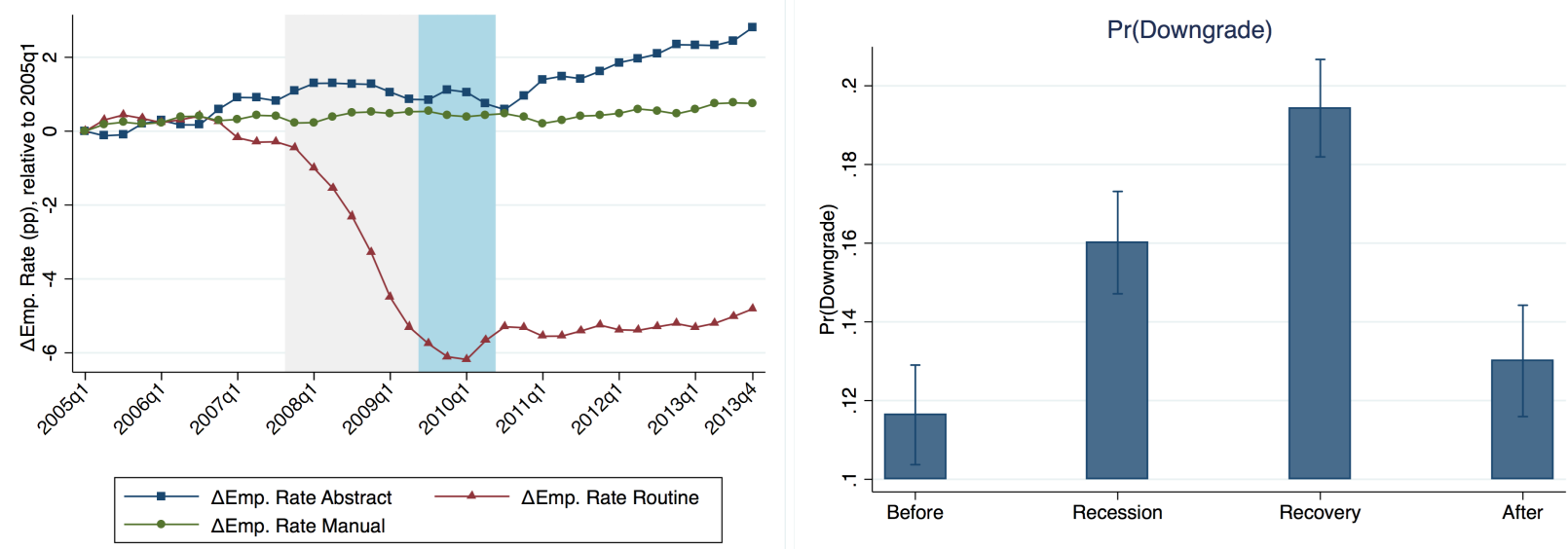

Note: The left-hand side plots the change in the employment rate for abstract, routine and manual jobs relative to $2005 \mathrm{q} 1$ (jobs are classified following Acemoglu and Autor (2011)). The grey and green shaded areas indicate respectively recession and recovery periods as defined by the NBER. Data is at quarterly frequency. The right-hand side plots the unconditional probability for a worker to move down the vertical ranking of occupations after exogenous job displacement (see Huckfeldt (2016) for details). I plot this probability for each cyclical phase before and after the GR, in accordance with the definition of recession and recovery from the NBER.

their skill-level constant over time. By doing so, I can evaluate match quality, track skill mismatched workers in the economy and account to which extent skill mismatch is efficient. Therefore, this work bridges the literature on job polarization with the literature on the cyclical reallocation of workers, match quality and efficiency. This represents a novelty since the few works on labor reallocation in the context of job polarization are under a long-run perspective (see Cortes, Jaimovich, Nekarda, and Siu (2014) and Cortes (2016)), preclude from the business cycle and do not consider workers by their skills, nor jobs by their different demand for skills. Hence, this paper is an advancement since it studies how the business cycle and the shift in the occupational structure interact and explain workers' reallocation on the job ladder and skills-to-job match quality.

The third strand of literature is on the collapse of aggregate matching efficiency in the post GR era. In fact, post-recession years were characterized by a very persistent fall in the job-filling rate and high and persistent unemployment rate. This generated a large shift-out of the Beveridge curve. Şahin, Song, Topa, and Violante (2014), Barlevy (2011), Barnichon and Figura (2011), Davis, Faberman, and Haltiwanger (2013) already address this issue. However, these are mainly compositional studies: they use a theoretical framework to impute which sector, industry, geography or occupation explains the shift-out of the curve for the most. The model of this paper endogenously generates such a shift out and reveals what variables are key to explain this phenomenon.

The paper is organized as follows: Section 2 and 3 describe the model and its estimation; Section 4 discusses model predictions, fit with the data and comparison with the social 
planner solution; in Section 5, I validate the aggregate predictions of the model and its basic mechanics within local labor market (in reduced form). Section 6 concludes.

\section{The Model}

In this section I develop a model of job polarization with endogenous skill-requirements, skill-dependent job opportunities and multiple occupations. This model combines elements of a Diamond-Mortensen-Pissarides ${ }^{1}$ search and matching framework with the model of crossskill mismatch as in Albrecht and Vroman (2002), and it reconciles results from other works on RBTC and polarization as in Jaimovich and Siu (2012), Acemoglu (2002), Acemoglu and Autor (2011).

Here, I imagine a world inhabited by a continuum of skill-heterogeneous workers and a segmented labor market with three jobs differing in technology, (endogenous) skill-requirements, subject to a long-run process of RBTC and exposed to a temporary aggregate shock. In each period, given the state of the economy and the process of technical change, firms decide how many vacancies of each type to post and the minimum skill-requirement necessary for a candidate to suit the position. Skill-requirements partition the job opportunity space of the worker and define the subset of jobs for which he is qualified. Then, the worker directs his search onto this subset only and randomizes over it. This generates different patterns of sorting depending on the worker position on the skill distribution, the state of the economy and the process of technical change, which jointly affect vacancy posting across occupations and the size of labor market frictions. When matched, a worker combines his own skills with a technology such that the job-specific return to skills and the set of job opportunities available to the individual jointly define the wage under Nash bargaining. Under these assumptions, the economy allows different types of workers to mix into the same occupation and delivers a nontrivial skill-pooling equilibrium within jobs, as observed in the data.

More interestingly, when a negative and transitory shock hits the economy, job polarization accelerates, with routine employment falling permanently. This causes hyper congestion at the entry of the abstract and manual market and therefore more persistent unemployment dynamics. Moreover, the shock causes a rise of skill-requirements which reshape the individual job opportunity set and the scope of the search for a large share of the population. Such mechanisms trigger the key result of the model: countercyclical skill-requirements, congestions and the ongoing RBTC lead to larger movements from the top to the bottom of the ladder and larger skill-to-occupation mismatches ${ }^{2}$ with workers coming from the right tail

\footnotetext{
${ }^{1}$ See, for example, Mortensen and Pissarides (1994) and Diamond (1982).

${ }^{2}$ From now onward, I use the word "mismatch" to describe the condition that sees a worker not sorted
} 
of the skill-distribution ending up into lower-paying jobs. This effect exacerbates from the half-life of the shock onwards, when the economy starts to converge to its long-run path, i.e. during the economic recovery. The dynamics of the model mimic fairly well those observed in the data: high-skilled workers move down the ladder during the recovery but go up to abstract jobs afterward (because routine jobs keep on being destroyed in the long-run), whereas the bulk of low-skilled workers are permanently mismatched to manual jobs because they are not skilled enough to enter the abstract market and are no longer demanded in the routine market due to the ongoing RBTC process and the consequent shrinking of that segment.

\subsection{Set $U p$}

Time is discrete with an infinite horizon. There is a unitary mass of workers who exhibit linear preferences over the consumption good, supply labor at the extensive margin only and discount the future by a factor $\beta<1$. Each worker is characterized by a skill-level $x$ that defines his position over a uniform distribution $U_{[0,1]}$. The skill-level $x$ must be thought as an endowment inherited from previous (not modeled) educational choices such that agents' position in the skill distribution cannot change over time. In every period, the worker can be either employed in an abstract (a), routine (r), manual (m) job or be unemployed. Jobs are defined by a technology $z_{j}$ with $j=\{a, r, m\}$, and firms post vacancies $v_{j}$ for each type of occupation.

\subsection{Routine Biased Technical Change and Exogenous Aggregate Shocks}

As in Jaimovich and Siu (2012), the long-run disappearance of routine vacancies and employment is entirely due to a fall in productivity in routine jobs, i.e. routine biased technical change (RBTC). Here, I assume that abstract and manual technologies are expected to be constant over time, whereas routine technology follows a deterministic trend for some periods $T$ and thereafter stays constant. ${ }^{3}$ On top of the deterministic component, an aggregate shock hits the economy. The source of the shock comes from a stochastic process that asymmetrically affects each job-specific technology. Given these assumptions, the technological

with the best technology available in his job opportunity set.

${ }^{3}$ This leads to stationarity in the long-run so that the model can be solved backward. See Online Appendix A.2 for further discussion. 
process pervading the economy is:

$$
z_{j, t}=\bar{z}_{j}+\sigma_{j} \epsilon_{t}, \forall t>0, j=\{a, m\} \quad ; \quad z_{r, t}= \begin{cases}z_{r, 0}\left(1+g_{z_{r}}\right)^{t}+\sigma_{m} \epsilon_{t} & , \forall t \in[0, T] \\ z_{r, T}+\sigma_{m} \epsilon_{t} & , \forall t>T\end{cases}
$$

where $\bar{z}_{j}$ is the productivity parameter for job $j=\{a, m\}, z_{r, 0}$ is the initial productivity level in routine jobs at $t=0, g_{z_{r}}<0$ is the growth rate for the trend in routine technology, $\sigma_{j}$ is the parameter governing the impact of the aggregate shock $\epsilon$ on technology $z_{j}{ }^{4}$ The shock follows a first-order Markov process of the form

$$
\epsilon_{t}=\rho \epsilon_{t-1}+\nu_{t}
$$

where $\rho$ is the parameter governing the persistence of the shock and $\nu \stackrel{\text { i.i.d }}{\sim} N(0,1)$.

\subsection{Production, Skill-Requirements and Vacancies}

Firms mix workers' skills and technology according to three different production functions: 5

$$
y_{a}\left(x ; z_{a}\right)=z_{a} x^{\lambda_{a}} ; y_{r}\left(x ; z_{r}\right)=z_{r} x^{\lambda_{r}} ; y_{m}\left(x ; z_{m}\right)=z_{m}
$$

Under this formulation, skills matter only in abstract and routine jobs such that a worker with skill $x$ has a return respectively equal to $\lambda_{a}$ and $\lambda_{r}$ in those markets. On the other hand, manual jobs are skill neutral so that the production depends only on technology. Hence, the value of production from a worker with skill-level $x$ is:

$$
J\left(x ; z_{j}\right)=y\left(x ; z_{j}\right)-w\left(x ; z_{j}\right)+\beta \mathbb{E}\left\{s_{j}^{\prime}(x)(1-\delta) J^{\prime}\left(x ; z_{j}^{\prime}\right)+\left[1-s_{j}^{\prime}(x)(1-\delta)\right] V^{\prime}\left(z_{j}^{\prime}\right)\right\}
$$

where $w\left(x ; z_{j}\right)$ is the wage paid to worker $x$ when using a technology $j$, and $s_{j}^{\prime}(x)$ is the probability for worker $x$ to remain qualified for the given job between two consecutive periods. Formally, this survival rate for the employee is:

$$
s_{j}^{\prime}(x)=s\left(x, e_{j}^{\prime}\right)=\operatorname{Pr}\left(x \geq e_{j}^{\prime}\right)
$$

\footnotetext{
${ }^{4}$ Under this set up, I am imposing uneven technological growth rates across occupations, similarly to Ngai and Pissarides (2007). Moreover, the response to an aggregate shock is asymmetric across sub-markets, as in Lilien (1982), and in line with the empirical evidence. In fact, as documented by Jaimovich and Siu (2012), in the last two recession routine jobs were destroyed more than abstract and manual jobs such that the largest employment-to-unemployment flows were from this segment of the labor market.

${ }^{5}$ To avoid heavy notation, from now onwards I wright a variable $\kappa_{t}$ simply as $\kappa$, and $\kappa_{t+1}$ simply as $\kappa^{\prime}$. The same holds for value functions.
} 
where $e_{j}$ is the minimum skill-requirement to work in $j$. In this way, the workforce in job $j$ will always be composed by qualified workers. All individuals that move from being qualified to non-qualified between two consecutive periods are immediately and endogenously displaced. The others remain employed only if they also survive to the exogenous destruction component, here represented by the exogenous separation rate $\delta$.

Abstract and routine employers choose the minimum skill-requirement in order to generate a (weakly) positive value of production. Under this formulation, the entry requirements $e_{a}$ and $e_{r}$ necessary to fill an abstract or a routine vacancy are simply pinned down by the following two reservation conditions: ${ }^{6}$

$$
J\left(e_{a} ; z_{a}\right)=0 ; J\left(e_{r} ; z_{r}\right)=0 .
$$

Once the entry requirements are defined, employers post vacancies by targeting the number of qualified workers in the unemployment pool. Therefore, the job creation condition for market $j$ is:

$$
V\left(z_{j}\right)=-c_{j}+\beta \mathbb{E}\left\{p_{j} J^{\prime}\left(x ; z_{j}^{\prime}\right)+\left(1-p_{j}\right) V^{\prime}\left(z_{j}^{\prime}\right)\right\}
$$

where $c_{j}$ is the cost of posting a vacancy $j$ today, $J^{\prime}\left(x, z_{j}^{\prime}\right)$ is the value of production in sub-market $j$ obtained tomorrow when worker $x$ matches today. Vacancies are filled at the rate

$$
p_{j}=\psi_{j}\left(\frac{v_{j}}{u_{j}}\right)^{-\alpha}=\psi_{j} \theta_{j}^{-\alpha}
$$

where $\psi_{j}$ is the matching efficiency in submarket $j, \alpha$ is the return on vacancy posting (assumed equal across markets) and $\theta_{j}$ is the job-specific market tightness, i.e. the ratio between the total number of vacancies posted in market $j\left(v_{j}\right)$ and the number of workers qualified for market $j$ currently available in the unemployment pool $\left(u_{j}\right)$.

\subsection{The Job Opportunity Set, Unemployment and Employment Value}

The two skill-requirements partition the skill distribution in subsets such that each individual with skill-level $x$ knows his current job opportunities. Then, he directs his search only to the subset of jobs for which he is qualified and randomizes over it.

Define $\Omega(x)=\left\{j: e_{j} \leq x\right\}$ as the set of job-opportunities available to worker $x$. Then,

\footnotetext{
${ }^{6}$ Since I am assuming that skills matter only for the abstract and routine market, I am implicitly assuming that the requirement to access a manual job is $e_{m}=0$, and $s_{m}(x)=1, \forall x \in[0,1]$.
} 
the value of unemployment for worker with skill-level $x$ is :

$$
U(x ; \boldsymbol{z})=b+\beta \mathbb{E}\left\{\sum_{j \in \Omega(x)} q\left(\theta_{j}\right) N^{\prime}\left(x ; z_{j}^{\prime}\right)+\left[1-\sum_{j \in \Omega(x)} q\left(\theta_{j}\right)\right] U^{\prime}\left(x ; \boldsymbol{z}^{\prime}\right)\right\}
$$

where $b$ is the value of leisure, $q_{j}=\psi_{j} \theta_{j}^{1-\alpha}$ is the arrival rate of a vacancy to the qualified worker in the unemployment pool, $\boldsymbol{z}=\left[z_{a}, z_{r}, z_{m}\right]$ is the vector of all technologies currently available in the job-opportunity set of worker $x . N($.$) is the value of employment and is$ defined as:

$$
N\left(x ; z_{j}\right)=w\left(x ; z_{j}\right)+\beta \mathbb{E}\left\{s_{j}^{\prime}(x)\left[(1-\delta) N^{\prime}\left(x ; z_{j}^{\prime}\right)+\delta U^{\prime}\left(x ; \boldsymbol{z}^{\prime}\right)\right]+\left[1-s_{j}^{\prime}(x)\right] U^{\prime}\left(x ; \boldsymbol{z}^{\prime}\right)\right\} .
$$

From equation (6), it is clear that the value of unemployment for a worker with skill-level $x$ depends on all job opportunities available in $\Omega(x)$ and the respective value of employment. Therefore, the broader the job opportunity set, the higher is the value of unemployment through higher job opportunities.

\subsection{Wage Setting}

Once they meet, employer $j$ and worker $x$ share the surplus generated by the match under Nash bargaining. This leads to the following sharing rule:

$$
\eta\left[J\left(x ; z_{j}\right)-V\left(z_{j}\right)\right]=(1-\eta)\left[N\left(x ; z_{j}\right)-U(x ; \boldsymbol{z})\right]
$$

where $\eta$ is the employer bargaining power. Combining the above value functions with the sharing rule and using the slackness condition $V\left(z_{j}\right)=0$, the wage equation for worker $x$ in job $j$ is:

$$
w\left(x ; z_{j}\right)=(1-\eta) b+\eta y\left(x ; z_{j}\right)+\eta\left\{\sum_{j \in \Omega(x)} c_{j} \theta_{j}\right\} .
$$

Differently from the baseline search and matching model, here the outside option of the worker depends not only on the value of leisure $b$, but also on the number of job opportunities available to the worker. Therefore, the more the individual is skilled, i.e. the larger is his opportunity set, the bigger is his outside option. The value of leisure and the outside option define the intercept of the wage equation in the $(w, x)$-plane, whereas the slope of the curve depends on $y\left(x ; z_{j}\right)$, i.e. on the technology and return to skills in occupation $j$.

Therefore, when an aggregate shock hits the economy, the value of the outside option changes due to the aggregate effects of the shock on the job-specific market tightness $\theta_{j}$ of each submarket available in the worker job-opportunity set $\Omega(x)$, and due to the idiosyncratic 
reshaping of $\Omega(x)$ followed by changes in skill requirements. This leads to a shift in the intercept of the wage equation. On the other hand, changes in the slope of the wage equation are explained only by the effect of the aggregate shock on the job-specific technology $z_{j}$.

\subsection{Employment Dynamics}

Aggregate employment within each occupation $j=\{a, r, m\}$ follows this dynamics:

$$
n_{j}^{\prime}=s_{j}^{\prime}(1-\delta) n_{j}+u_{j} q_{j}
$$

with $s_{j}=\int_{x \geq e_{j}^{\prime}} s\left(x \mid x \geq e_{j}\right) d x$. Equation (9) states that the employment in market $j$ in the next period is equal to the number of workers that remain qualified for the job between two consecutive periods and survive the exogenous separation process, plus the flow from unemployment to employment of new and qualified hires.

The role of $s_{j}$ is fundamental for the amplification and persistence of unemployment dynamics. In fact, a decline in $s_{j}$-a fall in the probability of remaining qualified for job $j$ magnifies the flows from employment to unemployment. Under a negative aggregate shock, this enables the model to reproduce the abnormal displacement rate and employment-tounemployment flows observed at the beginning of the Great Recession and documented in Hall (2010) and Elsby, Hobijn, Şahin, and Valletta (2011). Hence, under this setup, any shock that affects skill-requirements and the endogenous survival rate $s$ has two consequences. First, it has an aggregate effect on labor productivity within each submarket $j$. Second, it has an idiosyncratic impact on individuals' employment uncertainty due to skill heterogeneity such that agents are differently affected depending on their position on the skill distribution and the size of their job opportunity set. ${ }^{7}$ On the other hand, the exogenous separation rate $\delta$ grants that some qualified workers will always join unemployment because of exogenous job destruction.

\subsection{Skill-pooling and Skill-separating Equilibrium}

Say that the skill-requirements $e_{a}$ and $e_{r}$ partition the skill distribution as follows:

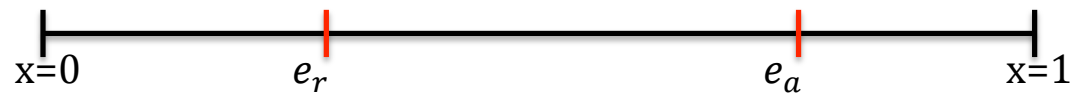

\footnotetext{
${ }^{7}$ The concept of employment uncertainty was recently developed by Ravn and Sterk (2015), but differently from their model -where they generate uncertainty through an exogenous shock on the separation rate $\delta$ here I endogenize the process through productivity shocks.
} 
then, the model delivers two alternative equilibria, both depending heavily on parameterization. Under a skill-separating equilibrium, workers with $x \geq e_{a}$ match only to abstract jobs, workers $x \in\left[e_{r}, e_{a}\right)$ match only to routine jobs and those with $x<e_{r}$ match only to manual jobs, despite the size of the individual job opportunity set. If this happens and -say$z_{m}<z_{r}<z_{a}$, there is no skill mismatch because all individuals on the skill distribution are matched only to the best technology available in their job opportunity set and they are never overqualified for their current job. In other words -if jobs are vertically ranked by technology and there is a separating equilibrium- there is positive assortative matching between skills and technology, with the best workers employed in the most productive jobs.

Alternatively, we can have a skill-pooling equilibrium in which individuals with $x \geq e_{a}$ can match to all jobs, individuals with $x \in\left[e_{r}, e_{a}\right)$ can match not only to routine jobs but also to manual ones, and those with $x<e_{r}$ can match to manual jobs only. If this happens and $z_{m}<z_{r}<z_{a}$, there is not always positive assortative matching of skills and technology and some workers with higher skills are matched to worse jobs. ${ }^{8}$

These alternative equilibria depend on whether specific conditions on the surplus from the match are satisfied. In light of this, I provide a definition and the existence condition of a skill-pooling equilibrium for this economy:

Definition 1. A skill-pooling equilibrium is a vector $\left\{\theta_{j}, n_{j}, w\left(x, z_{j}\right), e_{j}\right\}_{t=0}^{\infty}$ for any $j=$ $\{a, r, m\}$ and $x \in[0,1]$ satisfying simultaneously (3), (5), (8) and (9), i.e. the job creation condition, the minimum requirement condition, the wage equation and employment dynamics.

Condition 1. A skill-pooling equilibrium exists if and only if routine and manual employers find profitable to fill a vacancy with workers coming from different subset of the skill distribution and viceversa. Formally, a skill-pooling equilibrium exists in the routine (manual) market if and only if there is at least a worker $x \in\left[e_{a}, 1\right]\left(x \in\left[e_{r}, 1\right]\right)$ for which the surplus from the match $S\left(x, z_{r}\right) \geq 0\left(S\left(x, z_{m}\right) \geq 0\right)$.

Also Albrecht and Vroman (2002) and Blázquez and Jansen (2008) show the properties and existence conditions of skill-pooling and separating equilibria in a similar but simpler environment, with only two jobs and no endogenous requirements.

\section{Model Estimation}

In this section, I bring the model to the data to assess its ability to fit the long-run trend of job polarization under RBTC and the occupational employment dynamics observed

\footnotetext{
${ }^{8}$ See Online Appendix A.1 for a graphical representation of the skill-separating and skill-pooling equilibrium and further discussion.
} 
around the GR (from 2005q1 to 2015q4) under a transitory aggregate shock. There are several advantages from focusing only on this time window: first of all, it can be easily assumed that the task-content of these major jobs did not change over this period; second, during the GR, job-to-job transitions were small and occurred mostly between sub-categories of jobs within each of the three major occupations used here to define the job ladder; third, reallocation over the three major occupations occurred mostly through unemployment, such that it is not really necessary to further complicate the model by adding on-the-job search.

Data comes from the Current Population Survey (CPS) from which I build employment rates by job. Following the classification of occupations in Acemoglu and Autor (2011), abstract jobs are managerial and professional specialty occupations; routine jobs are technical, sales, administrative support occupations and precision, production craft and repair occupations; manual jobs are service occupations. ${ }^{9}$ Instead of considering a continuum of skills, I reduce the analysis to two major groups only: high-skilled (HS) and low-skilled (LS) workers. According to the International Standard Classification of Education (ISCED), the International Labor Organization (ILO) defines high-skilled workers as those with a bachelor, or a master, or a doctorate degree or professional specialization, while the low-skilled as those with a high school diploma or lower, or a vocational degree or some years of college but no degree (see also Barro and Lee (2000)). Therefore, I use individual educational attainments from the CPS as a sufficient statistic for the theoretical skill distribution, and I identify high and low-skilled workers in the data. Then, I build employment rates series for the two groups across jobs and collect data on average hourly wages of workers by skill-group and job over time.

Under the set-up shown in the previous section, the labeling of these two groups implies the existence of an exogenous and unknown threshold $\gamma \in(0,1)$ in the skill distribution such that workers with $x \geq \gamma$ are high-skilled (low-skilled otherwise). ${ }^{10}$ In other words, $\gamma$ is the minimum skill-level that defines the worker as high-skilled and is equivalent to the skills embedded into a bachelor degree. I leave this parameter $\gamma$ for estimation. Finally, to refine the model without changing any feature of the set-up, I also assume that the share of lowskilled in the population is declining at the quarterly rate $g_{L S}=-1.2 \times 10^{-3}$, consistently with the secular positive trend of tertiary education. ${ }^{11}$ The rest of preset parameters is standard in the literature: $\beta=0.99$ to match quarterly frequencies; the value of leisure $b=0.4$ and the exogenous separation rate $\delta=0.1$ as in Shimer (2005); the employer bargaining power $\eta$

\footnotetext{
${ }^{9}$ See Online Appendix D for further details on data construction.

${ }^{10}$ The existence condition of the skill-pooling equilibrium does not change with this assumption.

${ }^{11}$ The decline of the share of low-skilled workers in the population is measured by fitting a linear trend from 1990 to 2005 (See Online Appendix A.2). Then, I assume that the share of LS workers in the economy declines by $g_{L S}$ each quarter in the model.
} 
and the matching elasticity $\alpha$ are set equal to 0.5. Finally, I set the initial level of the trend of routine technology $z_{0, r}=1$ and leave the other technological levels for estimation. The list of preset parameters is given in Table 1.

Table 1: Preset Parameters

\begin{tabular}{lcc}
\hline \hline Parameter & Description & Value \\
\hline$\beta$ & Discount factor (quarterly) & 0.99 \\
$b$ & Value of leisure & 0.40 \\
$\delta$ & Separation rate & 0.10 \\
$\eta$ & Employer bargaining power & 0.50 \\
$\alpha$ & Matching elasticity & 0.50 \\
$g_{L S}$ & Growth of LS pop. Share & $-1.2 \times 10^{-3}$ \\
$\mathrm{z}_{r, 0}$ & Technology in routine jobs & 1 \\
\hline \hline
\end{tabular}

The remaining 16 unknown parameters are estimated via simulated method of moments ${ }^{12}$ and are used with two purposes. A first subset of parameters $\left(z_{a}, z_{m}, c_{j}\right.$ and $\psi_{j}$ for $j=$ $\left.\{a, r, m\},{ }_{a}, \lambda_{r}, \gamma\right)$ allows to characterize the labor market at an initial point in time (2005q1) by matching aggregate employment in the three jobs, the mean share of high-skilled workers in each occupation and in the unemployment pool, the mean ratio of routine wage over abstract wage and manual wage over abstract wage by skill-group at that period. The second subset of parameters $\left(g_{z_{r}}, \sigma_{j}\right.$ for $\left.j=\{a, r, m\}, \rho\right)$ allows to reproduce the evolution of the economy from 2005 q1 onward by matching the secular decline of routine employment ${ }^{13}$, the employment change in the three occupations between the peak and trough of the $\mathrm{GR}^{14}$ and the first-order auto-correlation of unemployment. Hence, there are 16 moments for 16 unknown parameters. The list of targeted moments with model and data values is given in Table 2 while the list of estimated parameters is given in Table 3.

First of all, the estimation confirms the existence of a vertical ranking of technologies. At the initial time, abstract jobs are $8 \%$ more productive than routine jobs and $46 \%$ more than manual jobs. Since high-skilled workers are only $(1-\gamma) \%=27 \%$ of the population $(28 \%$ in the data) at the starting point and they potentially search in all markets, the matching efficiency $\psi_{a}$ is the highest. This increases the probability for abstract employers to meet highly qualified workers first and allows the model to match well the share of high-skilled

\footnotetext{
${ }^{12}$ I use a simulated annealing algorithm with four different starting parametrizations. After 50000 iterations, the algorithm converges to the same set of unknown parameters that minimize the loss function. See Online Appendix A.2 for further details on the estimation.

${ }^{13}$ The long-run growth rate of routine employment is measured by fitting a linear trend of the log of routine employment from 1990 to 2005. See Online Appendix A.2 for further details.

${ }^{14}$ I study the evolution of abstract, routine a manual employment by taking the percentage change in the employment rate by occupation between the beginning and the end of the Great Recession, according to the NBER official dates.
} 
Table 2: Targeted moments and model moments

\begin{tabular}{lcc}
\hline \hline Moment & Data & Model \\
\hline$n_{a}$ in 2005 & 0.281 & 0.280 \\
$n_{r}$ in 2005 & 0.512 & 0.511 \\
$n_{m}$ in 2005 & 0.151 & 0.150 \\
HS Share of $n_{a}$ in 2005 & 0.650 & 0.615 \\
HS Share of $n_{r}$ in 2005 & 0.154 & 0.127 \\
HS Share of $n_{m}$ in 2005 & 0.101 & 0.108 \\
HS Share of $u$ in 2005 & 0.129 & 0.113 \\
$w_{r, H S}$ in 2005 & 0.683 & 0.686 \\
$w_{a, H S}$ & 0.552 & 0.614 \\
$w_{m, H S}$ in 2005 & 0.831 & 0.880 \\
$w_{r, L S}$ in 2005 & 0.613 & 0.622 \\
$\frac{w_{a, L S}, L S}{w_{a, L S}}$ in 2005 & $-0.162 \%$ & $-0.12 \%$ \\
$n_{r}$ long-run growth rate & 0.002 & 0.006 \\
$\Delta n_{a}$ during GR & -0.048 & -0.048 \\
$\Delta n_{r}$ during GR & 0.003 & 0.005 \\
$\Delta n_{m}$ during GR & 0.916 & 0.887 \\
$C o r r\left(u_{t}, u_{t-1}\right)$ & \\
\hline \hline
\end{tabular}

workers in abstract jobs observed in the data. For the same reasoning $\psi_{r}$ is bigger than $\psi_{m}$ : since most of the low-skilled workers search in both routine and manual markets, a higher $\psi_{r}$ allows to match well the share of low-skilled workers in routine jobs observed in the data. Finally, $\psi_{m}$ is the smallest since all workers can access these jobs such that it is easier for manual employers (relative to others) to fill this type of vacancies since every candidate is good. Also the cost of vacancy-posting is vertically ranked: the cheapest vacancy is for abstract occupations, followed by routine and manual ones. This cost menu is fundamental to explain why high-skilled workers generate a positive surplus when matched with a manual vacancy. In fact, since they have the largest job opportunity set, their outside option depends on all three vacancy costs and market tightnesses. Therefore, a higher cost in routine and manual occupations partially compensates the high-skilled worker for the wage differential in the unlikely case of not being matched with the abstract technology. From the perspective of the employer, a smaller vacancy cost in the abstract market allows routine and manual employers to hire high-skilled workers at an over-price still not excessive, such that the generated surplus remains positive.

There are (slightly) increasing returns to skills in abstract occupations while routine jobs exhibit decreasing returns to skills. This is fundamental to explain the occupational premium observed for each skill-group. For example, increasing returns to skills and higher labor productivity in the abstract market give a bigger job premium to high-skilled workers 
Table 3: Estimated Parameters

\begin{tabular}{lcc}
\hline \hline Parameter & Description & Value \\
\hline Technology & Tech. in abstract jobs & 1.08 \\
$z_{a}$ & Tech. in manual jobs & 0.74 \\
$z_{m}$ & \\
Labor Market & & \\
$c_{a}$ & Vacancy posting cost in abstract & 0.01 \\
$c_{r}$ & Vacancy posting cost in routine & 0.02 \\
$c_{m}$ & Vacancy posting cost in manual & 0.05 \\
$\psi_{a}$ & Matching efficiency in abstract & 0.69 \\
$\psi_{r}$ & Matching efficiency in routine & 0.54 \\
$\psi_{m}$ & Matching efficiency in manual & 0.40 \\
Skills & & \\
$\lambda_{a}$ & Return to skills in abstract & 1.13 \\
$\lambda_{r}$ & Return to skills in routine & 0.40 \\
$\gamma$ & Lowest skill for HS workers & 0.73 \\
Dynamics & & \\
$g_{z_{r}}$ & Growth of routine tech. & $-2.4 \times 10^{-5}$ \\
$\sigma_{a}$ & Std. for tech. shock in a & 0.11 \\
$\sigma_{r}$ & Std. for tech. shock in r & 0.18 \\
$\sigma_{m}$ & Std. for tech. shock in m & 0.03 \\
$\rho$ & Persistence of the shock & 0.89 \\
\hline \hline
\end{tabular}

when matched to the best technology available in their job-opportunity set. In fact, the average wage-loss for a high-skilled worker would be roughly $30 \%$ if matched to a routine job instead of an abstract one, and roughly $40 \%$ if matched to a manual job. The same argument holds for low-skilled workers. On average, the wage-loss for a low-skilled worker qualified for an abstract job would be roughly $20 \%$ if employed in a routine occupation, and $40 \%$ if employed in a manual occupation.

Under this calibration, the endogenous skill-requirement for abstract and routine workers are respectively $e_{a}=0.67$ and $e_{r}=0.12$ at the initial time. This means that, before putting the economy on the RBTC trend, only the top $8 \%$ of low-skilled people can access the abstract market, and the bottom $16 \%$ is qualified for a manual job only.

Finally, the aggregate shock has an asymmetric impact on labor productivity across jobs, with routine technology -not surprisingly- being more sensitive (i.e. $\sigma_{r}>\sigma_{a}>\sigma_{m}$ ). The estimated growth rate for routine technology is negative hence corroborating the RBTC hypothesis, i.e. routine jobs are becoming less productive and less demanded over time. Although small, such growth rate delivers a long-run decline of routine employment close to what observed in the data. 
This parametrization is consistent with the existence of a skill-pooling equilibrium. ${ }^{15}$ Therefore, compliance with Condition 1 allows highly ranked individuals to move down the ladder, i.e. to be mismatched into lower technological and lower-paying jobs.

\section{Discussion}

\subsection{Model Predictions}

Figure 2 shows the dynamics of the model under the estimated set of parameters. The simulation aims to replicate the evolution of the U.S economy from 2005 q1 onwards, with a shock occurring after 13 quarters (or equivalently in 2008q1, the beginning of the GR). ${ }^{16}$ Consider the first part of the simulation when the economy is moving on the trend $(t \in$ $[0,13))$. Under RBTC, the model delivers job polarization, with a secular increase of abstract and manual employment and routine employment declining at a rate close to the one observed in the data. ${ }^{17}$ Concerning skills, this phenomenon implies a faster growth of HS workers into abstract occupations, and a faster growth of LS workers into manual jobs in the long-run. In other words, abstract jobs are becoming more high-skilled intensive whereas manual jobs are becoming more low-skilled intensive along the trend. More interestingly, LS employment is declining faster than HS employment in routine jobs. In fact, due to the permanent decline in routine labor productivity, entry barriers in the routine market rise over time because employers want to compensate for the fall in $z_{r}$ through a more productive workforce. This explains the higher retention of HS workers in this segment. Differently, since abstract jobs are becoming relatively more productive than routine jobs, abstract employers are lowering skill-requirements. However, such a decline is too small for the abstract market to expand enough and absorb all workers coming from the routine segment. This mechanism causes higher congestion and queuing at the entry of this segment. Also manual jobs become relatively more productive over time, but employers do not impose any entry barrier there. As a consequence, congestion and queuing at the entrance of this segment are way less severe with respect to the abstract market. This explains why the manual market widens more and absorbs most of all ex-routine workers. Consequently, most of the employment reallocation occurs through the lower step of the job ladder along the trend. All these features are magnified for a transitory negative shock.

\footnotetext{
${ }^{15}$ See Online Appendix A.3 for further discussion and figures on the shape of each job-specific surplus as a function of skills.

${ }^{16}$ The first vertical line indicates the period at which the shock is realized. The second one indicates the half-life of the shock.

${ }^{17}$ See Online Appendix A.5 for further discussion on the role of the RBTC trend to replicate long-run dynamics.
} 
Fig. 2. IRFs under RBTC and temporary shocks
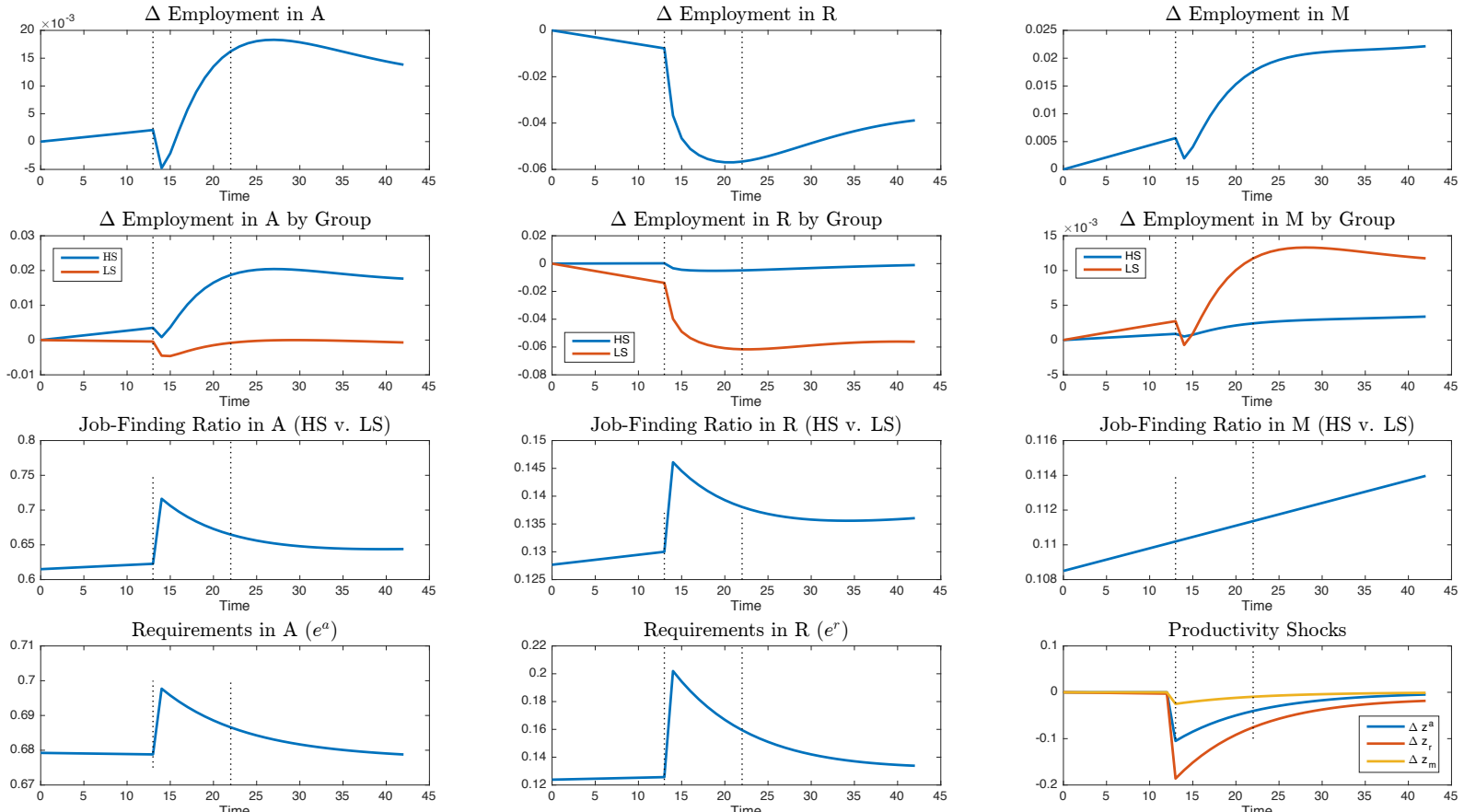

Note: This figure plots the changes in aggregate employment rate by job, changes in employment rate by skill-group and job, the ratio of the HS and LS job-finding rates by job, the skill-requirements dynamics and the change in job-specific technology. For the first 12 periods, the economy is moving on a RBTC trend. On $t=13$, an aggregate shock hits the economy such that variables deviate from the trend, and the transition of the economy begins. Vertical dotted lines indicate respectively the timing of the shock and its half-life.

When the shock hits at $t=13$, the economy deviates from its long-run trend. Employment falls in all occupations, with LS workers affected the most. In fact, for a negative shock, employers become pickier and demand higher skills, i.e. skill-requirements are countercyclical. This generates endogenous displacement of LS workers in the abstract and routine market. Consequently, LS workers become relatively less likely to fill abstract and routine vacancies. Hence, the job-finding rate of LS workers (relative to HS falls) in these segments along with their job opportunities since a large share of them now no longer qualify for these jobs. The only market in which their job-finding rate (relative to HS workers) is not affected by the shock is the manual one since no entry barrier is set there. However, the probability that these jobs do not arrive to a LS worker is steadily increasing over time. This happens due to population dynamics, i.e. the share of LS workers is declining over time.

After the shock $(t>13)$, employment quickly rebounds in the abstract and manual occupations, with the former becoming more HS-intensive and the latter more LS-intensive. On the other hand, there is no rebound of routine employment. In fact, due to the shock and the undergoing RBTC process, these jobs are permanently destroyed. Thus, routine employment permanently collapses and slowly converges back to its long-run path from below. Such a collapse is mostly explained by endogenous job destruction. In fact, due to the 
Fig. 3. Polarization and Unemployment: model vs. data
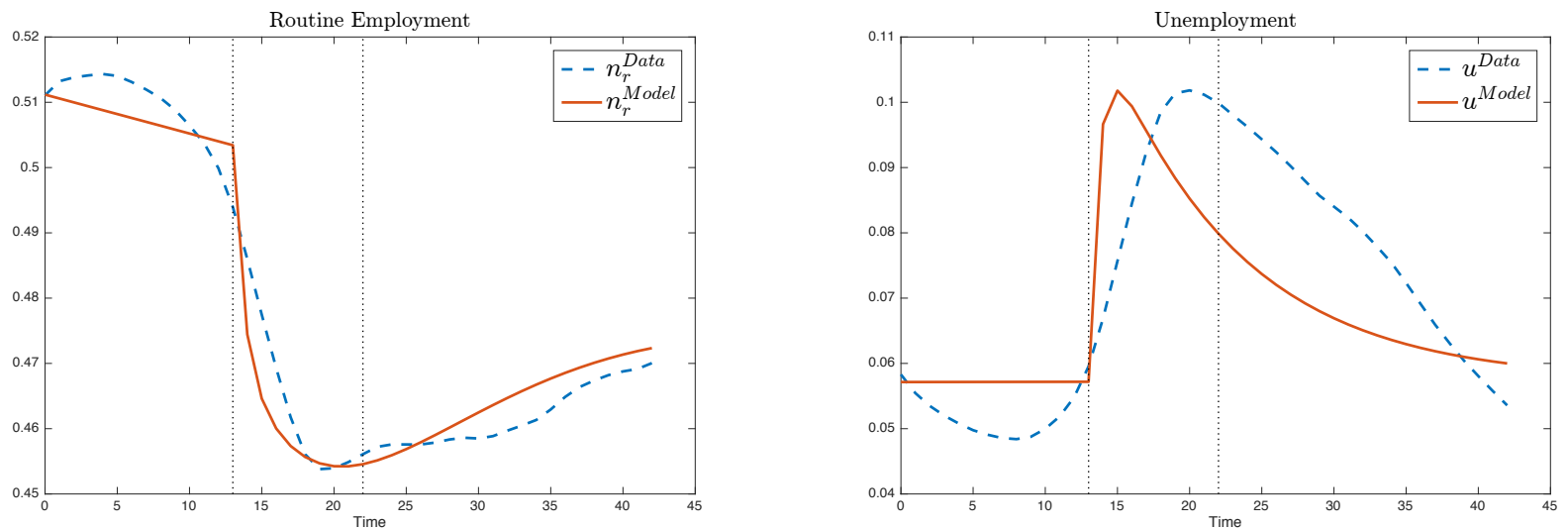

Note: This figure plots the evolution of routine employment and aggregate unemployment generated from the model, and compares it with the time-series from the data. For the first 12 periods, the economy is moving on a RBTC trend. On $t=13$, an aggregate shock hits the economy such that variables deviate from the trend, and the transition of the economy begins. Vertical dotted lines indicate respectively the timing of the shock and its half-life.

higher sensitivity of this market to the shock, employers increase requirements way more than in any other market and more persistently. This translates into a massive endogenous displacement of LS workers from the routine market. These layoffs explain almost entirely the rise in unemployment in the economy. As shown in Figure 3, these two margins -the undergoing RBTC process and the rise in skill-requirements due to a negative transitory shockallow the model to replicate well the cyclical features of job polarization and unemployment observed in the data. However, there is an important shortcomings worth to mention. As explained above, congestion in the abstract and manual markets and the high persistence of the shock prevent the unemployment rate from the model to converge back as fast as in the data. This behavior is evident in the last few quarters of the simulation, where only the true unemployment rate moves back to its natural level. This difference can be explained by a higher non-participation rate in the data. In fact, from the middle of the recession onwards labor force participation of LS workers collapsed so to deflate aggregate unemployment. The participation margin is not modeled in this paper and the demographic dynamics of HS and LS workers only partially compensate for this drawback. ${ }^{18}$

\subsection{Cyclical Reallocation of Skills: Theory vs. Data}

In the theoretical model, the cyclical disappearing of routine jobs leads to congestion and queuing in the other markets, particularly in the abstract one. This, jointly with the heterogeneous change in skill demand across jobs, determines heterogeneous patterns of skills reallocation that vary over the cycle and across major skill-groups. Figure 4 plots changes

\footnotetext{
${ }^{18}$ See Online Appendix $\mathrm{C}$ for further discussion on the participation margin.
} 
in group-specific employment shares -the conditional probability of being employed in a job when belonging to a specific group- from the model and as observed in the data. Consider first the theoretical employment share of HS workers employed in routine jobs. Since the shock in the routine market is more severe (i.e. $\sigma_{r}>\sigma_{a}>\sigma_{m}$ ), vacancy posting here decreases more relative to other markets. This leads to a fall in the employment stock of HS workers in that occupation due to exogenous separation, and a collapse in the HS employment share. Such a collapse is mechanically compensated by an almost equivalent expansion of the employment share of HS workers in the abstract market. However, due to the different changes in labor productivity, the rebound in vacancy posting in the abstract market ${ }^{19}$ is not large enough to absorb all the HS unemployed workers. Hence, the abstract market congests quickly and it gets more difficult for HS workers to end up in the best job available. This causes the reversal of the employment share from the half-life of the shock onwards. Such a decline is compensated by an increase of the employment share in the routine market itself where -due to the larger shock and a bigger and more persistent rise in skill-requirements- vacancies are posted more abundantly and targeted to highly qualified workers only. As a consequence, it is more likely for HS workers queuing for an abstract job to end up into the routine market when the economy is transitioning back to its expansion path, since their skills are more demanded in that occupation and the routine market is tighter. This dynamic is consistent with Beaudry, Green, and Sand (2016) which shows how HS employment has declined in cognitive jobs after the 2001 recession and expanded down the ladder. For this reason, they claim a "great reversal" in demand for skills occurred in cognitive jobs.

The theoretical patterns for LS employment are different. In fact, the more severe shock and the higher and more persistent rise in skill-requirements in the routine market lead to a larger fall in the employment share in this submarket due to endogenous separation. Such collapse is almost entirely compensated by an expansion of the employment share in the manual market. Conversely, the rise of the employment share in the abstract market is small and explained only by the few LS workers qualified for this job. Differently from HS workers, there is only a small decline in the employment shares from the half-life of the shock onwards in these submarkets, such that the shifts in employment shares result to be way more persistent. This is because requirements remain persistently high in the routine market, thus not allowing a recovery in employment share through these jobs. Consequently, the occupation through which LS employment recovers the most is the manual one, i.e. the only market for which requirements are never binding. ${ }^{20}$

\footnotetext{
${ }^{19} \mathrm{As}$ in the basic search-and-matching model, vacancy posting rebounds after a negative productivity shock. The stronger is the shock, the bigger is the rebound.

${ }^{20}$ See Online Appendix A.4 for further discussion on the role of asymmetric shocks in explaining skill-group employment dynamics across occupations.
} 
Fig. 4. Employment Shares by Skill-Group: model vs. data
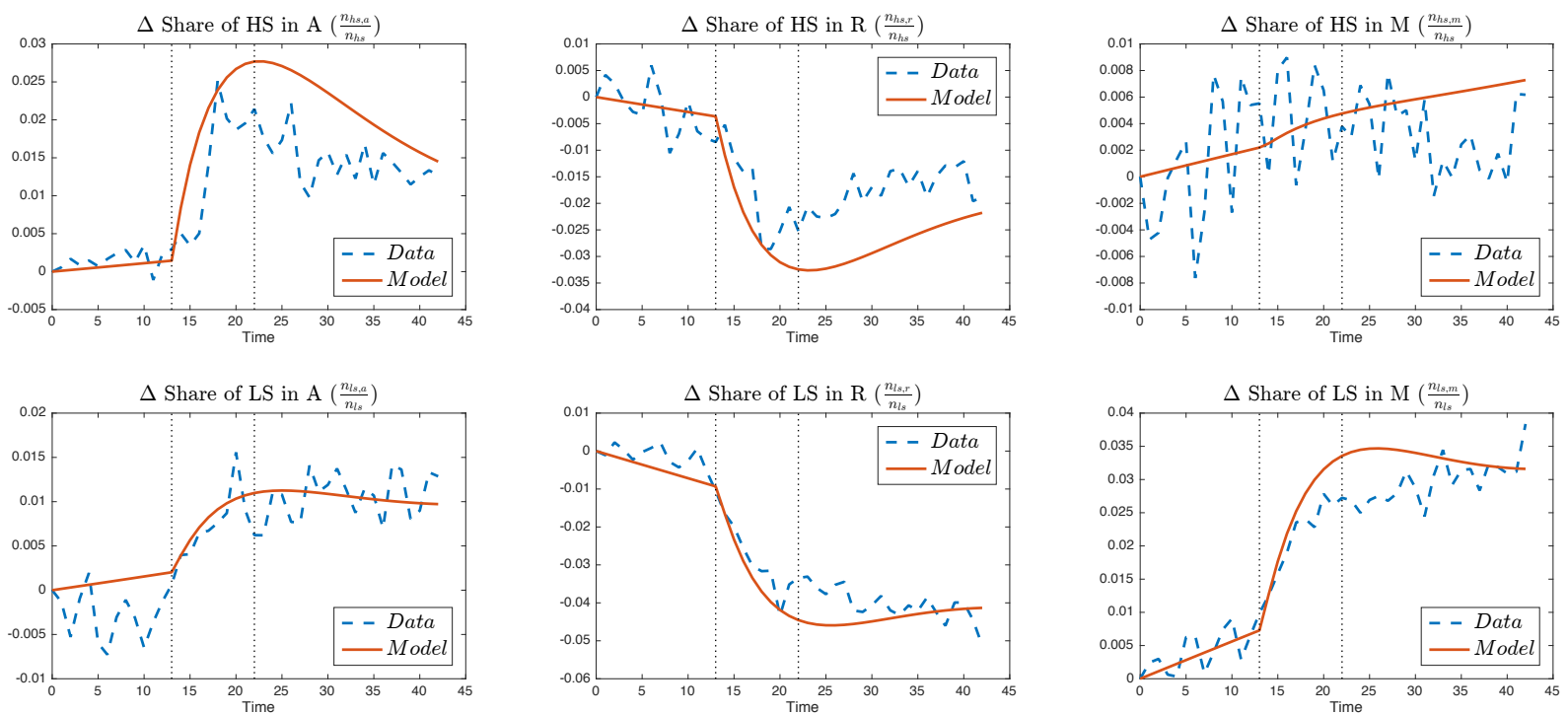

Note: This figure plots the change in the skill-group employment share by occupation, and compares it with the time-series from the data. For the first 12 periods, the economy is moving on a RBTC trend. On $t=13$, an aggregate shock hits the economy such that variables deviate from the trend, and the transition of the economy begins. Vertical dotted lines indicate respectively the timing of the shock and its half-life.

As Figure 4 shows, the reallocation patterns generated from the model are consistent with the ones observed in the data. ${ }^{21}$ In fact, the model is quite impressive in replicating the dynamic of the LS employment share across the three jobs, whereas it exhibits some larger errors when considering the dynamic of the HS employment shares. This is particularly evident from the half-life of the shock onwards, where the model over-predicts the decline (increase) of the employment share in the routine (abstract) market.

Overall, this exercise gives us an important result: targeting the employment dynamics of job polarization -both in the long-run (under the RBTC trend) and in the short-run (with an aggregate shock)- in a model with heterogeneous agents, search-and-matching frictions and endogenous skill-requirements is sufficient to explain well the endogenous reallocation patterns for high-skilled and low-skilled workers. Or, in other words, there exist reallocation patterns specific to the process of job polarization. To my knowledge, no paper in the literature gives such evidence and proves the importance of heterogeneous occupational dynamics for the reallocation of skills in the context of job polarization.

\footnotetext{
${ }^{21}$ These theoretical sorting patterns are also consistent with data on flows from unemployment to employment for each major skill-group. See Online Appendix B for further discussion and evidence.
} 


\subsection{Skill Mismatch Dynamics and the Social Planner}

Here, I study how skill-mismatched employment evolves during the transition -i.e. once the economy deviates from the trend- and compare it to the social planner solution and the data. Since a worker is mismatched if he is not using the best technology available in his job opportunity set, to study the evolution of skill mismatch means to measure the deviation of the economy from the skill-separating equilibrium. At the same time, by comparing skill mismatch dynamics from the economy and the social planner over the transition, it is possible to understand how much of the skill mismatch was actually efficient during the GR.

Following Bhattacharya and Bunzel (2003), imagine a planner chooses each period the market tightness $\theta_{j}$, the minimum skill-requirement $e_{j}$ and the level of employment $n_{j}^{\prime}$ in every market $j$ in order to maximize the present discounted value of production and unemployment, net of vacancy costs. Hence the (constrained) central planner's problem is:

$$
\begin{array}{ll}
\max _{\left\{\theta_{j}, e_{j}, n_{j}^{\prime}\right\}_{t=0}^{\infty}} & \mathbb{E} \sum_{t=0}^{\infty} \beta^{t}\left\{\tilde{y}_{a} n_{a}+\tilde{y}_{r} n_{r}+y_{m} n_{m}+b\left(1-n_{a}-n_{r}-n_{m}\right)-\sum_{j} c_{j} \theta_{j} u_{j}\right\} \\
\text { s.t. } \quad & n_{j}^{\prime}=s(1-\delta) n_{j}+u_{j} q\left(\theta_{j}\right) \\
& \tilde{y}_{j}=\int_{e_{j}}^{1} y\left(x ; z_{j}\right) U_{\left[x \geq e_{j}\right]} d x .
\end{array}
$$

Under job-specific technology and the aggregate shock (as from equation (1) and (2)), the solution of the maximization problem above pins down the equilibrium of all endogenous variables. It is very easy to prove that the equilibrium solution of the planner's problem is identical to the solution of the decentralized economy when a skill-separating equilibrium realizes under Hosios condition. ${ }^{22}$ In fact, if markets are perfectly segmented and workers search only for the best job available in their job opportunity set, the condition $\alpha=\eta$ is sufficient for the social planner and the market solution to coincide. Panel A of Table 4 reports the equilibrium levels of employment by skill-group and job, skill-requirement and unemployment under the social planner and the economy described in Sections 2 (both equilibria are evaluated under the parameterization of Table 1 and 3). Moreover, Panel B reports the amount of skill-to-job mismatch of each type of workers within each occupation.

As from the Panel A, the social planner allocates more workers (52\%) in abstract jobs, since these are the most productive occupations. In descending order by productivity, lower employment is allocated to routine (40\%) a manual job (4\%). In order for the abstract market to absorb such a high number of workers, skill-requirements must be lower there. In fact $e_{a}$ is set at 0.56 , well below the level set by the decentralized economy (for the

\footnotetext{
${ }^{22}$ See Online Appendix A.6.1.
} 
same reasoning, also $e_{r}$ is lower). More interesting is the distribution of skills across jobs. Under the planner solution, all employed HS individuals are working in abstract jobs. On the other hand, no HS is working in lower qualifying jobs. In other words, under the social planner solution, HS workers search only for and are employed only in the best job available in their job-opportunity set. This is true also for LS workers. In fact, those LS workers satisfying the minimum skill requirement $e_{a}$ search only in the abstract market, similarly those workers with $x \in\left[e_{r}, e_{a}\right)$ search only for routine jobs and workers with $x<e_{r}$ search only in the manual market. Again, as for HS workers, depending on their position on the skill distribution LS workers search for and are employed only in the best job available in their job opportunity set. In other words -as long as the Hosios condition holds- the central planner delivers a skill-separating equilibrium such that there is no skill-to-job mismatch (Panel B). On the other hand, skill mismatch employment exists under the economy and is equal to $9 \%$ for HS and $15 \%$ for LS workers.

Table 4: Planner vs. Economy in Equilibrium

\begin{tabular}{|c|c|c|c|c|c|c|c|c|c|c|c|c|}
\hline & $n_{a}$ & $n_{r}$ & $n_{m}$ & $e_{a}$ & $e_{r}$ & $u$ & $n_{h s, a}$ & $n_{h s, r}$ & $n_{h s, m}$ & $n_{l s, a}$ & $n_{l s, r}$ & $n_{l s, m}$ \\
\hline \multicolumn{13}{|c|}{ Panel A: Equilibrium under Tab. 2,3 Param. } \\
\hline Planner & 0.52 & 0.40 & 0.04 & 0.56 & 0.11 & 0.03 & 0.26 & 0 & 0 & 0.26 & 0.40 & 0.04 \\
\hline Economy (skill-pooling) & 0.28 & 0.51 & 0.15 & 0.67 & 0.12 & 0.06 & 0.17 & 0.07 & 0.02 & 0.11 & 0.44 & 0.15 \\
\hline \multicolumn{13}{|c|}{ Panel B: Skill-to-job Mismatch } \\
\hline Planner & & & & & & & 0 & 0 & 0 & 0 & 0 & 0 \\
\hline Economy (skill-pooling) & & & & & & & 0 & 0.07 & 0.02 & 0 & 0.04 & 0.11 \\
\hline
\end{tabular}

In light of this discussion, we can say that the skill-pooling equilibrium is inefficient since it allocates too many workers in the 2 nd productive job (rather than in the most productive) and because it allows workers to search down the ladder thus increasing congestions and misallocation. On the contrary, under the social planner solution, a skill-separating equilibrium would realize, with more workers efficiently allocated in the abstract market. For this reason, if a planner had to take action in the long-run, he would like the economy to destroy routine jobs as fast as possible in order to quickly relocate more workers in the most productive occupation.

But how about during the transition? Would the planner take care more about the reallocation of workers towards more productive jobs or to lower unemployment? And what about skill-to-job mismatch? Consider the economy described in the previous sections -with skill-pooling in the routine and manual markets- moving over time according to the RBTC trend and deviating from it due to an aggregate shock. Imagine now, that the social planner takes action only once the aggregate shock realizes, i.e. only when the transition begins. 
Fig. 5. Emp. Mismatch Dynamics

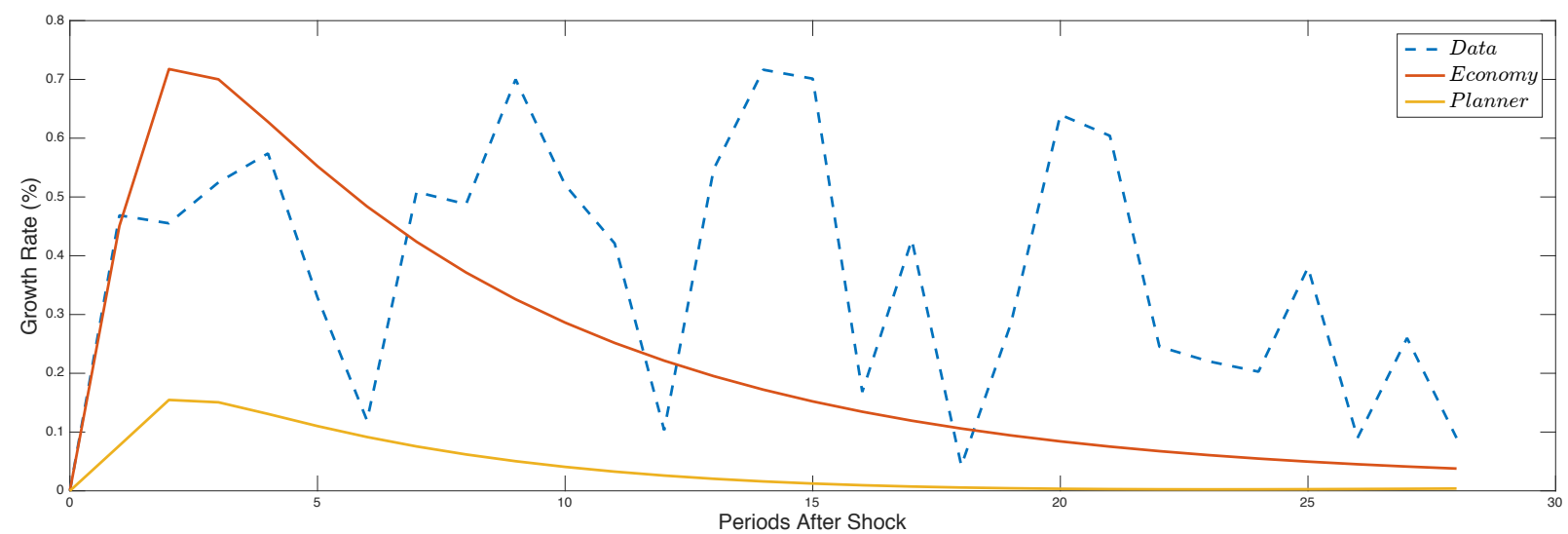

Note: This figure plots growth rate of employment mismatch -i.e. the employment rate of workers not matched to the best technology available in their job opportunity set- when the economy is transitioning after the aggregate shock realizes. The time series in red is for transitional dynamics under the market solution. The time series in yellow is for transitional dynamics under the social planner solution. The time-series from the data (in dashed blue) is build as follows: since I do not know the share of LS overqualified workers in manual and routine jobs from the data, I take seriously the predictions of the model and use the time-series of the minimum skill-requirement in routine and manual jobs $\left(e_{a, t}\right.$ and $\left.e_{r, t}\right)$ to proxy LS mismatch employment.

How would the dynamics of skill mismatch look like under the centralized solution? ${ }^{23}$ Figure 5 plots the growth rate of aggregate employment mismatch along the transition for the decentralized economy, for the centralized economy and the data. ${ }^{24}$

After the shock, mismatch growth peaks at $0.72 \%$ for the decentralized economy. Thereafter, it starts converging through a very persistent dynamic as the economy moves back to its long-run trend. This increase in mismatch is explained by workers qualified for abstract and routine jobs ending up in lower-qualifying occupations, i.e the distance between the skill-separating and skill-pooling equilibrium is larger.

When a central planner operates over the transition, the growth rate of mismatch is $3 / 4$ smaller, i.e. a planner is able to attenuate skill-to-job mismatch and put the economy closer to the skill-separating equilibrium. This happens because the planner reacts to the negative shock by forcing routine employers to post more vacancies and to keep the skill-requirement low. By doing so, only a few routine workers lose the job and routine employment -just after a small decline- bounces back on its long-run trend very quickly. ${ }^{25}$ Consequently, there

\footnotetext{
${ }^{23}$ See Online Appendix A.6 for further discussions on how social-planner dynamics are built in order to be comparable with the dynamics of the decentralized economy under the skill-separating equilibrium over the transition.

${ }^{24}$ The time-series from the data plotted in Figure 5 is built as follows. First, I take seriously the estimation of the model of Section 3 and use the model-generated series $e_{a}$ and $e_{r}$ of Section 4 to identify in the data the share of LS workers mismatched in manual and routine jobs. Hence, I have the mismatch employment rate for both HS (as in the data) and LS workers (as filtered through $e_{a}$ and $e_{r}$ ). Second, I sum HS and LS mismatch employment rates and I calculate its inter-quarter growth rate as plotted in Figure 5.

${ }^{25}$ See Figure A.8, A.9 and A.10 in Online Appendix A.6.2 for the dynamics of the endogenous variables when the social planner operates over the transition. See also Figure A.11 for the evolution of HS employment
} 
Fig. 6. Emp. Mismatch Dynamics, Lump-sum Taxes and Vacancy Costs Subsidies
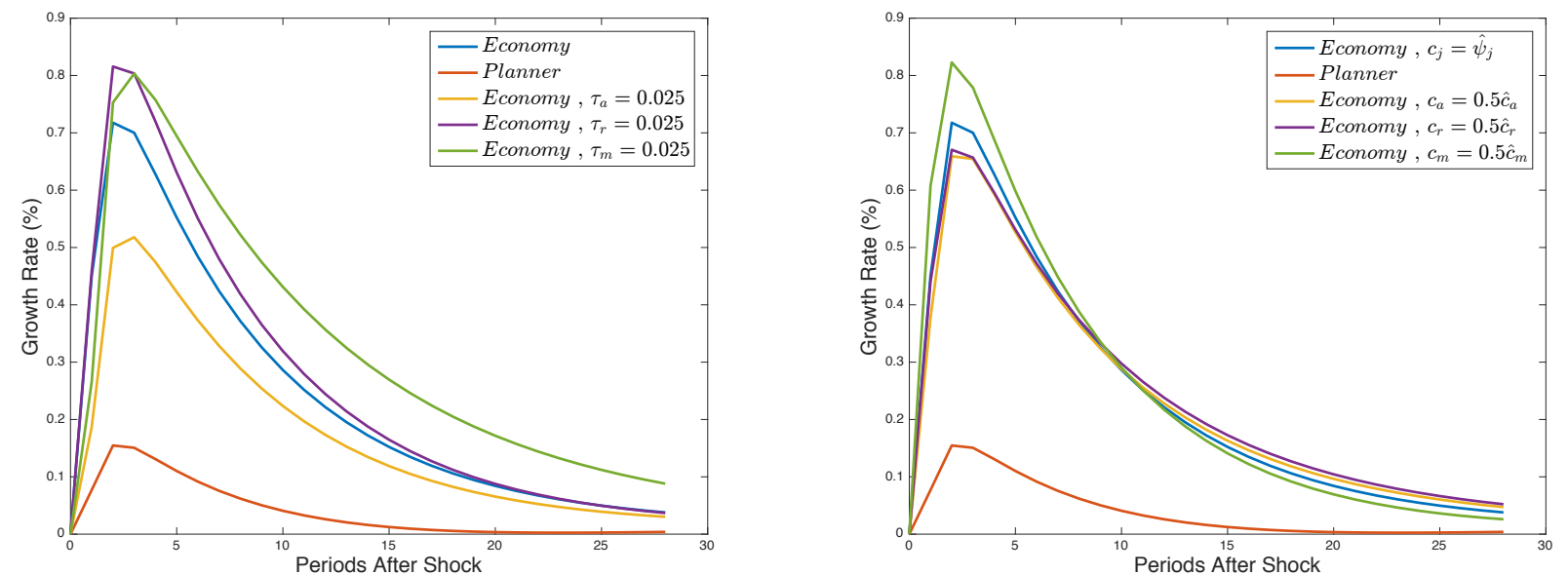

Note: This figure plots the evolution of employment mismatch over the transition when a job-specific lump-sum tax $\tau_{j}$ is put on wages, and for different values of vacancy $\operatorname{costs} c_{j}$ with $j=\{a, r, m\}$. In the left-hand panel, $\tau_{j}$ is set to the value 0.025 for each job separately. In the right-hand panel, vacancy costs are separately set to the $50 \%$ of the estimated parameters.

is not much risk for qualified routine workers to end up in the manual market since the best occupation in their job opportunity set now does not disappear as fast as under the decentralized solution. In other words, the planner maximizes welfare by strongly defending routine employment such that the cyclical features of polarization are severally attenuated and unemployment due to endogenous displacement is minimized.

However, the fact that skill mismatches increase over the transition also under the planner implies that $1 / 4$ of mismatch fluctuations in the economy are actually efficient. In fact, the reshaping of the occupational structure due to both RBTC and the aggregate shock requires some workers to be mismatched for social welfare to be maximized. Who are these workers? Since the routine market is key for welfare maximization, but routine jobs are becoming less productive over time and are hit the most by the aggregate shock, the planner reacts by consistently reducing the size of the abstract market and by enlarging the skill-pooling equilibrium in the routine market. Hence, more HS workers are allocated in routine jobs. This mechanism helps routine employers to better cope with the decline in productivity and the negative aggregate shock. In fact, through a more productive workforce, now routine employers can keep more routine jobs alive and avoid a massive endogenous displacement of LS workers.

In this context, the inefficient part of employment mismatch over the transition is fully due to search-and-matching frictions, here magnified due to the existence of the skill-pooling equilibrium in the routine and manual market, and job polarization.

In light of this, there are two potential policy channels through which the mismatch dymismatch under the planner and the economy solution over the transition. 
namics of the economy (under skill-pooling) and the planner can coincide over the transition: the first one requires the introduction of a job-specific lamp-sum tax $\tau_{j}$; the second requires changes in vacancy posting $\operatorname{costs} c_{j}$, say through subsidization in job-specific creation. Consider these two policy instruments separately.

Lump-sum Taxes on Wages The left panel of Figure 6 shows transitional dynamics of employment mismatch when a time-invariant lump-sum tax $\tau_{j}=0.025$ is imposed on workers wage $w\left(x ; z_{j}\right)$ for each job $j=\{a, r, m\}$ separately. When the tax is put only on abstract wages, mismatch increases less than under the decentralized solution. This happens because higher taxation on top income jobs reduces the value of the outside option for many HS workers such that the wage difference between an abstract and a routine job decreases. Therefore, HS workers are more willing to take routine jobs such that the skill-pooling equilibrium in the routine market is now larger. At the same time, employers in the routine market are able to post more vacancies. Therefore, LS workers are less exposed to mismatch and the probability to find or to stay in a routine job increases for them. On the other hand, if $\tau_{r}=0.025$ ( or $\tau_{m}=0.025$ ), mismatch increases above the level predicted under the decentralized solution. This happens because the value of routine employment for most of LS workers falls. This has a spillover effect on vacancy posting in the manual market which expands way too much. Thus, the manual segment absorbs more LS workers than under the decentralized solution and mismatch increases, i.e. the skill pooling equilibrium is too large in the manual market. In light of this exercise, a job-specific taxation -in particular a lower tax burden for routine workers- would help the economy to replicate the social planner dynamics over the transition. ${ }^{26}$

Vacancy Costs The right panel of Figure 6 shows transitional dynamics of employment mismatch when $c_{j}$ is set to $50 \%$ of its estimated value $\hat{c}_{j}$ (as reported in Table 3 ) for each job $j=\{a, r, m\}$ separately. When $c_{a}=0.5 \hat{c}_{a}$, employment mismatch grows less than under the decentralized solution. This happens because abstract employers can post more vacancies and lower skill requirements. Consequently, workers qualified for that job become relatively more likely to end up there. When $c_{r}=0.5 \hat{c}_{r}$, routine workers become less expensive and employers post more vacancies here than in the manual sector. Moreover, for a lower $c_{r}$, skill requirements are persistently low in the routine sector such that endogenous job displacement during the transition is severally reduced. Hence, routine employment is more preserved and the mismatch is reduced since the risk for routine-qualified workers to end up in manual jobs falls. Finally, if $c_{m}=0.5 \hat{c}_{m}$, the expansion of the manual sector is so big

\footnotetext{
${ }^{26}$ Online Appendix A.6.1 provides the formal definition of optimal taxation by job.
} 
that more routine-qualified workers will end up there and bigger endogenous displacement will occur in the routine market thus accelerating the cyclical process of polarization. ${ }^{27}$

To sum up, skill mismatches rise during the transition and are explained by job polarization and its cyclical properties. In fact, due to the accelerated disappearance of the routine market -not compensated by the expansion of others- and changes in skill demand across jobs, the number of overqualified workers in lower-paying jobs increases. In particular, by studying the correlation between time series from the model (and the data), a 1pp decline in routine employment leads to an increase in aggregate employment mismatch by $0.18 \mathrm{pp}$ (0.31 in the data). Skill mismatch is mostly explained by LS workers that cannot go back to routine jobs, even though qualified, because of the slackness of this market. On the other hand, skill mismatch is only partially explained by HS workers not able to find an abstract job. This happens because the abstract market does not expand enough during the transition and higher skills are demanded for routine jobs. In this context, if a planner takes action over the transition, he will do everything possible to keep the routine sector alive and minimize the cyclical properties of job polarization and the endogenous displacement of routine workers. This will put the economy closer to a skill-separating equilibrium. Yet, some skill mismatch is efficient: it is preferable to have some overqualified workers in lower qualifying jobs rather than high and persistent unemployment.

\subsection{The Shift-out of the Beveridge Curve and Job Polarization}

In recent years, researchers have being focusing on the cyclical behavior Beveridge curve, in particular in light of its shift-out after the GR (see Figure 7, right panel). As documented in Barnichon and Figura (2011), Diamond and Şahin (2015) and Şahin et al. (2014), the shift can be attributed to deterioration in matching efficiency, particularly in skill-intensive occupations and industries. Yet, the causes of this phenomenon remain unclear. As suggested in the same literature, a structural change in the economy and a persistent change in skill demand might rationalize the shift in the Beveridge curve. The model in this paper shows that this is indeed the case: the structural change implied by RBTC and the aggregate shock, and the consequential rise in skill demand endogenously deliver the shift-out of the curve and explain the deterioration of aggregate matching efficiency. Under the estimated parameters, the model explains $38 \%^{28}$ of the shift-out of the Beveridge curve in the data. Consider the left panel of Figure 7. When the economy is hit by the shock, vacancy posting

\footnotetext{
${ }^{27}$ Online Appendix A.6.1 provides the formal definition of optimal subsidy by job.

${ }^{28}$ Measured as the average percentage distance between the job opening rates from JOLTS and from the model over the time-window under consideration.
} 
Fig. 7. The Beveridge Curve: model vs. data
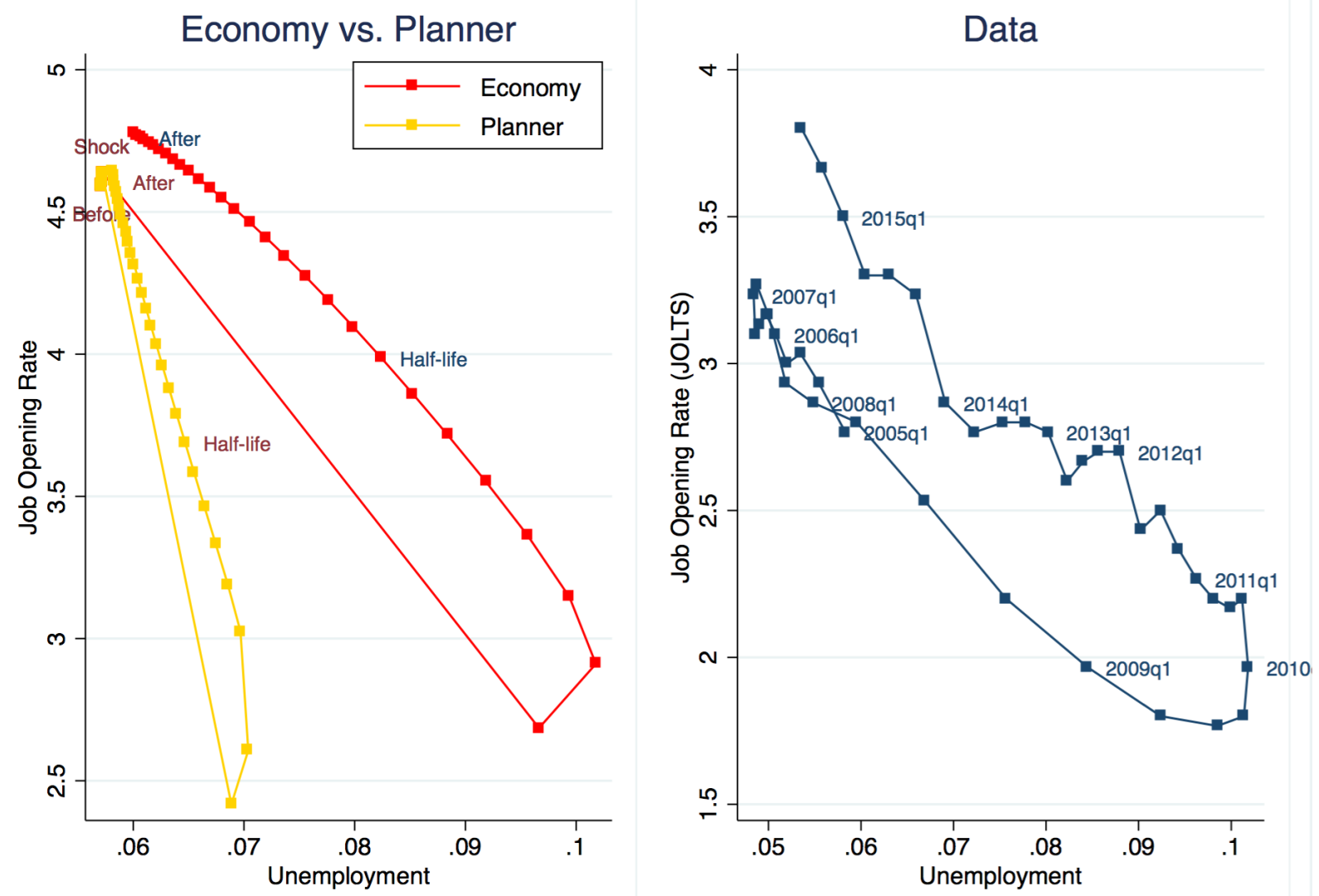

Note: This figure plots the Beveridge curve generated from the theoretical model for the economy and the social planner, and the one observed in the data. Data on aggregate job openings come from the Job Opening and Labor Turnover Survey (JOLTS).

falls dramatically ${ }^{29}$ and unemployment rises. Due to the increase in skill-requirements, the unemployment pool becomes relatively richer (scarcer) of unqualified (qualified) workers. This is because unqualified workers are endogenously displaced more abundantly whereas only a few qualified workers flow into unemployment due to exogenous displacement. At the same time, the fall in labor productivity fosters the demand for skills, in particular in the routine market where skill-requirements rise by more and more persistently. Therefore, when willing to rebuild routine and abstract employment stocks, employers need to flood the market with vacancies in order to increase their chances to meet qualified workers for such a large unemployment pool. This causes the shift-out of the curve and a larger gap between skills supplied and vacancies posted in skill-intensive markets. In this sense, the joint effects of polarization and the shock lower aggregate matching efficiency in the economy: it gets

\footnotetext{
${ }^{29}$ The fall in vacancies at the time of the shock is mostly explained by the fall in vacancies in the routine sub-market since $\sigma_{r}$ is larger than $\sigma_{a}$ and $\sigma_{m}$.
} 
really hard for abstract and routine employers to find the right workers when "cyclical" polarization makes higher skills scarce and the unemployment large. On the contrary, under the social planner, unemployment does not increase much because skill requirements -in particular in the routine market- are kept low. Therefore, lower endogenous occurs, the unemployment pool is more homogeneous, and to fill vacancies is easier. Consequently, vacancy posting does not exacerbate and the shift out of the curve is very small.

\section{Empirical Analysis}

In this section, I validate the aggregate predictions of the model within local labor markets, i.e. within States. First, I analyze how displaced workers use the job ladder over the cycle within local labor markets. Second, I exploit state-level variation to show how skillgroup employment shares move over the cycle. Third, I show that local markets experiencing larger destruction of routine jobs during the recession witnessed larger employment reallocation down the job ladder afterward. Fourth, I document the upskilling phenomenon and show which specific educational attainments matter the most and when. Fifth, I estimate the return to skills within occupations and compare them with the corresponding estimated parameters from the model. Finally, I study the wage ladder for high and low-skilled workers and compare the data with the model.

Data come from Current Population Survey (CPS) and its Displaced Workers Supplement (DWS) and I use it at the individual-level or aggregated at the state-level. Occupations and skill-groups are classified as before. The time-window in consideration spans from 2005q1 to 2015q4. Since the time of the Gdp peak and trough defined by the NBER to identify recession and recovery periods is not always consistent with the State-specific cycle, I define ad-hoc recession and recovery dummies for each of the 50 States by analyzing quarterly state-level series for real GDP as supplied by the Bureau of Economic Analysis (BEA). In this way, I add an extra source of variation to the panel without unfairly imposing that recession, recovery and expansion periods coincide across States. ${ }^{30}$

\subsection{Vertical Displacement and the Business Cycle}

DWS collects data on workers who lost their job for reasons that are "orthogonal" to individual characteristics, such as plant closing, abolished job or slack of work. This allows to properly identify the employment patterns for heterogeneous workers when hit by a negative

\footnotetext{
${ }^{30}$ More details on data construction and variables' definitions can be found in Online Appendix D.
} 
shock, meant as an exogenous "layoff". ${ }^{31}$ Here, I exploit the DWS to study the likelihood for a worker $i$ belonging to group $g=\{H S, L S\}$ and resident in state $s$ of moving down the ladder and how such probability fluctuates over the cycle. Consider the following regression for each group $g$ :

$$
\operatorname{Pr}\left(y_{i, s}=1 \mid X\right)=\Phi\left(\boldsymbol{\delta}_{\boldsymbol{s}}^{\prime} \beta+X_{i, s}^{\prime} \gamma\right)
$$

where $y_{i, s}=1$ if worker $i$, from skill-group $g$ and resident in State $s$, moved down the occupational ladder ${ }^{32} ; \boldsymbol{\delta}_{\boldsymbol{s}}$ is a vector of mutually exclusive dummy variables for state-specific expansions, recession and recovery periods and indicates when the layoff occurred, $X$ controls for sex, age, experience, marital status, number of children. The first column of Figure 8 plots margins for the probability of downgrading over the business cycle for HS and LS workers. The second column shows the conditional probability of moving one step down the ladder when laid-off from an abstract job if HS or from a routine job if LS. ${ }^{33}$ Clearly, for both groups the conditional and unconditional probability of moving down the ladder follows the cycle: it rises during the recession, peaks during the recovery and goes down to pre-recession levels in the next expansion. Notably, the (conditional or unconditional) probability of downgrading is always higher for HS workers across each cyclical phase, thus suggesting higher mobility over the ladder and broader opportunities in other jobs in case of exogenous layoff. When conditioning on the previous job, the likelihood of vertical displacement is magnified for HS workers and it is about $50 \%$ in recovery periods (20\% higher than in expansion periods). Conversely, there is not much difference between the conditional and unconditional probability of downgrading for LS workers. In fact, the probability of moving down the ladder is almost perfectly explained by routine workers moving to manual jobs. Moreover, such probability is only $20 \%$ during the recovery $(10 \%$ higher than in expansion periods and almost 30\% lower than the same probability for HS workers). This suggests lower mobility and lower employability for this category of workers.

\subsection{Employment Shares and State-level Cycles}

Job polarization is a feature of the labor market allover the U.S. If the dynamic from the model are correct, similar responses should be observable across local markets. In order to test this fact, I build a panel data-set of employment by skill-groups across occupations and I exploit state-level business cycle dates to study the evolution of employment shares within

\footnotetext{
${ }^{31}$ See Topel (1990), Farber (1996), Schmieder, von Wachter, and Bender (2010), and Farber (2015) for details on how the specific causes of layoff can be used as instruments.

${ }^{32} y_{i, g, s}=0$ when worker $i$ did not change job after displacement.

${ }^{33} \mathrm{In}$ this case $y_{i, g, s}=1$ when worker $i$ moved down the ladder by 1 job-category only; $y_{i, g, s}=0$ when worker $i$ did not change job after displacement.
} 
Fig. 8. Probability of Vertical Downgrade over the Cycle
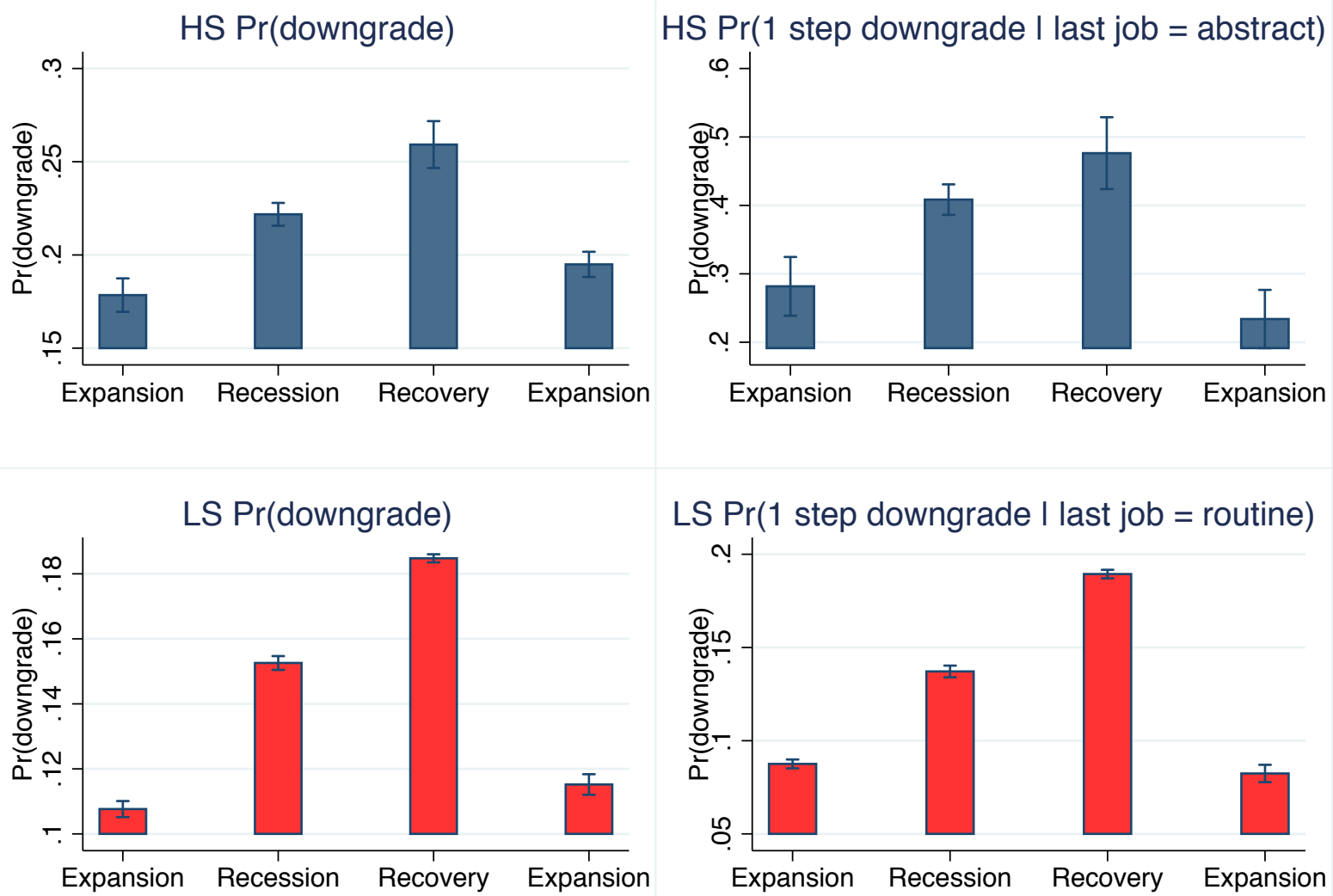

Note: errors are clustered by year of job loss. In all sub-graphs, the dependent variable is the probability for a displaced worker to move down the vertical ranking of occupations after having lost the job. The sub-graphs of the first row plot respectively the unconditional probability for a high-skilled worker (HS) to move to down the ladder, and the conditional probability for a HS worker -previously employed in the abstract market- to move to the routine market. The sub-graphs of the second row plot respectively the unconditional probability for a low-skilled worker (LS) to move to down the ladder, and the conditional probability for a LS worker -previously employed in the routine market- to move to the manual market.

each state from the beginning of the local recession onwards. For each group $g$ and job $j, \mathrm{I}$ evaluate the following:

$$
\Delta Y_{s, t}=\text { Byear }_{s, t}+X_{s, t}^{\prime} \gamma+\epsilon_{s, t}
$$

where $\Delta Y_{s, t}$ is the change in employment share for group $g$ in job $j$ from the beginning of the recession in state $s$, year ${ }_{s}$ is a time dummy for years from the beginning of the recession in state $s, X$ controls for group specific participation rates. Figure 9 plots the time specific $\beta$ coefficients for each group in each occupation.

Consider HS workers first. As predicted by the model and shown in Figure 4, the employment share of HS workers in the abstract market is a reverted u-shape: it grows immediately after the beginning of the downturn and start reverting after three years as in the theoretical 
Fig. 9. Employment Shares Dynamics after State Recession
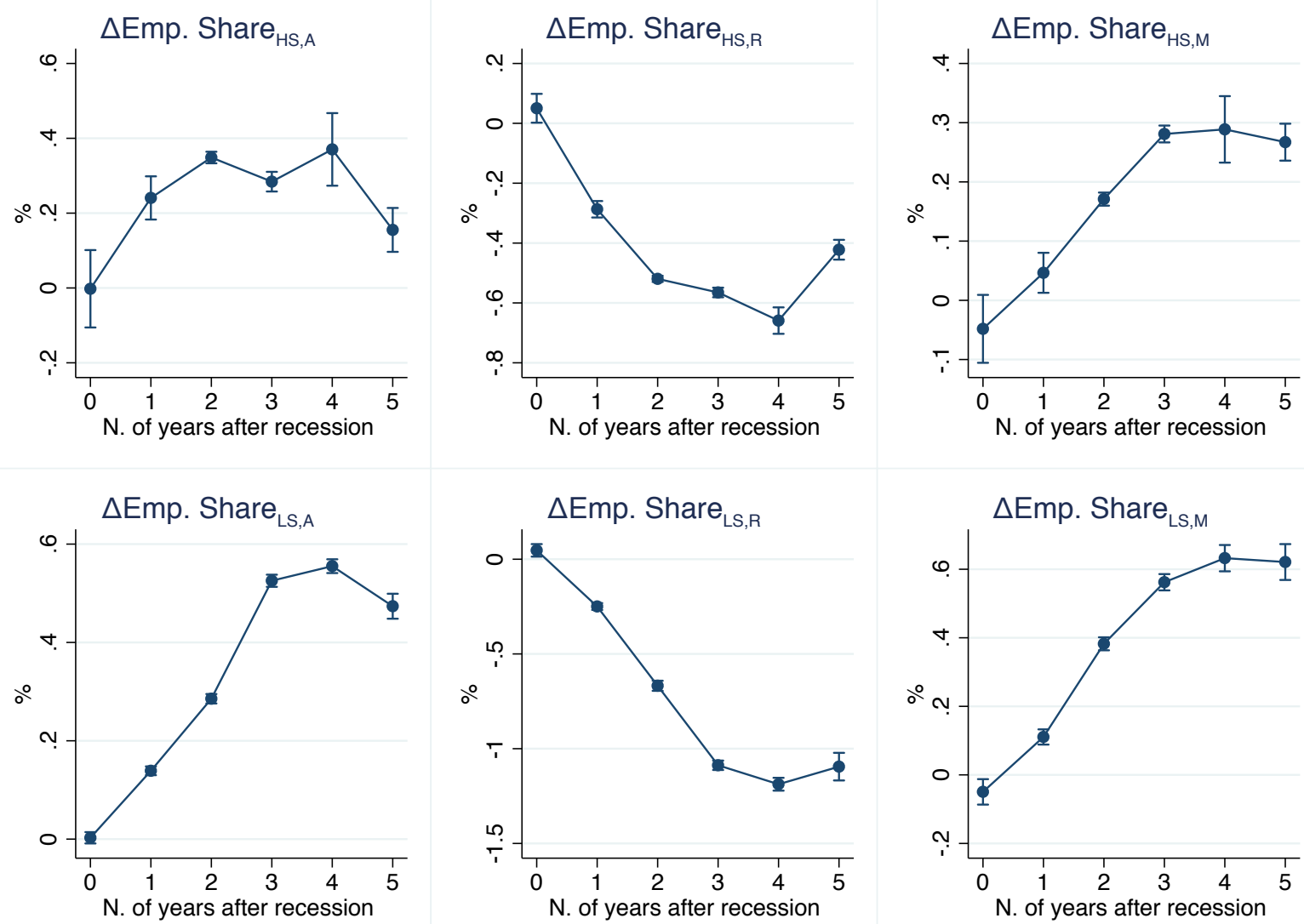

Note: Errors are clustered at state-level and year after the beginning of the local recession. Each sub-graph plots the change of the skill-group specific employment share by occupation as a function the number of years passed from the beginning of the local recession onwards.

model. ${ }^{34}$ Such s decline is compensated by an increase in the employment share in routine jobs. Differently, the employment share remains constant in the manual market.

As from the model, the joint effect of polarization and the business cycle affects permanently LS employment in routine jobs, with the corresponding shares falling permanently after the recession. Such a decline is compensated by an expansion in the abstract and manual market, but with a caveat: if the expansion in the abstract market slightly reverts on the fourth year after the recession, on the other hand it is permanent in the manual market.

To conclude, also within local labor markets, the way workers reallocate over the job ladder when the market polarises is consistent with what observed in aggregate data: when routine jobs disappear, we observe larger movements from the top to the bottom of the job ladder. These movements occur during the economic recovery when the probability of downgrading peaks (as shown in Figure 8).

\footnotetext{
${ }^{34}$ Reversion starts 11 quarters after the shock in the theoretical model.
} 


\subsection{Local Polarization and Labor Market Outcomes}

In this section, I exploit state-level variation to show how much the shift in the occupational structure during the downturn affected the reallocation of skills afterward. To do so, I build a simple measure of polarization capturing the degree to which the local market destroyed more routine jobs relative to non-routine ones during the Great Recession, i.e. how the ratio between non-routine and routine employment changed in local labor markets between the peak and trough of the business cycle. Consider

$$
\text { Polarization }_{s, G R_{s}}=\bigwedge_{G R_{s}}\left(\frac{\text { Employment }_{s} R}{\text { Employment }_{s}^{R}}\right)
$$

where $G R_{s}$ indicates that the change in the ratio of non-Routine to routine employment is evaluated between the beginning and the end of the Great Recession in state $s .{ }^{35}$ According to this definition, an increase in the measure of polarization implies a faster decline of routine employment with respect to non-routine, and therefore a faster polarization. ${ }^{36}$

Recession Polarization and Workers Reallocation Here, I use my polarization index to test if those local markets that experienced faster polarization during the recession, witnessed larger and more persistent employment reallocation down the ladder afterward, i.e. during the recovery and the next economic expansion. For each group $g$ and job $j$, consider the following model:

$$
\begin{aligned}
\Delta Y_{s, t} & =\beta_{1}\left(\delta_{s, t}^{\text {Recovery }} * \text { Polarization }_{s, G R_{s}}\right)+\beta_{2}\left(\delta_{s, t}^{\text {Expansion }} * \text { Polarization }_{s, \text { GR }_{s}}\right) \\
& +\gamma \Delta g d p_{s, t}+\eta \Delta X_{s, t}+\delta_{s, t}^{\text {Expansion }}+\epsilon_{s, t}
\end{aligned}
$$

where $\Delta Y$ is the change in the employment share of group $g$ in job $j$ in State $s$ between the end of the recession and time $t ; \delta_{s}^{\text {Recovery }}$ and $\delta_{s}^{\text {Expansion }}$ are two mutually exclusive time dummies for state $s$ recovery and expansion periods. $\Delta g d p_{s, t}$ captures the change of gdp in $s$. $\Delta X$ controls for group $g$ demographic dynamics and participation in state $s ; \epsilon_{s, t}$ is the error term. Table 5 shows results for the HS group at State-level (model (1)) and for different demographic subgroups (model (2) to (6)). ${ }^{37}$ As reported in Panel A, local labor markets that polarized more during the recession were not able to absorb HS workers into abstract jobs afterward. In fact, during the recovery, we observe a fall in the HS employment share in

\footnotetext{
${ }^{35}$ According to state $s$ recession periods.

${ }^{36}$ Figure A.15 in Online Appendix D summarizes the degree of polarization of the States during the Great Recession by quintiles.

${ }^{37}$ Model (2) for male sample; (3) for female sample; (4) for 16-to-35 years old cohort; (5) for 36-to-55 years old cohort; (6) for 56-to-75 years old cohort.
} 
Table 5: The effect of Polarization on Post Recession High-Skill Employment

\begin{tabular}{cccccc}
\hline \hline$(1)$ & $(2)$ & $(3)$ & $(4)$ & $(5)$ & $(6)$ \\
State & Males & Females & 1st cohort & 2nd cohort & 3rd cohort \\
\hline
\end{tabular}

Panel A: HS Employment in Abstract Jobs

$\begin{array}{lcccccc}\delta_{s, t}^{\text {Recovery }} * \text { Polarization }_{s, G R_{s}} & -0.0351^{* *} & -0.0002 & -0.0346^{* *} & -0.0282^{* *} & -0.0392^{*} & 0.0257^{*} \\ & {[0.016]} & {[0.012]} & {[0.015]} & {[0.013]} & {[0.020]} & {[0.015]} \\ \delta_{s, t}^{\text {Expansion }} * \text { Polarization }_{s, G R_{s}} & -0.0513 & 0.0081 & -0.0553 & -0.0113 & -0.0917^{* *} & 0.0465^{*} \\ & {[0.037]} & {[0.029]} & {[0.034]} & {[0.023]} & {[0.035]} & {[0.027]} \\ R^{2} & 0.301 & 0.125 & 0.163 & 0.104 & 0.208 & 0.092\end{array}$

Panel B: HS Employment in Routine Jobs

$\begin{array}{lcccccc}\delta_{s, t}^{\text {Recovery }} * \text { Polarization }_{s, G R_{s}} & 0.0236^{*} & 0.0139 & 0.0107 & 0.0209^{* *} & -0.0025 & 0.0044 \\ & {[0.014]} & {[0.011]} & {[0.009]} & {[0.010]} & {[0.009]} & {[0.008]} \\ \delta_{s, t}^{\text {Expansion }} * \text { Polarization }_{s, G R_{s}} & 0.0240 & -0.0326^{* *} & 0.0539^{* *} & 0.0318 & -0.0170 & 0.0103 \\ & {[0.031]} & {[0.015]} & {[0.027]} & {[0.020]} & {[0.020]} & {[0.013]} \\ R^{2} & 0.281 & 0.120 & 0.229 & 0.151 & 0.170 & 0.143\end{array}$

Panel C: HS Employment in Manual Jobs

\begin{tabular}{lcccccc}
$\delta_{s, t}^{\text {Recovery }} *$ Polarization $_{s, G R_{s}}$ & 0.0052 & 0.0051 & 0.0020 & 0.0061 & $-0.0061^{*}$ & 0.0059 \\
& {$[0.009]$} & {$[0.007]$} & {$[0.007]$} & {$[0.005]$} & {$[0.003]$} & {$[0.004]$} \\
$\delta_{s, t}^{\text {Expansion }} *$ Polarization $_{s, G R_{s}}$ & -0.0055 & -0.0134 & 0.0089 & 0.0121 & $-0.0180^{*}$ & 0.0003 \\
& {$[0.015]$} & {$[0.013]$} & {$[0.013]$} & {$[0.011]$} & {$[0.009]$} & {$[0.005]$} \\
$R^{2}$ & 0.130 & 0.065 & 0.115 & 0.089 & 0.253 & 0.034 \\
\hline \hline State Level Controls & Yes & Yes & Yes & Yes & Yes & Yes \\
Demographic Dynamics & Yes & Yes & Yes & Yes & Yes & Yes \\
Expansion Dummy & Yes & Yes & Yes & Yes & Yes & Yes \\
\hline Observations & 919 & 919 & 919 & 919 & 919 & 919 \\
\hline \hline
\end{tabular}

Notes: Standard errors in parentheses, clustered at State-level. The unit of observation in column (1) is the change in the employment share of HS workers in abstract jobs (panel A), routine job (panel B), manual jobs (panel C). Such a change is farther dis-aggregated by gender (column (2) and (3)) and cohort groups (column (4) for 16-to-35 years old cohort; (5) for 36 -to-55 years old cohort; (6) for 56-to-75 years old cohort). The index Polarization $_{s, G R_{s}}$ captures the degree at which State $s$ shifted the occupational structure in favour of non-routine jobs during the Great Recession, and it is the change of the ratio of non-routine employment over routine employment between the peak and trough of the local business cycle. $\delta_{s, t}^{\text {Recovery }}$ and $\delta_{s, t}^{\text {Expansion }}$ are dummies for post-recession recovery and expansion periods according to business cycle dates of state $s$. $*, * *$, $* * *$ indicate significance at $1 \%, 5 \%$ and $10 \%$ level. 
Table 6: The effect of Polarization on Post Recession Low-Skill Employment

\begin{tabular}{cccccc}
\hline \hline$(1)$ & $(2)$ & $(3)$ & $(4)$ & $(5)$ & $(6)$ \\
State & Males & Females & 1st cohort & 2nd cohort 3rd cohort
\end{tabular}

Panel A: LS Employment in Abstract Jobs

$\begin{array}{lcccccc}\delta_{s, t}^{\text {Recovery }} * \text { Polarization }_{s, G R_{s}} & -0.0212^{* * *} & -0.0038 & -0.0162^{* * *} & -0.0160^{* * *} & -0.0210^{* * *} & 0.0169^{* * *} \\ & {[0.006]} & {[0.005]} & {[0.005]} & {[0.005]} & {[0.006]} & {[0.006]} \\ \delta_{s, t}^{\text {Expansion }} * \text { Polarization }_{s, G R_{s}} & -0.0173 & 0.0072 & -0.0218 & 0.0092 & -0.0308^{*} & 0.0032 \\ & {[0.030]} & {[0.012]} & {[0.021]} & {[0.012]} & {[0.016]} & {[0.011]} \\ R^{2} & 0.258 & 0.198 & 0.171 & 0.186 & 0.228 & 0.372\end{array}$

Panel B: LS Employment in Routine Jobs

$\begin{array}{lcccccc}\delta_{s, t}^{\text {Recovery }} * \text { Polarization }_{s, G R_{s}} & 0.0077 & 0.0294^{* * *} & -0.0233^{* * *} & 0.0084 & -0.0234^{* * *} & 0.0132 \\ & {[0.006]} & {[0.009]} & {[0.009]} & {[0.008]} & {[0.008]} & {[0.009]} \\ \delta_{s, t}^{\text {Expansion }} * \text { Polarization }_{s, G R_{s}} & -0.0626^{* *} & -0.0329 & -0.0247 & -0.0135 & -0.0320 & -0.0141 \\ & {[0.025]} & {[0.025]} & {[0.028]} & {[0.009]} & {[0.021]} & {[0.016]} \\ R^{2} & 0.667 & 0.340 & 0.431 & 0.368 & 0.276 & 0.120\end{array}$

Panel C: LS Employment in Manual Jobs

\begin{tabular}{lcccccc}
$\delta_{s, t}^{\text {Recovery }} *$ Polarization $_{s, G R_{s}}$ & $0.0222^{* * *}$ & $0.0141^{* *}$ & $0.0102^{* * *}$ & $0.0220^{* * *}$ & 0.0070 & $-0.0097^{*}$ \\
& {$[0.002]$} & {$[0.006]$} & {$[0.003]$} & {$[0.007]$} & {$[0.006]$} & {$[0.005]$} \\
$\delta_{s, t}^{\text {Expansion }} *$ Polarization $_{s, G R_{s}}$ & $0.0551^{* * *}$ & 0.0272 & $0.0274^{* * *}$ & 0.0140 & $0.0271^{*}$ & 0.0125 \\
& {$[0.011]$} & {$[0.021]$} & {$[0.008]$} & {$[0.027]$} & {$[0.015]$} & {$[0.015]$} \\
$R^{2}$ & 0.130 & 0.061 & 0.122 & 0.068 & 0.191 & 0.033 \\
\hline \hline State Level Controls & Yes & Yes & Yes & Yes & Yes & Yes \\
Demographic Dynamics & Yes & Yes & Yes & Yes & Yes & Yes \\
Expansion Dummy & Yes & Yes & Yes & Yes & Yes & Yes \\
\hline Observations & 919 & 919 & 919 & 919 & 919 & 919 \\
\hline \hline
\end{tabular}

Notes: Standard errors in parentheses, clustered at State-level. The unit of observation in column (1) is the change in the employment share of LS workers in abstract jobs (panel A), routine job (panel B), manual jobs (panel C). Such a change is farther dis-aggregated by gender (column (2) and (3)) and cohort groups (column (4) for 16-to-35 years old cohort; (5) for 36 -to-55 years old cohort; (6) for 56-to-75 years old cohort). The index Polarization $_{s, G R_{s}}$ captures the degree at which State $s$ shifted the occupational structure in favour of non-routine jobs during the Great Recession, and it is the change of the ratio of non-routine employment over routine employment between the peak and trough of the local business cycle. $\delta_{s, t}^{R e c o v e r y}$ and $\delta_{s, t}^{\text {Expansion }}$ are dummies for post-recession recovery and expansion periods according to business cycle dates of state $s$. *, **, $* * *$ indicate significance at $1 \%, 5 \%$ and $10 \%$ level. 
abstract occupations by 3.5 percentage points. This fall is mainly due to women, and workers from the first two cohorts. The only possible occupation in which the share of HS employment could grow during the recovery was a routine one (Panel B), with younger workers more likely to downgrade during the recovery and women during the following expansion. This evidence is consistent with the idea, introduced by Beaudry et al. (2016), that a "great reversal" in the demand for skills is pervading the abstract market, thus pushing HS workers down the ladder. As Panel C shows, manual jobs could not significantly absorb HS workers during the recovery and the next expansion phase. It is important to notice that -within local labor markets- the effect of the shift of the occupational structure experienced during the recession has significant impact on the reallocation of HS workers only during the economic recovery but vanishes (at least at State-level) in the next expansion. This corroborates the fact that the reallocation down the ladder is only temporary for HS workers. Table 6 shows results for LS workers. As from model (1) of Panel A, higher state-level polarization did not allow LS workers to recover through abstract occupations in the aftermath of the GR. In fact, for a 1 percentage point increase in polarization, LS employment share in abstract jobs fell by 2 points during the recovery. Such a decline is mostly explained by women and the first two cohorts. Panel B shows results for LS employment in routine jobs. These jobs were mostly destroyed during the recession, but -once the economy reorganized and started expanding again- the polarization trend dominated with LS employment share declining by 6 percentage points with respect to the end of the recession. This suggests that local markets that polarized more tend to polarize also in the future at the expense of LS workers who, indeed, are dismissed abundantly from the routine market. In the aftermath of the Great Recession, the bulk of LS workers could recover only through manual occupations, with a 2.2 points increase for states that polarized more (Panel C). Such expansion of the LS employment share in the manual market continued afterward, with a further rise by 3.3 points, thus reaching an overall increase of 5.5 points from the end of the recession. This is mostly explained by women and the younger cohort.

In conclusion, the disruptive effects of polarization and its interaction with the cycle lead to different patterns of human capital reallocation across jobs. The degree at which a local market polarizes affects the size of future reallocation. In fact, stronger polarization magnifies movements from the top to the bottom of the job ladder, with HS workers only temporarily reallocating in routine jobs rather than abstract ones during the recovery, and LS workers persistently more likely to get manual jobs from the recovery onwards. 


\subsection{Skill-Requirements and the Great Recession}

In this section I loose the classification of skill-groups commonly used in the literature (HS vs. LS) when mapping education to job tasks. In practice, I introduce a broader spectrum of educational attainments and study which schooling degree matters the most and when for an unemployed individual to be hired. This will help to show (i) which skills mattered the most during the GR and for which jobs, and (ii) if there was cyclical up-skilling within each occupation. To do so, I use the longitudinal component of CPS data to look at flows from unemployment to employment. In particular, I consider a sample of 25 to 55 years old unemployed individuals interviewed in two consecutive months and whose unemployment spell is below or equal to 4 weeks. Each individual unemployed in the first month can flow to one of the three jobs ${ }^{38}$, remain unemployed or flow to non-participation in the next month. Therefore, a discrete choice model (i.e. a multinomial logit) can account for the odds of each individual to flow out of unemployment as a function of individual characteristics and business cycle phases. With the baseline choice normalized to remaining unemployed, the unconditional probability for individual $i$ to flow (F) from unemployment (U) to abstract $(A)$, routine $(\mathrm{R})$, manual $(\mathrm{M})$ or non-participation (NLF) between $\mathrm{t}$ and $\mathrm{t}+1$ can be written as:

$$
\operatorname{Pr}\left(F_{i, s, t+1}^{j} \mid U_{i, s, t}\right)=\frac{\exp \left(\Gamma_{i, F^{j}}^{\prime} X_{i, s, t}\right)}{1+\sum_{j} \exp \left(\Gamma_{i, F^{j}}^{\prime} X_{i, s, t}\right)}
$$

where $X_{i, t}$ is a vector of regressors and $\Gamma$ s are the parameters. The vector $X$ contains individual characteristics: educational attainments, a polynomial of potential experience, marital status, family size, number of children, sex, race, a state dummy and a economic phase dummy accounting for recession, recovery and expansions periods in that State. Such a time dummy is interacted with all regressors so to generate the marginal probabilities reported in Figure 10. The direction of the flow is indexed with $j=\{A, R, M, U, N L F\}$. Consider flows from $\mathrm{U}$ to $\mathrm{A}$. By the shape of the probability curve, it is clear that abstract jobs are typical of highly educated persons. However, the shape changes over different cyclical phases: it is concave in pre-recession periods, it becomes convex during the turmoil and it returns concave afterward. In particular, when the recession hits, a Master/PhD Degree gives 10\% more chances to get an abstract job than a Bachelor Degree and almost 20\% more with respect to those with some college education. ${ }^{39}$ In other words, abstract occupations are experiencing up-skilling, particularly severe during the recession and attenuated afterward.

\footnotetext{
${ }^{38}$ I consider flows to employment only for those individuals who report to be in a full-time job and not self-employed in the following month. Recalls are excluded.

${ }^{39}$ College dropouts and vocational graduates.
} 
Fig. 10. Transition Probabilities
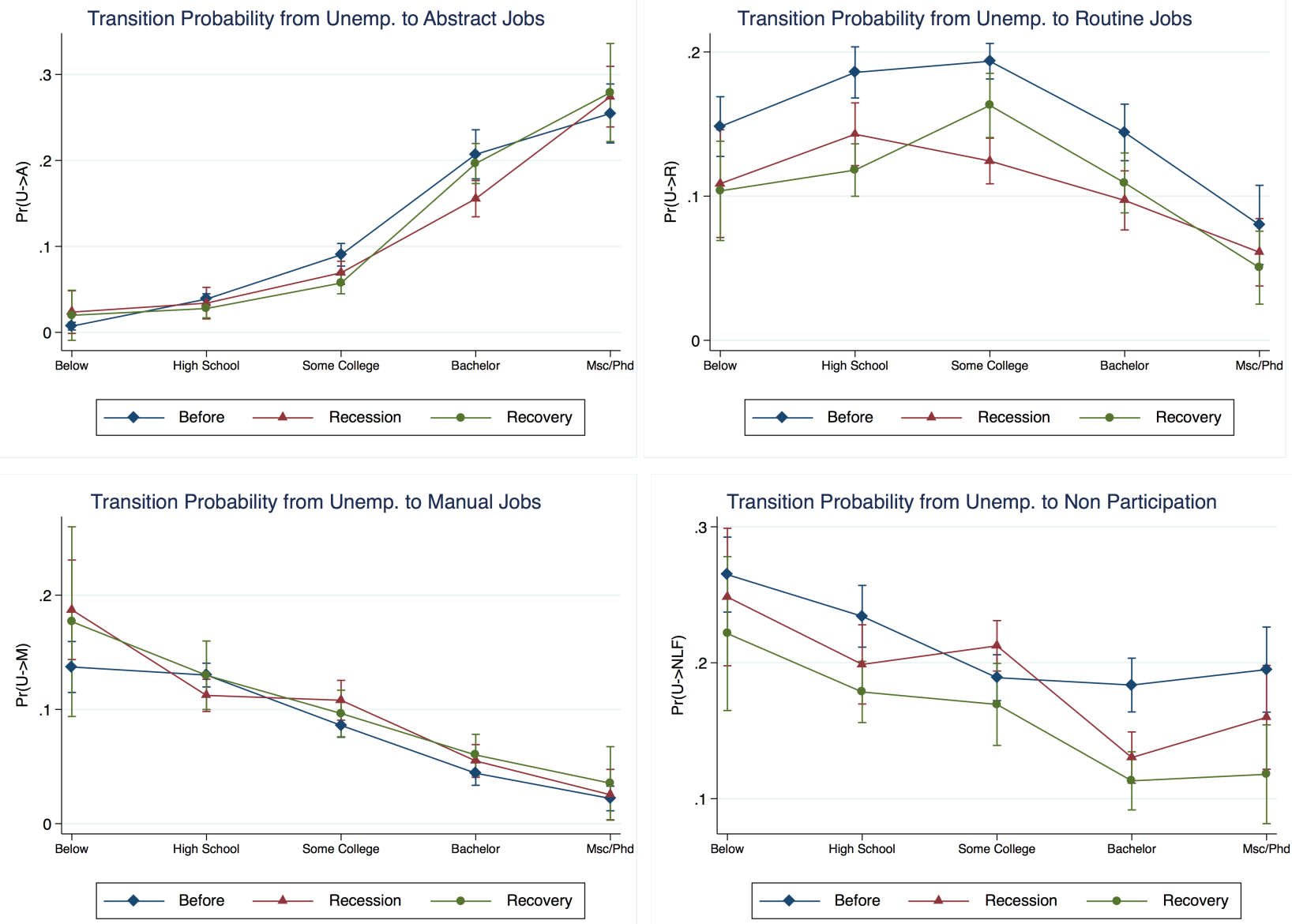

Note: The figure shows the transition probability for an unemployed worker to move from unemployment to an abstract, routine, manual job or to non-participation for different cyclical phases (before the GR, during the GR and during the economic recovery). This probability is expressed as a function of 5 educational attainments (as reported from CPS): below High School Diploma, High School Diploma, Some College (vocational degree, 2 years of college without degree, dropouts), Bachelor Graduates, Master and PhD Graduates (including other post-graduate titles). Errors are clustered by State and robust. Margins are computed at the mean age of a sample of 25-to-55 years old individuals with 4 weeks of unemployment spell (maximum). Recalls and self-employed are excluded. CPS individual weights used. For readability, the probability curves for periods after the recovery are here dropped, but they do not statistically differ from those for recovery periods.

Now consider flows from $\mathrm{U}$ to $\mathrm{R}$. The inverted u-shaped curve suggests that workers coming from the middle of the skill distribution (those falling under the "Some College", "High School" categories) match more frequently the labor demand in this occupation. When the recession hits, the probability curve shifts down. During the recovery, only the most skilled ones within the LS macro-group (i.e. those with Some College) are served first in the matching process. On the other hand, High School graduates do not catch-up, now facing a probability almost $10 \%$ lower than in pre-recession periods. In other words, there is a shift in the skill distribution towards higher degrees in post-recession periods also in routine jobs, where up-skilling occurs through trimming off the left-tail of the skill distribution. In addition, the fact that the curve does not shift up again to pre-recession levels confirms 
the difficulty do find routine jobs after the recession, due to the permanent shift in the occupational structure. Regarding flows from $U$ to $M$, the marginal probability is decreasing in educational attainments indicating that these jobs are typical of very low-skilled workers. for this occupation, the business cycle does not have any significant effect. Finally, the probability to flow from $U$ to non-participation peaks during the recession for those with some years of college: not able to upgrade or to go back to their previous occupation or not willing to downgrade, they prefer to stop searching and quit the labor force.

\subsection{Wages, Skills and Jobs}

Return to Education over the Cycle Here I study how hourly wages differ over the skills distribution and vary over the cycle within each job. Differently from Section 5.4, I expand even further the skills dimension in order to better understand the return to skills within each occupation and corroborate what the structural estimation of Section 3 predicts: returns to skills are linear in abstract jobs $\left(\lambda_{a}=1.13\right)$, but decreasing in routine ones $\left(\lambda_{a}=0.40\right)$. In light of this, I consider this Mincerian equation for each occupation:

$$
\begin{aligned}
\log \left(w_{i, s, t}\right) & =\alpha+\beta_{1} \delta_{s, t}+\beta_{2} \text { Attainment }_{i}+\beta_{3} \delta_{s, t} * \text { Attainment }_{i} \\
& +X_{i, t}^{\prime} \gamma_{1}+\text { Attainment }_{i} * X_{i, t}^{\prime} \gamma_{2}+\epsilon_{i, s, t}
\end{aligned}
$$

where $\log \left(w_{i}, t\right)$ is the $\log$ of the real hourly wage for worker $i$ in time $t$; $\alpha$ captures the mean log-wage across individuals; $\delta_{s, t}$ is a dummy variable indicating in which cyclical phase ${ }^{40}$ is the State of residence of worker $i$ in time $t$; Attainments is a dummy indicating the highest degree of worker $i$; the vector of controls $X$ contains a polynomial of experience, a dummy for sex, marital status, number of children and sector of employment. Figure 11 plots margins for the "average" worker.

First, consider abstract jobs. In this market, the return to skills is increasing and linear, thus confirming the meaningfulness and accuracy of the estimated return to skills from the structural model. Moreover, there is no significant cyclical variation of the return to schooling. Differently, there are decreasing returns to schooling in the routine market as predicted from the structural estimation. Here, the business cycle has more evident effects for those in the left tail of the skill distribution. In fact, although there is no significant difference across the first expansion, the recession and the recovery, returns for workers with some college education or below ${ }^{41}$ are significantly lower in the last expansion with respect to previous economic phases. This suggests that the routine market offers lower

\footnotetext{
${ }^{40}$ Before the recession, during the recession, during the recovery or after.

${ }^{41}$ This difference is significant at least at the $90 \%$ level for educational level below some years of college.
} 
Fig. 11. Wages, Skills and the Cycle
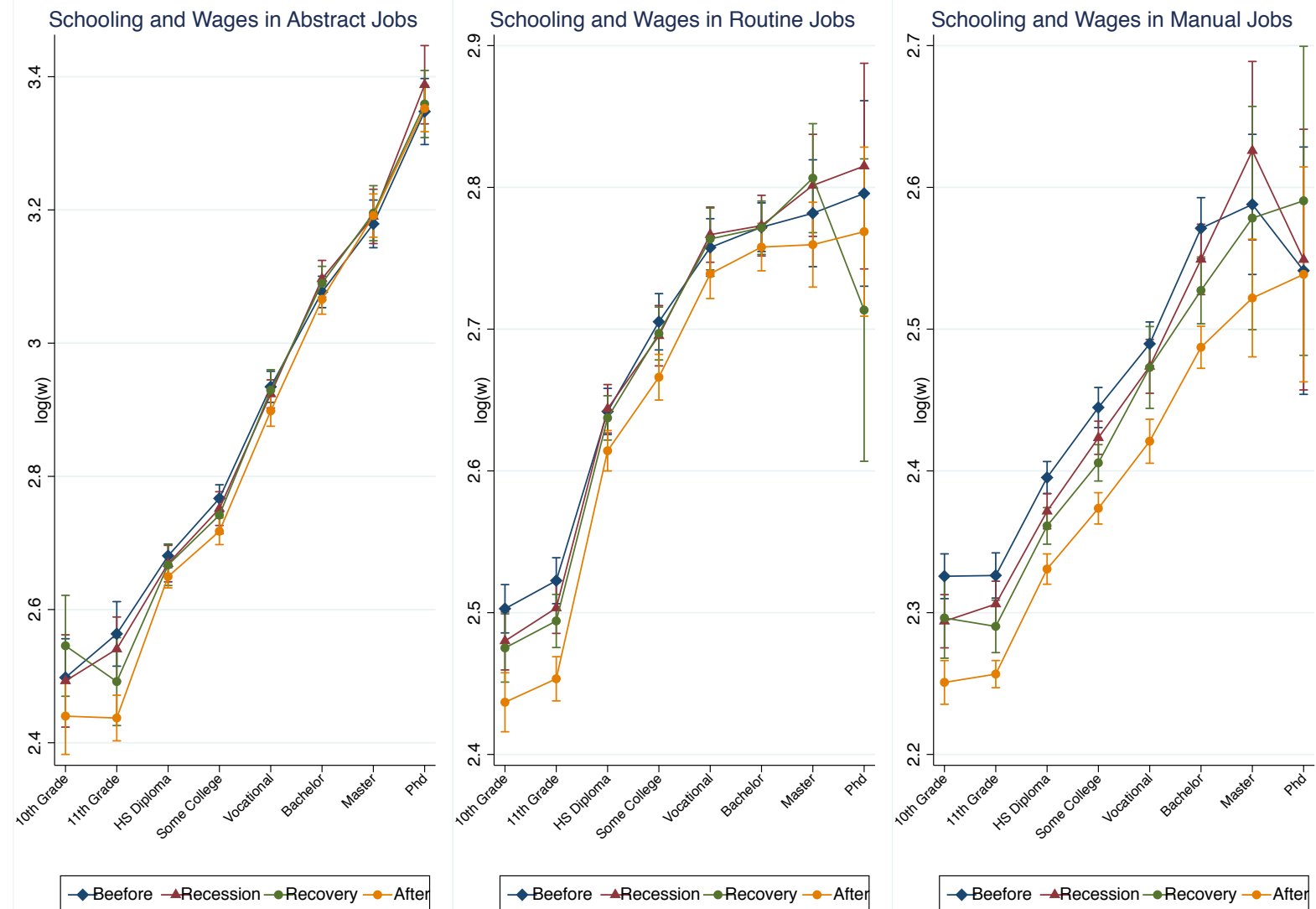

Note: The figure plots the logarithm of the inflation-adjusted hourly wage as a function of 8 educational attainments (as reported from CPS): 10th Grade, 11th Grade, High School Diploma, Some College (2 years of college without degree and dropouts), Vocational Diploma, Bachelor Graduates, Master and PhD Graduates (including other post-graduate titles), and four different cyclical phases (before the GR, during the GR, during the economic recovery, and in the next expansion). Errors are clustered by State and robust. Margins are evaluated at the mean experience. CPS individual weights used. Hourly wages are adjusted for inflation with 2009 deflator.

wages over time but tends to reward more workers with higher skills, for which the wage does not significantly change over the cycle.For manual jobs, hourly wages are increasing with educational attainments. Similarly to the routine market, the curve is shifting down over time with significant differences for all attainments below a bachelor degree. ${ }^{42}$

The Wage Ladder by Major Skill-Groups Here I study how the match between major skill-groups and jobs affects wages and then I drive comparisons with the results from the model. Following recent developments in the literature as Firpo, Fortin, and Lemieux (2010), Fortin, Green, Lemieux, Milligan, and Riddell (2012) and Lemieux (2014), I consider the

\footnotetext{
${ }^{42}$ This difference is significant at the $99 \%$ level for educational level below a bachelor diploma.
} 
following:

$$
w_{i, t}=\alpha+\mathcal{M}_{\boldsymbol{i}}(\boldsymbol{g}, \boldsymbol{j})^{\prime} \beta_{1}+X_{i, t}^{\prime} \gamma_{1}+\mathcal{M}_{\boldsymbol{i}}(\boldsymbol{g}, \boldsymbol{j})^{\prime} * X_{i, t}^{\prime} \gamma_{2}+\gamma_{3} \delta_{s, t}+\epsilon_{i, t}
$$

where $\mathcal{M}(\boldsymbol{g}, \boldsymbol{j})$ is matching vector of mutually exclusive dummies taking value 1 if -for any skill-group $g=\{L S, H S\}$ and job $j$ - worker $i$ from group $g$ is matched to occupation $j$ so that $\beta_{1}$ is a vector collecting skill-to-job productivity coefficients; all other control variables are the same before. The left-hand side of Figure 12 plots margins of $\boldsymbol{M}(\boldsymbol{g}, \boldsymbol{j})$ for the

Fig. 12. Major Groups Wage Ladder: model vs. data
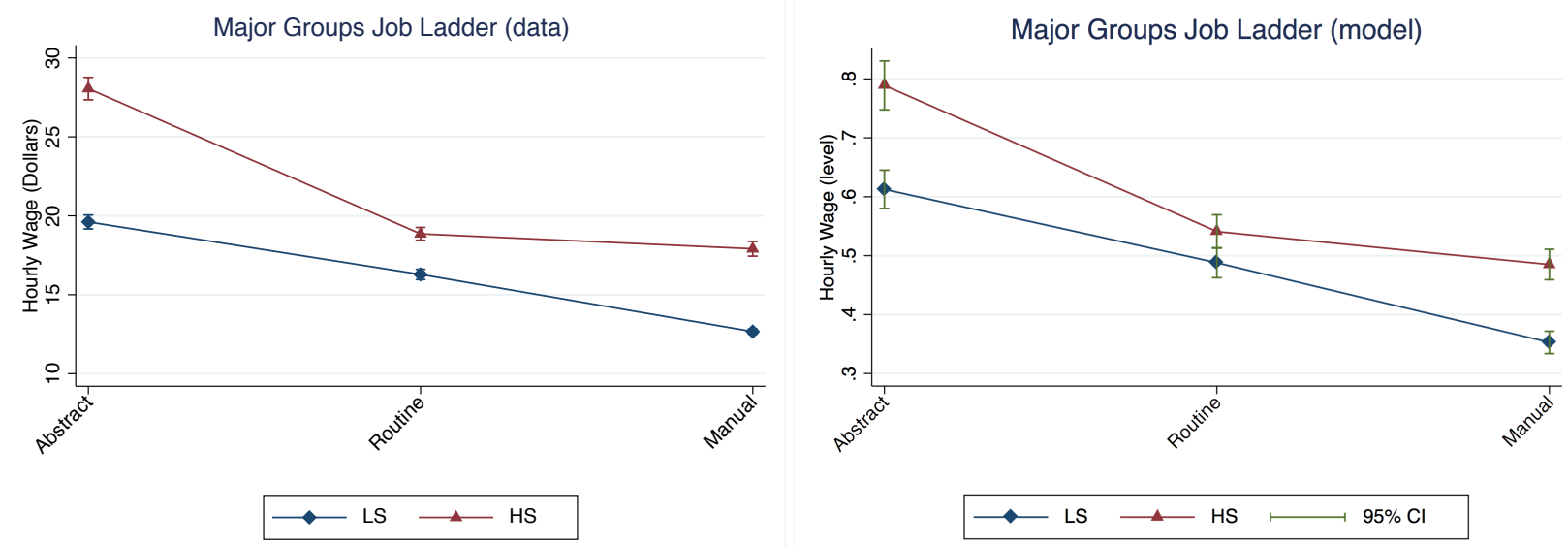

Note: This figure the wage ladder for HS and LS workers from the model and the data. For the regression results (left-hand side), the inflation-adjusted hourly wage is a function of the current job (abstract, routine, manual) of the worker. Errors are clustered by job and robust. Margins are evaluated at the mean experience. CPS individual weights used. Hourly wages are adjusted for inflation with 2009 deflator. For the model results (right-hand side), mean wages and their respective $95 \%$ confidence intervals are evaluated out of the simulation as described in Section 4.

average-experienced worker for every combination of $g$ and $j$, whereas the right-hand side plots results from the model simulation as described in Section 4. For both, the y-axis reports wages in level. At first sight, the wage ladders for HS and LS workers from the data look very similar to those generated from the model. In detail, LS workers are facing a wage ladder that is declining in a linear fashion when moving from abstract jobs to others. The same behavior occurs in the model, where the slope of the wage ladder is almost constant for LS workers. On the other hand, the shape of the wage ladder for HS workers differs: there is a sharp fall when moving from an abstract to a routine job, while the loss is small when moving from routine to manual jobs. The same convex pattern is generated by the model, with a sharp loss when moving from an abstract to a routine job and a less severe loss thereafter. In other words, HS wages are more volatile but the potential wage loss is attenuated as long as workers slide down the ladder from abstract to manual jobs. In the spirit of the model, this is because larger job opportunities (i.e. higher outside options) compensate HS workers when not matched to abstract jobs. This translates into a wage 
compression so that the salary in a routine and manual job do not differ much, i.e. there is a lower-bound in the wage loss. Under the same argument, it is the lack of outside options that generates an unbounded and (almost) linear wage loss for LS workers. Notice finally that HS workers have a wage premium in each occupation.

\section{Conclusion}

This paper studies the effect of job polarization and the Great Recession (GR) on the reallocation of skills across jobs. Despite the large literature on polarization, any study so far has carefully investigated how this process affects the reallocation of skills and the demand for skills across jobs, in particular during downturns. This paper fills the gap and shows that job polarization triggers movements of highly-qualified workers down the job ladder, and causes large skill-to-job mismatch, longer unemployment spells and sluggish labor mobility for a large share of the population. To show this, I introduces a search-and-matching model -with multiple jobs and heterogeneous agents- which generates an endogenous mapping between jobs and skills. This framework allows to track workers and their allocation of skills across occupations and to know what are workers' job opportunities given their skill-level. The model delivers long-run polarization under a routine biased technical change (RBTC) trend, and "cyclical polarization" under a transitory aggregate shock. Estimating the model for periods around the GR -a severe polarization episode- reveals that it is sufficient to target aggregate occupational dynamics in order for the model to reproduce the reallocation patterns of high and low-skilled workers and the skill-to-job mismatches observed in the data. In particular, the model predicts that $1 \mathrm{pp}$ decline in routine employment -as explained by RBTC and an aggregate shock- leads to an increase in skill-to-job mismatch employment by $0.18 \mathrm{pp}$ (0.31pp in the data). Skill mismatches are mostly concentrated during the economic recovery and are explained by movements from the top to the bottom of the job ladder. However, the dynamic and cost of mismatch differ across skill-groups: high-skill workers tend to be mismatched only temporarily, while mismatch is very persistent for low-skill workers. At the same time, the wage loss from mismatch is bounded for high-skill workers when moving down the ladder, while it is not true for the low-skilled. Comparison with the central planner solution reveals that $1 / 4$ of mismatches are actually efficient during the downturn. In fact, by pooling higher skills down the ladder, routine employers can keep routine jobs alive through a more productive workforce. Therefore, under the planner solution, the cyclical features of polarization are dramatically attenuated and welfare is preserved by protecting routine workers from unemployment or from lower-paying jobs. Finally, the model explains

$38 \%$ of the shift-out of the Beveridge curve in the post-recession era and rationalizes the 
factors driving aggregate matching efficiency deterioration.

Along with the theory, I validate the predictions and main mechanics of the model within local labor markets. The reduced-form analysis confirms that: (i) the joint effect of polarization and the great recession is common across local markets, with high-skill workers recovering temporarily through routine jobs and with low-skill workers recovering permanently through manual jobs; (ii) the more the local market polarizes during the recession, the larger these vertical movements are; (iii) skill-requirements matter to enter abstract and routine jobs over the cycle.

This paper is the first one showing how polarization and the cycle affect workers depending on their skills. Yet, important questions are left for future research. For example, how much the shift in employment opportunities can explain wage inequality over the life-cycle, how the government could optimally finance training subsidies for the low-skilled to become qualified for better jobs, which type of skills must be built and what kind of tax system is appropriate in the context of job polarization and technical change. These are fundamental questions whose answers will affect future generations and the structure of our society. 


\section{References}

Acemoglu, D., 2002. Directed technical change. The Review of Economic Studies 69, 781-809.

Acemoglu, D., Autor, D., 2011. Skills, tasks and technologies: Implications for employment and earnings. Handbook of labor economics 4, 1043-1171.

Albrecht, J., Vroman, S., 2002. A matching model with endogenous skill requirements. International Economic Review 43, 283-305.

Autor, D., et al., 2010. The polarization of job opportunities in the us labor market: Implications for employment and earnings. Center for American Progress and The Hamilton Project .

Autor, D. H., 2007. Technological change and earnings polarization: Implications for skill demand and economic growth. In: Massachusetts Institute for Technology, Economics Program Working Paper Series, part of the Supplemental Materials for Innovation and US Competitiveness The Conference Board report.

Autor, D. H., Dorn, D., 2013. The growth of low-skill service jobs and the polarization of the us labor market. The American Economic Review 103, 1553-1597.

Autor, D. H., Dorn, D., Hanson, G. H., 2013. The china syndrome: Local labor market effects of import competition in the united states. The American Economic Review 103, 2121-2168.

Autor, D. H., Dorn, D., Hanson, G. H., 2015. Untangling trade and technology: Evidence from local labour markets. Economic Journal 125, 621-46.

Autor, D. H., Katz, L. F., Kearney, M. S., 2006. The polarization of the us labor market. Tech. rep., National Bureau of Economic Research.

Autor, D. H., Levy, F., Murnane, R. J., 2002. Upstairs, downstairs: Computers and skills on two floors of a large bank. ILR Review 55, 432-447.

Barlevy, G., 2011. Evaluating the role of labor market mismatch in rising unemployment .

Barnichon, R., Figura, A., 2011. Labor market heterogeneities, matching efficiency and the cyclical behavior of the job finding rate. Unpublished manuscript, CREI .

Barro, R. J., Lee, J.-W., 2000. International data on educational attainment updates and implications. Tech. rep., National Bureau of Economic Research. 
Beaudry, P., Green, D. A., Sand, B. M., 2016. The great reversal in the demand for skill and cognitive tasks. Journal of Labor Economics 34, S199-S247.

Bhattacharya, J., Bunzel, H., 2003. Dynamics of the planning solution in the discrete-time textbook model of labor market search and matching. Economics Bulletin 5, 1-10.

Blázquez, M., Jansen, M., 2008. Search, mismatch and unemployment. European Economic Review 52, 498-526.

Carrillo-Tudela, C., Visschers, L., 2013. Unemployment and endogenous reallocation over the business cycle .

Cortes, G. M., 2016. Where have the middle-wage workers gone? a study of polarization using panel data. Journal of Labor Economics 34, 63-105.

Cortes, G. M., Jaimovich, N., Nekarda, C. J., Siu, H. E., 2014. The micro and macro of disappearing routine jobs: A flows approach. Tech. rep., National Bureau of Economic Research.

Davis, S. J., Faberman, R. J., Haltiwanger, J. C., 2013. The establishment-level behavior of vacancies and hiring. The Quarterly Journal of Economics 128, 581-622.

Davis, S. J., von Wachter, T. M., 2011. Recessions and the cost of job loss. Tech. rep., National Bureau of Economic Research.

Diamond, P. A., 1982. Wage determination and efficiency in search equilibrium. The Review of Economic Studies 49, 217-227.

Diamond, P. A., Şahin, A., 2015. Shifts in the beveridge curve. Research in Economics 69, $18-25$.

Drew, J. A. R., Flood, S., Warren, J. R., 2014. Making full use of the longitudinal design of the current population survey: Methods for linking records across 16 months. Journal of economic and social measurement 39, 121.

Elsby, M. W., Hobijn, B., Şahin, A., Valletta, R. G., 2011. The labor market in the great recessionan update to september 2011. Brookings Papers on Economic Activity 2011, 353384.

Farber, H. S., 1996. The changing face of job loss in the united states, 1981-1993. Tech. rep., National bureau of economic research. 
Farber, H. S., 2015. Job loss in the great recession and its aftermath: Us evidence from the displaced workers survey. Tech. rep., National Bureau of Economic Research.

Firpo, S., Fortin, N. M., Lemieux, T., 2010. Occupational tasks and changes in the wage structure .

Fortin, N., Green, D. A., Lemieux, T., Milligan, K., Riddell, W. C., 2012. Canadian inequality: Recent developments and policy options. Canadian Public Policy 38, 121-145.

Goos, M., Manning, A., 2007. Lousy and lovely jobs: The rising polarization of work in britain. The review of economics and statistics 89, 118-133.

Hall, R. E., 2010. The labor market in the current slump. Tech. rep., mimeo.

Haltiwanger, J., Hyatt, H., McEntarfer, E., 2015. Cyclical reallocation of workers across employers by firm size and firm wage. Tech. rep., National Bureau of Economic Research.

Huckfeldt, C., 2016. Understanding the scarring effect of recessions. Report, Economics Department, Cornell University .

Jaimovich, N., Siu, H. E., 2012. The trend is the cycle: Job polarization and jobless recoveries. Tech. rep., National Bureau of Economic Research.

Jarosch, G., 2014. Searching for job security and the consequences of job loss. V University of Chicago, Job Market Paper .

Krolikowski, P., 2017. Job ladders and earnings of displaced workers. American Economic Journal: Macroeconomics 9, 1-31.

Lemieux, T., 2014. Occupations, fields of study and returns to education. Canadian Journal of Economics/Revue canadienne d'économique 47, 1047-1077.

Lilien, D. M., 1982. Sectoral shifts and cyclical unemployment. Journal of political economy 90, 777-793.

Madrian, B. C., Lefgren, L., 1999. A note on longitudinally matching current population survey (cps) respondents.

McLaughlin, K. J., Bils, M., 2001. Interindustry mobility and the cyclical upgrading of labor. Journal of Labor Economics 19, 94-135.

Mortensen, D. T., Pissarides, C. A., 1994. Job creation and job destruction in the theory of unemployment. The review of economic studies 61, 397-415. 
Ngai, L. R., Pissarides, C. A., 2007. Structural change in a multisector model of growth. American economic review 97, 429-443.

Ravn, M. O., Sterk, V., 2015. Job uncertainty and deep recessions. Unpublished manuscript

Şahin, A., Song, J., Topa, G., Violante, G. L., 2014. Mismatch unemployment. The American Economic Review 104, 3529-3564.

Schmieder, J. F., von Wachter, T., Bender, S., 2010. The long-term impact of job displacement in germany during the 1982 recession on earnings, income, and employment. Tech. rep., IAB discussion paper.

Schmitt-Grohé, S., Uribe, M., 2004. Solving dynamic general equilibrium models using a second-order approximation to the policy function. Journal of economic dynamics and control 28, 755-775.

Shimer, R., 2005. The cyclical behavior of equilibrium unemployment and vacancies. The American Economic Review 95, 25-49.

Topel, R., 1990. Specific capital and unemployment: Measuring the costs and consequences of job loss. In: Carnegie-Rochester Conference Series on Public Policy, Elsevier, vol. 33, pp. 181-214. 


\section{ONLINE APPENDIX (not for publication)}

\section{Appendix A. The Model}

Fig. A.1. Skill-separating vs. Skill-pooling Equilibrium
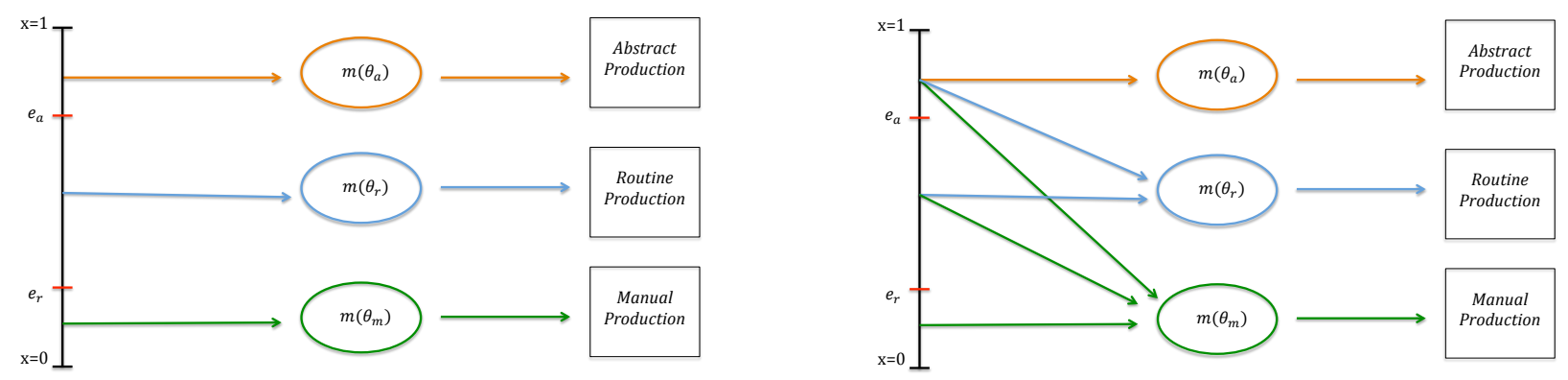

Note: This figure represents graphically the concept of skill-separating (left-panel) and skill-pooling (right-panel) equilibrium.

\section{A.1. Equilibria and Sorting Mechanisms in a Nutshell}

The focal point of the model is the sorting mechanism which depends on: (i) the individual position on the skill distribution; (ii) the endogenous skill-requirements; (iii) the value of the surplus from the match. To better understand this, imagine splitting the time of the matching process in three sub-periods. In the first one, employers post vacancies and set the endogenous skill-requirements $e_{a}$ and $e_{r}$. For the sake of the argument and simplicity, say that $e_{a}>e_{r}>0$. Then workers observe the skill-requirements and understand what are their job opportunities, i.e the jobs for which they satisfy requirements. Hence they direct their search only towards their job-opportunity set and they randomize their search on top of it. Therefore, individuals with $x \geq e_{a}$ search over all jobs, individuals with $x \in\left[e_{r}, e_{a}\right)$ search over routine and manual jobs, and individuals with $x \in\left[0, e_{r}\right)$ search over manual jobs only. In this sense, workers search selectively only in the submarkets for which they are qualified in that moment. In the second sub-period, vacancies arrive to workers such that matches are formed. Although the different job opportunities across individuals, matches become active only if they generate a positive surplus. Among the many, this sorting process defines two possible and alternative equilibria: a skill-separating equilibria (left-hand side of Figure A.1) and a skill-pooling equilibria (right-hand side of Figure A.1). In the first one, workers generate a positive surplus only when matched with the best job available in their job opportunity set. Hence, under a skill-separating equilibrium- there is no skill 
mismatch and workers are always employed in the best job they can get with their skills. The second equilibrium occurs if Condition 1 from section 2.7 is satisfied, i.e. if workers ranked high are willing to accept lower-paying jobs and firms are willing to hire them at a higher cost. In other words, if the match generates a positive surplus. If this is the case, the skill-pooling equilibrium realizes and highly qualified workers accept lower qualifying jobs down the occupational ladder. In the third sub-period production begins. Otherwise, the worker remains unemployed and the sorting mechanism starts all over again in the following period.

\section{A.2. Model Estimation: Further Discussion}

Here I continue to discuss the methodology I use to estimate the model. For a better understanding, I clarify first how the model is solved and dynamics are built. As explained in Section 2, the model moves over time following the RBTC trend (which governs the pace at which the labor market polarizes in the long-run). At the same time, I assume that the share of LS declines over time in order to feed the model with realistic demographic dynamics. Therefore, I need first to extract the long-run employment dynamics and change in labor force composition by regressing the log of routine employment and the log of the LS share in the laborforce over a time-trend, for the window 1990-2005 (see Figure A.2). The corresponding $\beta$ s define respectively the targeted long-run growth rate in routine employment (as reported in Table 2, Section 3) and the preset parameter $g_{L S}$ for the long-run growth rate of LS population share ${ }^{43}$ (as reported in Table 1, Section 3). If the latter is used to incorporate the secular change in laborforce composition, the former is used to estimate the technological growth rate $g_{z_{r}}$ necessary to explain the secular decline in routine employment. It is important to stress that assuming $z_{r}$ and the LS population share to follow a trend for $T=44$ periods simplifies substantially the estimation procedure. In fact, it allows solving the model backward from a final steady-state (in $T=44$ ) to an initial one (in $T=0$ ) such that I do not need to estimate all the parameters of the model twice for two different equilibria. At the same time, this methodology allows to build the counterfactual dynamics of the economy if the GR would have not occurred (i.e. if the economy would have followed the trend from 2008Q1 onwards). Therefore, knowledge of $g_{z_{r}}, g_{L S}$ and $T$ allows to simulate the long-run trend for all variables and to forecast where the economy is supposed to end-up in $T$ periods. Once this is done, I can study the deviation of the economy from the trend

\footnotetext{
${ }^{43}$ The decline in the LS population share is isomorphic to the process governing $z_{r}$ : the share of LS workers in the economy is declining for $T$ periods, and then it remains constant.

${ }^{43} T$ is set equal to 44 because it is -roughly- the number of periods it takes for unemployment to go back to its natural level, i.e. the pre-recession mean of unemployment as evaluated between 2005Q1 and 2007Q4
} 
Fig. A.2. Linear Trends for Routine Emp. and LS Share
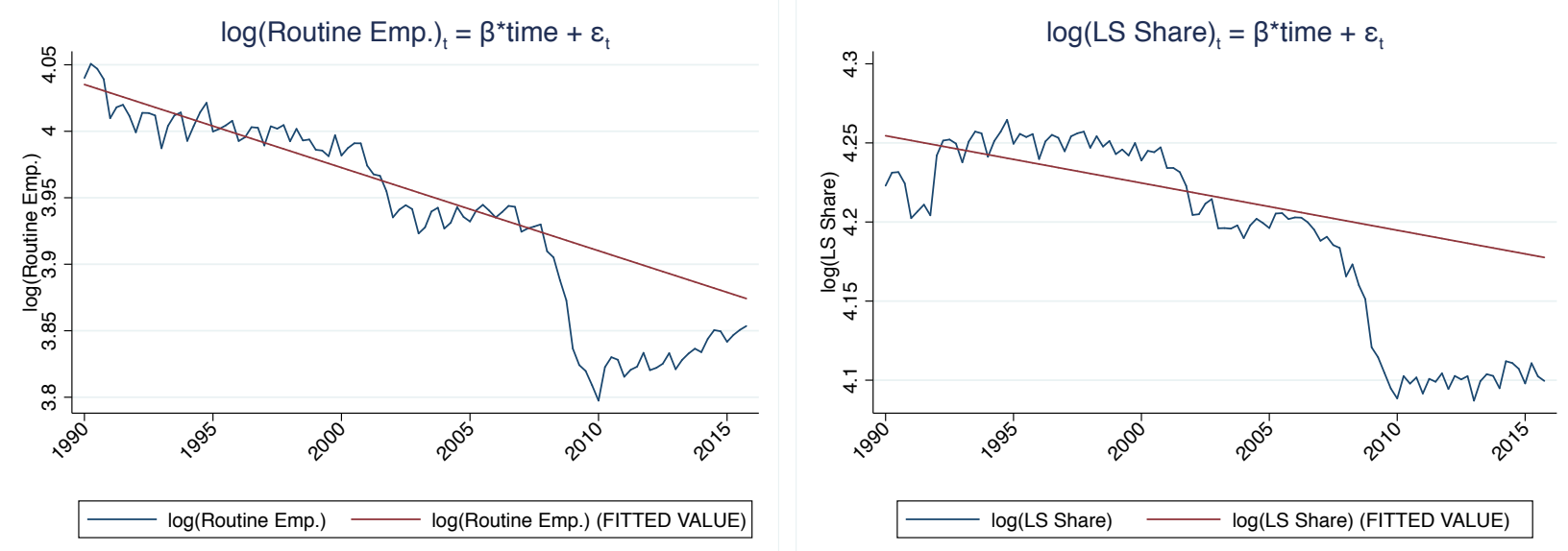

Note: This figure plots the time-series of the logarithm of routine employment (left-panel), and the logarithm of the share of LS workers in the population (right-panel). The linear trend for the two series is plotted in solid red.

under a first-order Taylor expansion (see Schmitt-Grohé and Uribe (2004)), with agents' expectations based on knowledge of the direction of the economy.

Given this structure, to estimate the model I use an annealing algorithm in which every iteration develops conceptually in three steps. First, it draws random parameters in a neighborhood of some initial point in the parameter space and solves the model in order to match aggregate employment rates, workforce composition by job, unemployment composition and wage ratios by job and skill-group for 2005Q1. By doing so, the algorithm pins down what are the parameters that characterize the labor market at an initial point in time. In particular, mean aggregate employment rates and employment composition by job (overall 6 moments) help to estimate the technological parameter $z_{a}$ and $z_{m}$, the matching efficiency parameters $\psi_{a}, \psi_{r}, \psi_{m}$, and the threshold $\gamma$. Relative wages and unemployment composition (5 moments) helps to identify vacancy posting costs $c_{a}, c_{r}$ and $c_{m}$ and returns to skills $\lambda_{a}$ and $\lambda_{r}$. More precisely, the vacancy costs and the returns to skill define wages, relative wages and therefore the value of production for the employers; the latter endogenously defines the minimum skill-requirements for routine and abstract jobs. Finally, the requirements pin down the composition of the unemployment pool. In the second step, once computed the initial point for the endogenous variables, the algorithm draws a growth rate for $z_{r}$, then it simulates the time-series of the model along the RBTC trend for $T$ periods, and check if the secular decline in routine employment corresponds to the negative growth rate as observed in the data (see Figure A.2, left-hand panel), i.e. the secular decline in routine employment identifies the RBTC process. As explained, this allows building a counterfactual dynamic of the model in case the GR would have not happened or -in other words- a forecast of where the economy should be in each point in time after 2008Q1. In the last step, at the $13^{\text {th }}$ 
period of the simulation (equivalent to 2008Q1), an aggregate negative shock happens and it propagates within each occupation through the job-specific weight $\sigma_{j}$ and with a persistence governed by $\rho$ (4 parameters). Information on the job-specific decline in employment between the peak and trough of the GR and unemployment auto-correlation are collected so to match those observed in the data (4 moments). In this way, I have 16 parameters for 16 moments.

For every iteration $n$, all moments from the simulation are stored along with the generating parameters in order to evaluate the loss function

$$
L_{n}=\left[m_{n}-m_{n}(p)\right]^{\prime} W_{n}\left[m_{n}-m_{n}(p)\right]
$$

with $W_{n}$ being an identity matrix, $m$ is vector of observed moments and $m(p)$ is the vector of moments generated from the vector of parameters $p=\left[p_{1}, p_{2}, \ldots, p_{16}\right]$. The simulated annealing algorithm repeats the procedure for 50000 iterations (starting from four different initial points of the parameter space) and "cools down" in the subset of the parameter space where the loss function is minimized. Whatever is the starting point among the four initially supplied, the vector minimizing the loss function is the same (at the 5th decimal digit).

\section{A.3. Match-specific Surplus and Validation of the Skill-pooling Equilibrium}

As it is clear from the data, in each occupation there is a mix of agents coming from different parts of the skill distribution, i.e. there is a skill-pooling equilibrium. Even though the estimated parametrization generates a workforce skill composition across occupations close to the data, yet it is crucial to check whether it respects the theoretical condition over the match-specific surplus, as expressed in condition 1 from Section 2.7.

In light of this, I compute -under free entry condition and Nash bargaining- the matchspecific surplus generated from worker with skill-level $x$ when meeting a technology $z_{j}$ :

$$
\begin{aligned}
S\left(x ; z_{j}\right) & =J\left(x ; z_{j}\right)+\left[N\left(x ; z_{j}\right)-U(x)\right] \\
& =J\left(x ; z_{j}\right)+\frac{\eta}{1-\eta} J\left(x ; z_{j}\right) \\
& =\frac{1}{1-\eta} J\left(x ; z_{j}\right) .
\end{aligned}
$$

Figure A.3 plots the job-specific surplus functions over skills (for $x \in[0,1]$ ). Consider first the surplus generated by matching skills with the "abstract" technology $z_{a}$ : the surplus is increasing in $x$ and convex due to the estimated parameters $\lambda_{a}>1$. As imposed by 
equation 4 , the surplus is positive for values of $x \geq e_{a}$ such that no match is formed for any other value. The surplus function looks different in the routine market: the function grows in a concave fashion due to the estimated return to skill $\lambda_{r} \in(0,1)$ and it takes negative values for $x<e_{r}$. Notably, the curve changes intercept for $x \geq e_{a}$ since individuals who are qualified for an abstract job must be paid more due to larger outside options. This erodes the surplus of the match thus leading to a vertical fall of the curve. For the same argument, the surplus generated in the manual occupation looks like a ladder: for $x<e_{r}$ the surplus is at its highest level, for $x \in\left[e_{r}, e_{a}\right)$ it falls due to the fact that the firm must pay more those individuals with both manual and routine jobs in their opportunity set, for $x \geq e_{a}$ the surplus falls to its lowest level due to higher wages paid to those workers with full mobility over the job ladder. Since manual production does not depend on skills, the curve is flat in each portion of the $x$-domain. Most importantly, even though the surplus function in the last two jobs falls (i.e. the curve changes intercept) for increasing values of $x$, it still remains positive. This ensures that a skill-pooling equilibrium is possible, i.e. highly skilled workers still find profitable to move down the ladder and employers can bear these extra costs. Condition 1 holds.

Finally, in order to validate the equilibrium over time, I check if the surplus condition holds along the transition generated by the simulation of Section 4. Figure A.4 plots the surplus over the skill distribution and time and for each occupation. Under the same argument above, the surplus in abstract and routine jobs is negative for values respectively below $e_{a}$ and $e_{r}$ which are varying over time such that the portion of individuals qualified for each job is also time-varying. Notice that, in the routine market, overqualified individuals $\left(x \geq e_{a}\right)$ generate a lower surplus with respect to the others but the value of the match remains positive along the transition although the change of intercept. This is true also in the manual

market: the value of the match remains positive along the transition in all portions of the $\mathrm{x}$-domain.

\section{A.4. The Role of Heterogeneous $\sigma_{j}$}

In this model, asymmetric shocks are necessary for the model in order to replicate occupational dynamics. Here I illustrate this fact by plotting the dynamics of routine employment and unemployment in three different cases: (i) when $\sigma_{j}=0.1, \forall j=\{a, r, m\}$; (ii) when $\sigma_{j}=0.2, \forall j=\{a, r, m\}$; (iii) when $\sigma_{r}=0.2$ and $\sigma_{a}=\sigma_{m}=0$. Consider Figure A.5. When the negative shock hits and $\sigma_{j}=0.1, \forall j=\{a, r, m\}$, routine employment falls less than in the data even though unemployment increases as much as observed. This suggests that a small common negative shock across occupation cannot match employment dynamics. This idea 
Fig. A.3. Match-specific Surplus
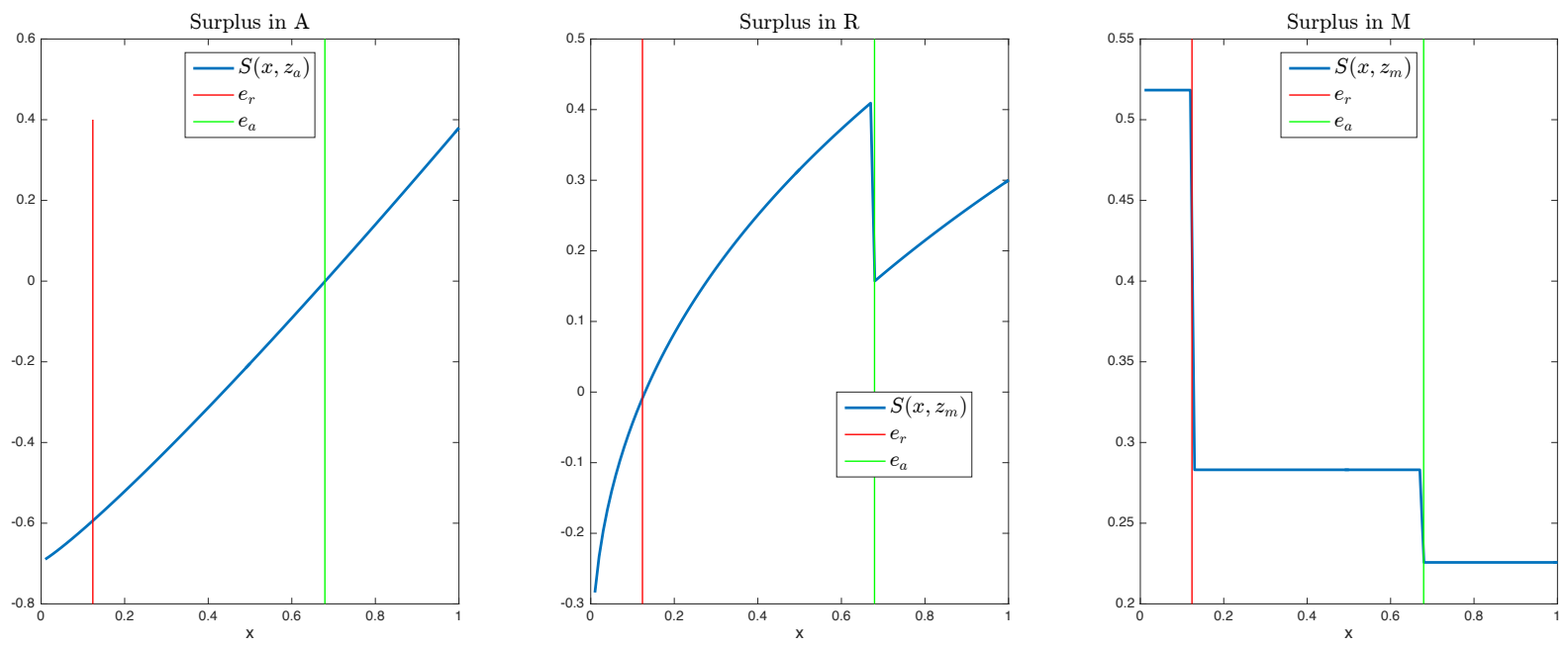

Note: This figure plots the value of the surplus $S\left(x, z_{j}\right)$ over the $[0,1]$ support of $\mathrm{x}$, for each occupation $j=\{a, r, m\}$ at the beginning of the simulation, i.e. at $t=0$.

Fig. A.4. Match-specific Surplus over Time
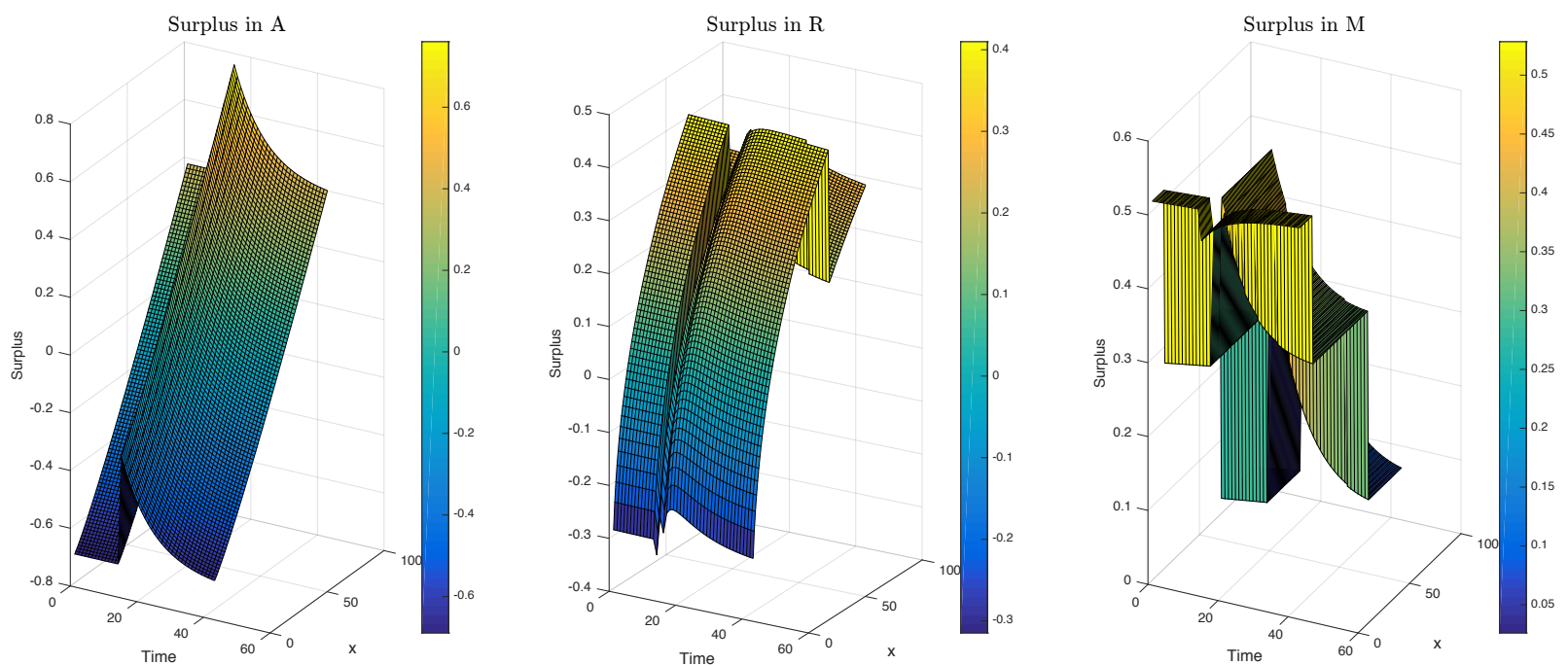

Note: This figure plots the value of the surplus $S\left(x, z_{j}\right)$ over the $[0,1]$ support of $\mathrm{x}$ and over time, for each occupation $j=\{a, r, m\}$.

is possibly clearer when considering $\sigma_{j}=0.2, \forall j=\{a, r, m\}$. Now the weight of the shock in the routine occupation is very close to the one estimated in Section 3 (see Table 3). However routine employment still falls less than what observed in the data, whereas unemployment now is way above the true level. This happens because $\sigma=0.2$ is too big for the abstract and manual submarket which shrink way too much once the shock hits. Finally, consider the case in which only the routine market receive the shock $\left(\sigma_{r}=0.2\right.$ and $\left.\sigma_{a}=\sigma_{m}=0\right)$. In this case, routine technology falls too much with respect to other technologies. There- 
Fig. A.5. Polarization and Unemployment: the importance of $\sigma_{j}$
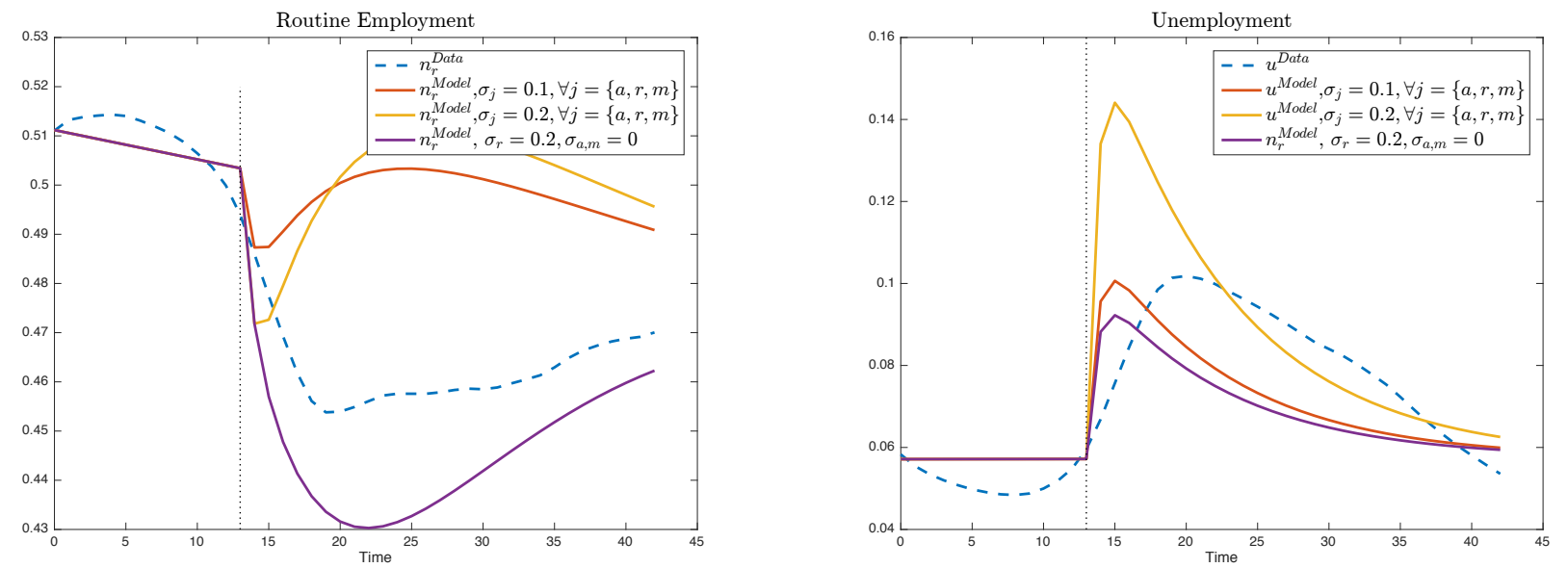

Note: This figure plots the dynamic of routine employment (left-panel) and unemployment (right-panel) for different values of $\sigma_{j}$ and compares it to the real data. For the first 12 periods, the economy is moving on a RBTC trend. On $t=13$, an aggregate shock hits the economy such that variables deviate from the trend, and the transition of the economy begins. The vertical dotted lines indicates the timing of the shock.

fore, routine employment collapses way more than in the data. However, the unemployment wave is smaller than in the data. This happens because the abstract and manual submarket expand a lot at the moment of the shock so that almost half of the displaced workers from the routine market reallocate immediately in other occupations. Figure A.6 shows results for group-specific employment shares across jobs under the three different parameterization of $\sigma$. As evident, group-specific employment dynamics differ a lot in the three scenarios. In particular, a common $\sigma$ reverses the dynamic of HS and LS employment share in manual jobs, and also in routine jobs for LS workers.

To conclude, heterogeneity in $\sigma$ is not only key to match aggregate employment dynamics, but allows to match correctly the implied reallocation patterns of HS and LS workers. In other words, it is sufficient to target only aggregate job dynamics in the estimation procedure to replicate well the reallocation patterns of skills over the job ladder.

\section{A.5. The Role of the RBTC Trend}

As explained in Section 2.2, the RBTC process is modeled as a trend in $z_{r}$. The growth rate governing the trend is estimated in Section 3 and is negative in order to match the longrun decline of routine employment. Moreover, the trend lasts only for $\mathrm{T}$ periods in order for the model to be solved backwards. Hence, to put the economy on the trend is equivalent to study the (counterfactual) case in which no recession occurs and the economy converges to the terminal point. When the economy is shocked, agents have perfect foresight and forecast where the economy will end up. In other words, the transition of the economy out of the 
Fig. A.6. Employment Shares by Skill-Group: the importance of $\sigma_{j}$
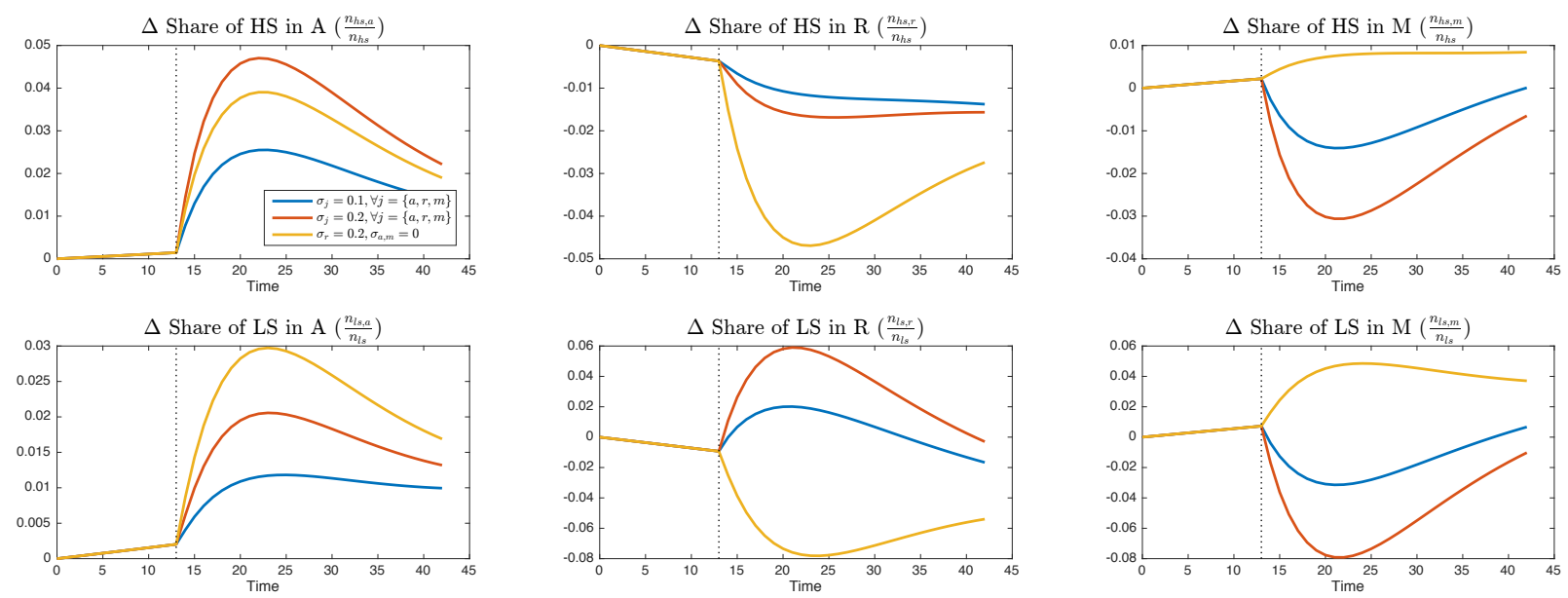

Note: This figure plots the change in the skill-group employment share by occupation for different values of $\sigma_{j}$. For the first 12 periods, the economy is moving on a RBTC trend. On $t=13$, an aggregate shock hits the economy such that variables deviate from the trend, and the transition of the economy begins. The vertical dotted lines indicates the timing of the shock and its half-life.

trend toward the final steady-state implies that agents are conscious of the undergoing RBTC process already at the moment of the shock such that they perfectly foresight the structural change in the economy. Given this, the role of the trend is key to match occupational dynamics. In order to clarify this issue, Figure A.7 plots the response to the aggregate shock for different values of $g_{z_{r}}$. When $g_{z_{r}}=0$ the model is always at its steady-state: once the economy is hit by the shock, routine employment slowly goes back to its pre-recession level. However, this is not what we observe in the data. The fact that routine employment is permanently lower after the shock implies that a structural change occurred to the economy. In fact, for $g_{z_{r}}<0$, agents know what the final equilibrium will be once the economy jumps out of the trend at the moment of the shock. Therefore, the out-of-trend transition is governed by expectations on which direction the economy is moving to. This allows the model to replicate well the dynamic of routine employment when $g_{z_{r}}=\widehat{g_{z_{r}}}$, i.e. the estimated growth rate. Assume finally that $g_{z_{r}}=3 \widehat{g_{z_{r}}}$, then not only the decline in routine employment in the model is too fast with respect to the data, but also -once the shock hits- agents assume a final steady-state too "far" away from the initial one. This generates a too large permanent fall in routine employment. 
Fig. A.7. Polarization and RBTC: the importance of the technological trend
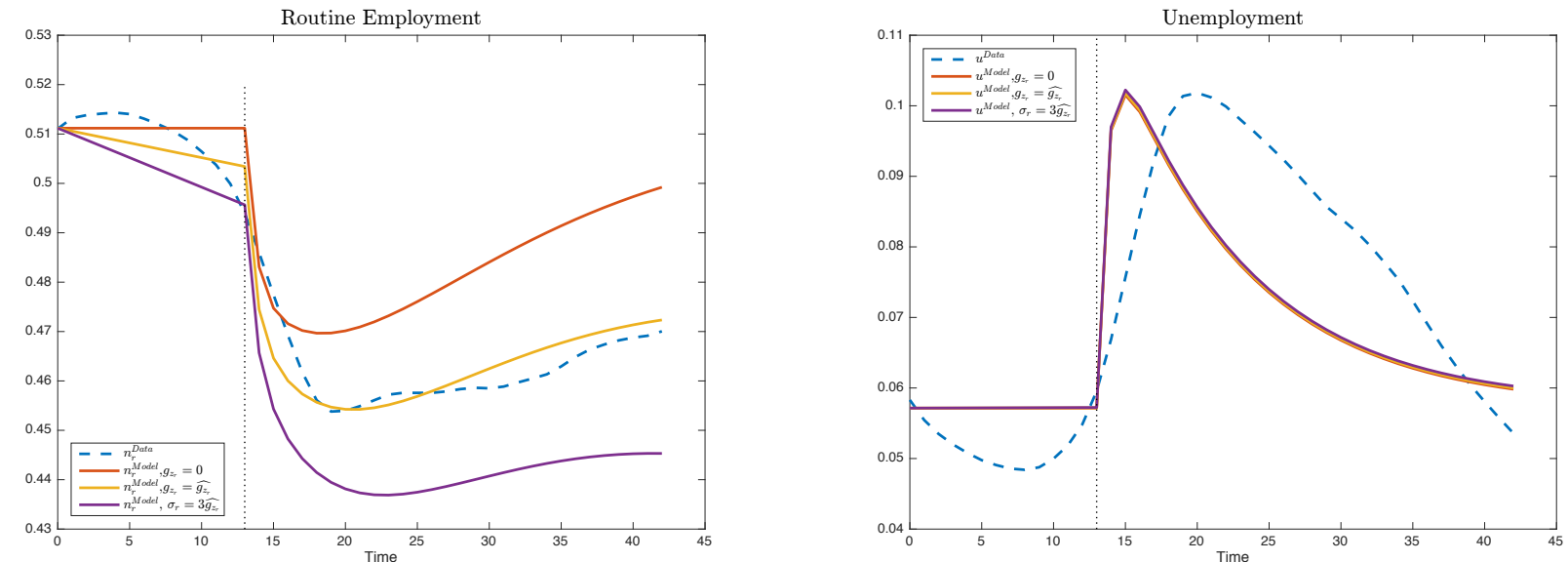

Note: This figure plots routine employment for different values of $g_{z_{r}}$ and compares it to the real data. For the first 12 periods, the economy is moving on a RBTC trend. On $t=13$, an aggregate shock hits the economy such that variables deviate from the trend, and the transition of the economy begins. The vertical dotted lines indicates the timing of the shock and its half-life. The dashed line is the series of routine employment from the data.

\section{A.6. A Note on the Social Planner}

\section{A.6.1. Economy vs. Planner}

The social planner solution differs from the decentralized economy solution only for the vacancy creation condition. Here, I report both conditions. Under the decentralized solution, the vacancy posting condition in market $j$ is

$$
c_{j}=\beta p_{j} \mathbb{E}\left\{(1-\eta)\left[y\left(x ; z_{j}^{\prime}\right)-b\right]-\eta\left\{\sum_{j \in \Omega(x)} c_{j} \theta_{j}^{\prime}\right\}+\frac{(1-\delta) s_{j}^{\prime}(x) c_{j}}{p_{j}^{\prime}}\right\}
$$

On the other hand, under the planner solution it is:

$$
c_{j}=\beta p_{j} \mathbb{E}\left\{(1-\alpha)\left[y\left(x ; z_{j}^{\prime}\right)-b\right]-\alpha c_{j} \theta_{j}^{\prime}+\frac{(1-\delta) s_{j}^{\prime}(x) c_{j}}{p_{j}^{\prime}}\right\} .
$$

In light of this, it is clear that the two solutions coincide if the decentralized economy delivers a skill-separating equilibrium under Hosios condition $(\eta=\alpha)$.

Therefore, it is possible to study which policy instruments can allow the economy and the planner solution to match.

Lump-sum Taxes Assume that a lump-sum tax $\tau_{j}(x)$ is imposed on wages such that the wage equation now is: 


$$
w\left(x ; z_{j}\right)=(1-\eta) b+\eta y\left(x ; z_{j}\right)+\eta\left\{\sum_{j \in \Omega(x)} c_{j} \theta_{j}\right\}-\tau_{j}(x) .
$$

Then, by solving allover the problem for the decentralized economy and by equating the resulting vacancy posting condition with the one from the social planner, it is easy to show that the optimal tax in job $j$ for worker $x$ is:

$$
\tau_{j}^{*}(x)=\eta\left\{\sum_{i \neq j \in \Omega(x)} c_{i} \theta_{i}\right\}
$$

In words, it is optimal to tax each individual $x$ in occupation $j$ by the value of the outside option given from searching in other markets $i \neq j$ available in his job opportunity set $\Omega(x)$.

Vacancy Costs Subsidization Assume that a subsidy $\xi_{j}(x)$ can be given to lower vacancy posting $\operatorname{cost} c_{j}$, then the vacancy posting condition for the decentralized economy would be:

$c_{j}-\xi_{j}(x)=\beta p_{j} \mathbb{E}\left\{(1-\eta)\left[y\left(x ; z_{j}^{\prime}\right)-b\right]-\eta\left\{c_{j}-\xi_{j}(x)+\sum_{i \neq j \in \Omega(x)} c_{i} \theta_{i}^{\prime}\right\}+\frac{(1-\delta) s_{j}^{\prime}(x)\left(c_{j}-\xi_{j}(x)\right)}{p_{j}^{\prime}}\right\}$.

By equating this to the vacancy posting solution for the social planner, and then solving for $\xi_{j}(x)$ gives the optimal subsidy when employer $j$ creates a vacancy for worker $x$ :

$$
\xi_{j}^{*}(x)=\frac{\beta p_{j} \eta \mathbb{E}\left\{\sum_{i \neq j \in \Omega(x)} c_{i} \theta_{i}^{\prime}\right\}}{\mathbb{E}\left[\beta p_{j} \eta \theta_{j}^{\prime}+\frac{(1-\delta) s_{j}^{\prime}(x)}{p_{j}^{\prime}}\right]+1} .
$$

In words, the optimal subsidy in market $j$ must be a fraction of the value of all other possible outside options for worker $x$.

\section{A.6.2. Simulations under the Social Planner Solution}

As explained in Appendix A.2, the simulations plotted in Figure 2 to 6 for the decentralized economy are build as follows: (i) the model is put on the RBTC linear trend for $\mathrm{T}=44$ quarters, and all series of the endogenous variables are stored; (ii) I take a first-order Taylor expansion of the model around the trend and feed the model with a shock a $t=13$. The shock put the economy out of the trend, such that dynamics of convergence are regulated by the eigenvalues computed from the linear approximation of the economy (see Schmitt-Grohé and Uribe (2004)).

When comparing the planner and the economy as in Figure 6 and 7, I build a first-order 


\section{Fig. A.8. IRFs under RBTC and temporary shocks (Planner Solution)}
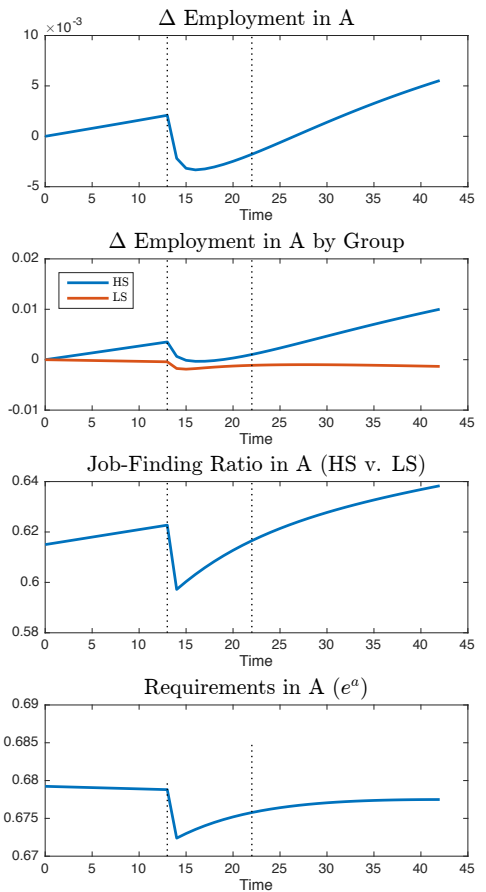

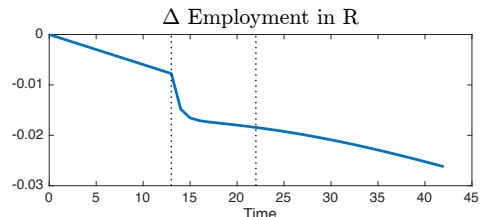

$\Delta$ Employment in R by Group

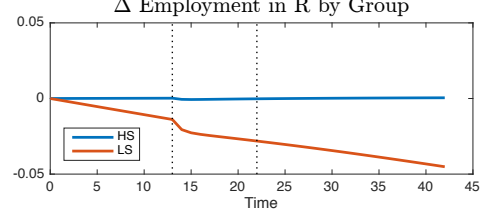

Job-Finding Ratio in R (HS v. LS)
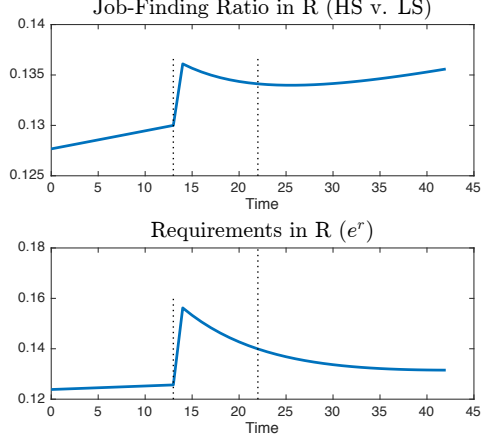
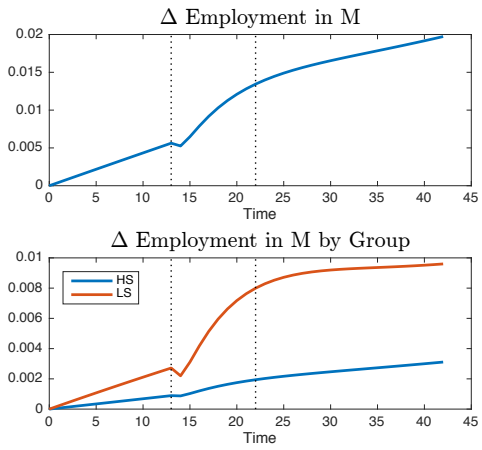

Job-Finding Ratio in M (HS v. LS)
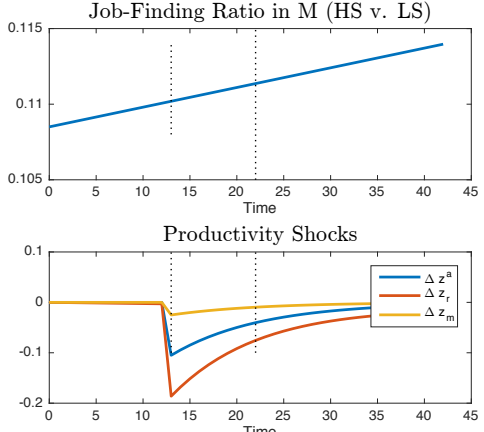

Note: This figure plots endogenous variable dynamics under the social-planner solution. These variables are the changes in aggregate employment rate by job, changes in employment rate by skill-group and job, the ratio of the HS and LS job-finding rates by job, the skill-requirements dynamics and the change in job-specific technology. For the first 12 periods, the economy is moving on a RBTC trend. On $t=13$, an aggregate shock hits the economy such that variables deviate from the trend, and the transition of the economy begins. Vertical dotted lines indicate respectively the timing of the shock and its half-life.

\section{Fig. A.9. Polarization and Unemployment: planner vs. data}
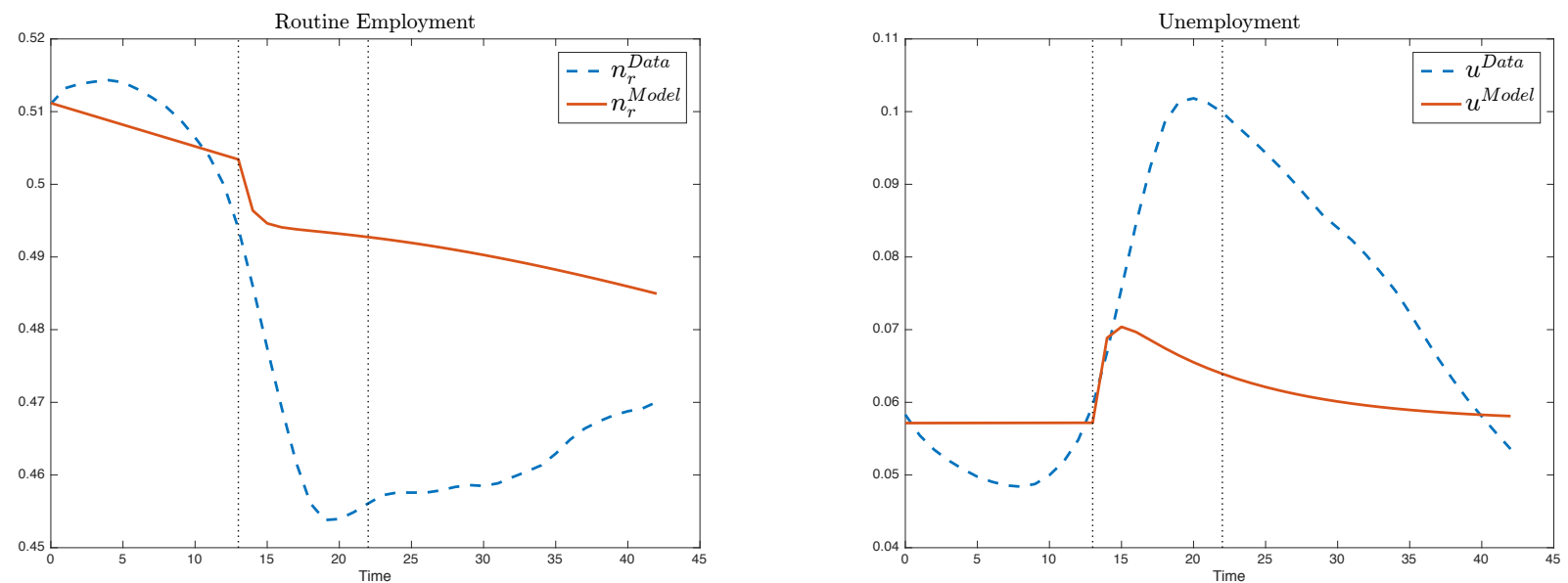

Note: This figure plots the evolution of routine employment and aggregate unemployment generated under the social planner solution, and compares it with the time-series from the data. For the first 12 periods, the economy is moving on a RBTC trend. On $t=13$, an aggregate shock hits the economy such that variables deviate from the trend, and the transition of the economy begins. Vertical dotted lines indicate respectively the timing of the shock and its half-life.

Taylor expansion of the solution to the planner problem (as introduced in Section 4.3) around the same trend of the decentralized economy. In other words, I am assuming that the planner 
Fig. A.10. Employment Shares by Skill-Group: planner vs. data
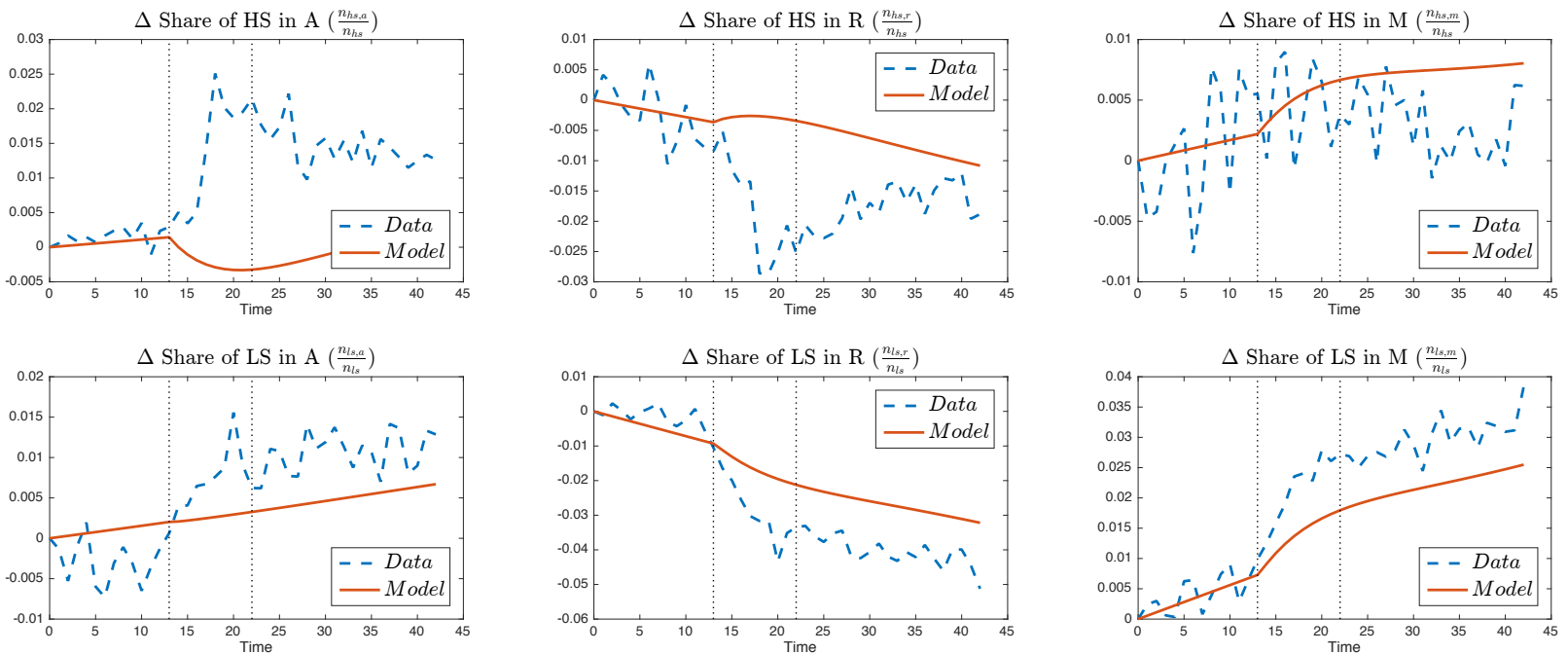

Note: This figure plots the change in the skill-group employment share by occupation as generated under the social planner solution, and compares it with the time-series from the data. For the first 12 periods, the economy is moving on a RBTC trend. On $t=13$, an aggregate shock hits the economy such that variables deviate from the trend, and the transition of the economy begins. Vertical dotted lines indicate respectively the timing of the shock and its half-life.

Fig. A.11. Emp. Mismatch Dynamics for HS and LS workers
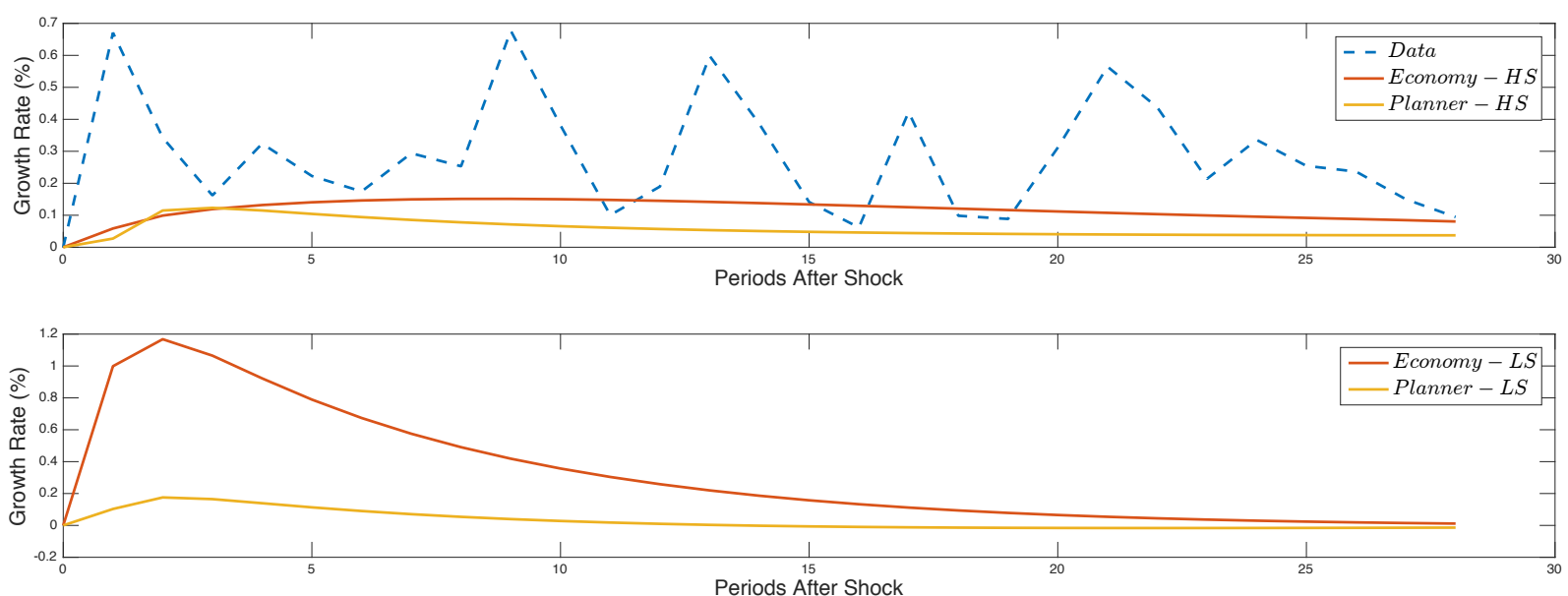

Note: This figure plots growth rate of HS and LS employment mismatch -i.e. the employment rate of workers not matched with the best technology available in their job opportunity set- when the economy is transitioning after the aggregate shock realizes. The upper panel plots series for HS employment mismatch under the decentralized and planner solution, and the dynamics of mismatch from the data (HS employment mismatch is equal to HS employment in routine and manual jobs and it can be calculated directly from the data). The lower-panel plots mismatch dynamics for LS workers under the decentralized and planner solution.

operates only when there is a deviation from the long-run path of the decentralized economy. In this way, once the shock hits, the dynamics for the planner and the economy depart from the same levels. Hence, the centralized and decentralized solutions are fully comparable over the transition. Figure A.8 plots the dynamics of the endogenous variables of the model when the social planner takes action once the same temporary shock realizes. Figure A.9 plots the time series for routine employment and aggregate unemployment as generated under 
the social planner solution and compares it with the data. Figure A.10 plots the change in the employment shares across jobs for each skill-group and compare it with the data. These three graphs combined show that -under the social planner solution- routine employment does not collapse that much once the economy is hit by a shock, and unemployment increases less than under the decentralized solution. In other words, the cyclical dynamics of job polarization are drastically attenuated under the social planner solution. Notice that, in this case, abstract employment falls by more and more persistently. In fact, the planner is shrinking the abstract market in order to move very qualified workers from the top of the job ladder to the routine market, so to enlarge the skill-pooling equilibrium in the latter. This helps routine employers to better cope with the negative shock and compensate for the fall in routine labor productivity through a more productive labor force. For this reason, under the social planner solution, the employment share of HS workers in routine jobs increases once the shock hits, whereas it falls in the abstract market. On the other hand, the employment share of LS workers now fall just a little in the routine market and does not expand much in the manual market.

Figure A.11 (upper panel) compares the dynamic of HS employment mismatch from the data with the economy and the planner solution. Since HS employment mismatch is equal to HS employment in routine and manual jobs, I can compare directly the evolution of the time-series generated by the model with the original data. As evident, the model replicates fairly well the evolution of HS employment mismatch. It is worth to underline that the dynamics of HS mismatch generated from the economy is very close to the one generated by the social planner. In other words, having some HS workers moving down the ladder is efficient. The lower panel of Figure A.11 shows the dynamics of mismatch for LS workers. In this case, the difference between the economy and planner solution is large. As explained above, the planner -by minimizing the destruction of routine jobs- reduces LS employment mismatch.

\section{Appendix B. Flows from Unemployment to Job by Skill- Group}

Figure A.12 plots flows from unemployment to employment for high and low-skilled workers. Every flow is normalized by the group-specific unemployment level.

Figure A.12(a) plots the share of HS workers who transition to abstract jobs. Such tran-

\footnotetext{
${ }^{43}$ Differently, in order to study LS employment mismatch, I have to filter the data with $\gamma$ and the timeseries of $e_{a}$ and $e_{r}$ as generated from the model. Under this procedure, I study the evolution of aggregate employment mismatch as in Figure 5.
} 
sition probability peaks at the end of the downturn and then declines rapidly. This dynamic is consistent with the predictions of the model as from Figure 5. In fact, the best timing for a HS workers to enter an abstract job is just after the shock, when the demand for skills is at its highest level and vacancy posting rebounds in this market. However, the persistence of such dynamic is very low, i.e. this transition probability goes back to the pre-recession level very quickly. On the contrary, the more persistent shock in the routine sector and the more persistent demand for higher-skills there create more chances for the HS unemployed to flow into routine jobs during the recovery. In fact, as plotted in Figure A.12(b), while the probability to get an abstract job declines during the recovery and next expansion, the probability to fill a routine vacancy increases and stays temporarily higher during the same periods. In other words, during the post-recession era, we observe temporary mismatch patterns of HS workers into routine jobs. Figure A.12(c) plots the transition probability for a HS unemployed to manual jobs. The series follows a slightly increasing trend. Also the pattern

Fig. A.12. Flows from Unemployment to Job

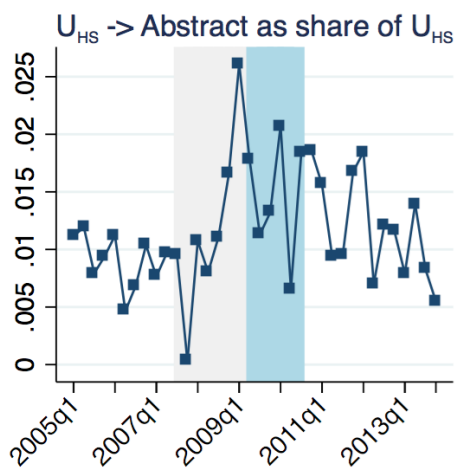

(a)

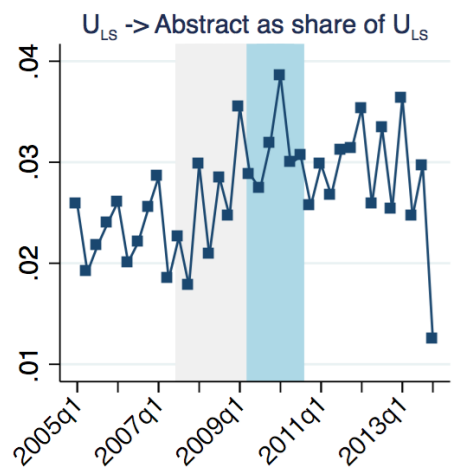

(d)

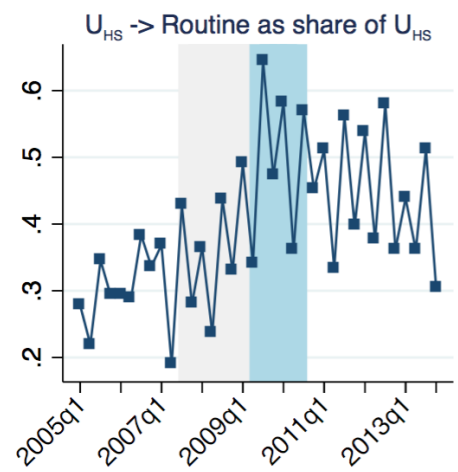

(b)

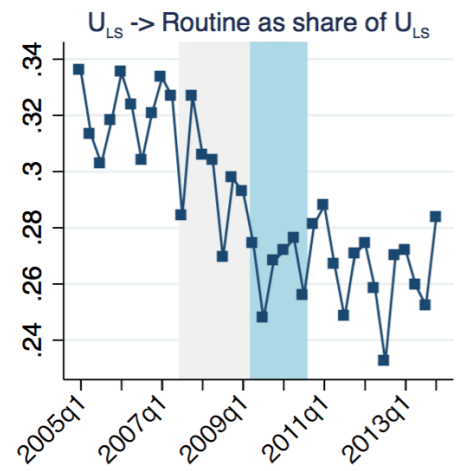

(e)

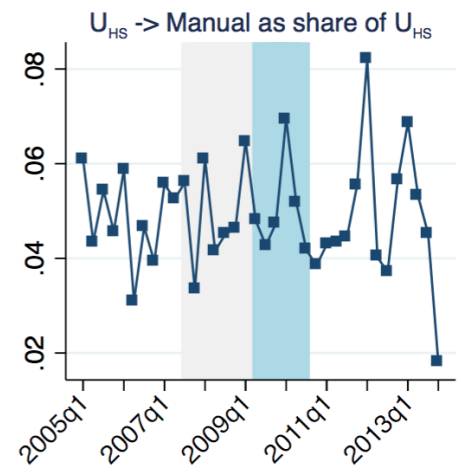

(c)

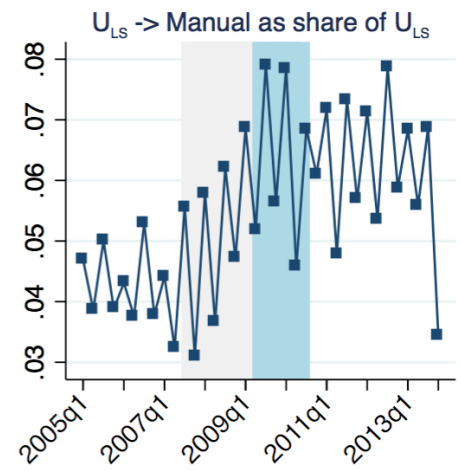

(f)

Note: This figure plots flows from unemployment to employment, by skill-group and job. The grey and green shaded areas indicate respectively recession and recovery periods as defined by the NBER. Data is at quarterly frequency. 
of sorting of LS workers is very similar to the one described in Figure 5. As from Figure A.12(d), the share of LS unemployed workers that reach the abstract market increases very persistently. The largest fall in the transition probability is in the routine market (Figure A.12(e)), where flows fall during the recession and stay permanently low afterward. Again, this corroborates the idea that the routine sector sizes down and persistently seeks highskilled workers in the post-recession era. Finally, as plotted in Figure A.12(f), the transition probability increases and stays permanently high in the manual market, suggesting that this is the occupation through which LS employment recovers.

To sum up, the transition probabilities for LS workers permanently change in favor of non-routine jobs, with LS workers getting more manual jobs than abstract ones in the postrecession era. On the contrary, the transition probability for a HS workers to get non-abstract jobs is higher during the recovery. However, such a change is not as persistent as the change in transition probabilities for LS workers: the chances for a HS workers not to get an abstract job increase only temporarily in the post-recession era.

\section{Appendix C. Participation, Non-Participation and Pop- ulation Dynamics}

Participation and demographic dynamics matter and explain why we observe aggregate employment reverting to its natural level in the data but not in the model. Figure A.13 shows the evolution of participation and non-participation margin for HS and LS workers and their share out of the total population. The share of HS workers in the population is growing over time and tracks well both the participation and non-participation margin. This dynamic is explained by the secular growth in higher education.

For LS workers, the dynamic is different. Overall, they are progressively disappearing over time with the population share tracking well the participation margin. However, from the middle of the recession onwards, the non-participation and participation margin divert. This suggests that, despite population dynamics, the rate at which LS workers quit the labor force for non-participation was endogenous and not determined by demographics, and triggered by the dramatic change in the employment structure and by fewer job opportunities.

\section{Appendix D. Data Construction}

Occupations and Skill-Groups The CPS is a monthly U.S. household survey and it is representative of the civilian populations of the U.S.A. In each month around 70,000 
Fig. A.13. Participation (HS vs. LS)
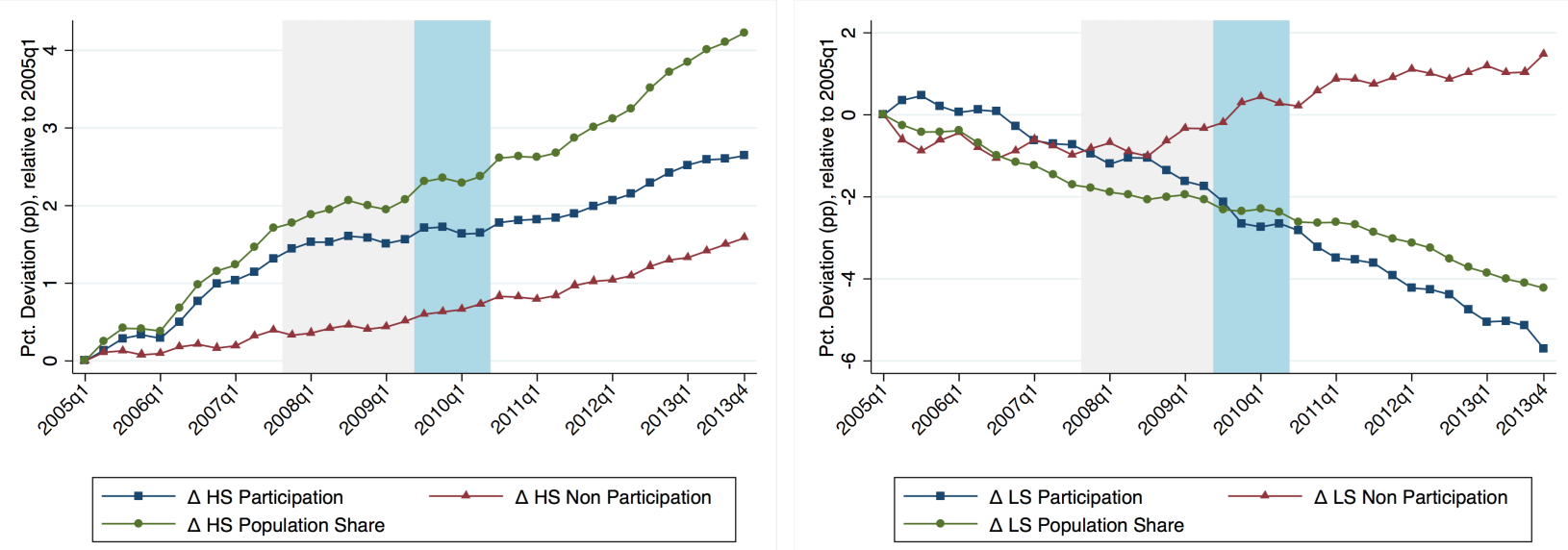

Note: This figure plots changes in participation, non-participation and populations share for HS (left-panel) and LS (rightpanel). Participation and non-participation by skill-group are divided by total population so that the two sum up to the group specific share. The grey and green shaded areas indicate respectively recession and recovery periods as defined by the NBER. Data is at quarterly frequency.

households are interviewed. More precisely, household members are surveyed in 4 consecutive months, then they leave the sample for the following 8 months, then are interviewed for 4 consecutive months again and leave forever. Thus, the CPS 4-8-4 rotating structure gives two types of information: (i) by using the cross-sectional dimension of the survey, I build employment rates and shares of each skill-group into each type of occupation; (ii) by using the longitudinal dimension of the survey, I match respondents in consecutive periods in order to study the flows from unemployment to employment for each type of skill-group into each type of occupation. Given the sampling structure and recent development of new linking algorithms ${ }^{44}$, up to 95 of the individuals are potentially matched across consecutive months. The remaining 5 is lost due to attrition.

Jobs are defined following Acemoglu and Autor (2011) where occupations are labeled according to the main task performed and the nature of the job into cognitive, routine-cognitive, routine-manual, manual. Slightly differently, here I collapse the two routine categories into one and leave the rest unchanged. Hence, there are three types of job:

- Abstract jobs: managerial and professional specialty occupations

- Routine jobs: technical, sales and administrative support occupations; precision production, craft, and repair occupations

- Manual jobs: service occupations.

For skills, agents are grouped by educational attainments into:

\footnotetext{
${ }^{44}$ The CPS is an address-based survey so that households that migrate or move to another address are not perfectly followed. For more details on the matching algorithm I use in this paper, see Madrian and Lefgren (1999) and more recent Drew, Flood, and Warren (2014).
} 
- High-Skilled: from 3 years of college to doctorate degree big lie

- Low-Skilled: from no education to one or two years of college (but no degree) or to a vocational program degree

Under this classification, I consider a sample of individuals aged between 16 and 75 years old, with a full-time job. All observations related to individuals occupied in Farming, Fishing, Forestry and Military activities and individuals reporting to be self-employed or in a part-time job are dropped from the sample. Then, I build national quarterly time-series and a quarterly State-level panel for employment rates and shares for each skill-group into each occupation for the years 2005-2015. All series are seasonally adjusted.

Causes of Exogenous Displacement I use the same classification of occupations and skill-groups to extract information on career and reallocation patterns from the Displacement Worker Supplement (DWS), a survey contained in the January CPS file. This survey is ran every two years and ask workers what is their current job, what was their previous job, when they started the new and previous job, when they interrupted the previous job, the hourly wage in the current and previous job, and the cause that led to the termination of the previous occupation. I track information for individuals whose cause of previous job interruption is exogenous, i.e. not dependent on their individual characteristics (see Topel (1990)). These reasons (coded under DWRES 01-03) are: (i) "Plant or company closed down or moved", (ii) "Plant or company operating but lost/left job because of insufficient work", (iii) "Plant or company operating but lost/left job because position or shift abolished". Job terminations because of seasonal cob completion or because of failure of self-operated business are excluded.

Job Openings and Labor Turnover Survey (JOLTS) Jolts data serve as demand-side indicators of labor shortages at the national level. This dataset reports aggregate vacancy openings, desegregated by main industries and sectors. I use aggregate vacancies and aggregate unemployment to compute the job opening rate, i.e. the ratio between vacancies and unemployment, and generate the graph on the right-hand side of Figure 9.

Gdp and Business Cycle Dummies I use data from the Bureau of Economic Analysis (BEA) to build a quarterly State-level panel for real Gdp for the years 2005-2013 (the only years currently available). Since the time of the Gdp peak and trough defined by the NBER to identify a recession period is not always consistent with the cyclical phases of each State economy, I define ad-hoc recession dummies for each of the 50 States. Precisely, I build an algorithm that determines for each State (i) the peak of Gdp closest in time to the NBER 
Fig. A.14. State-level Business Cycle Dates Definition
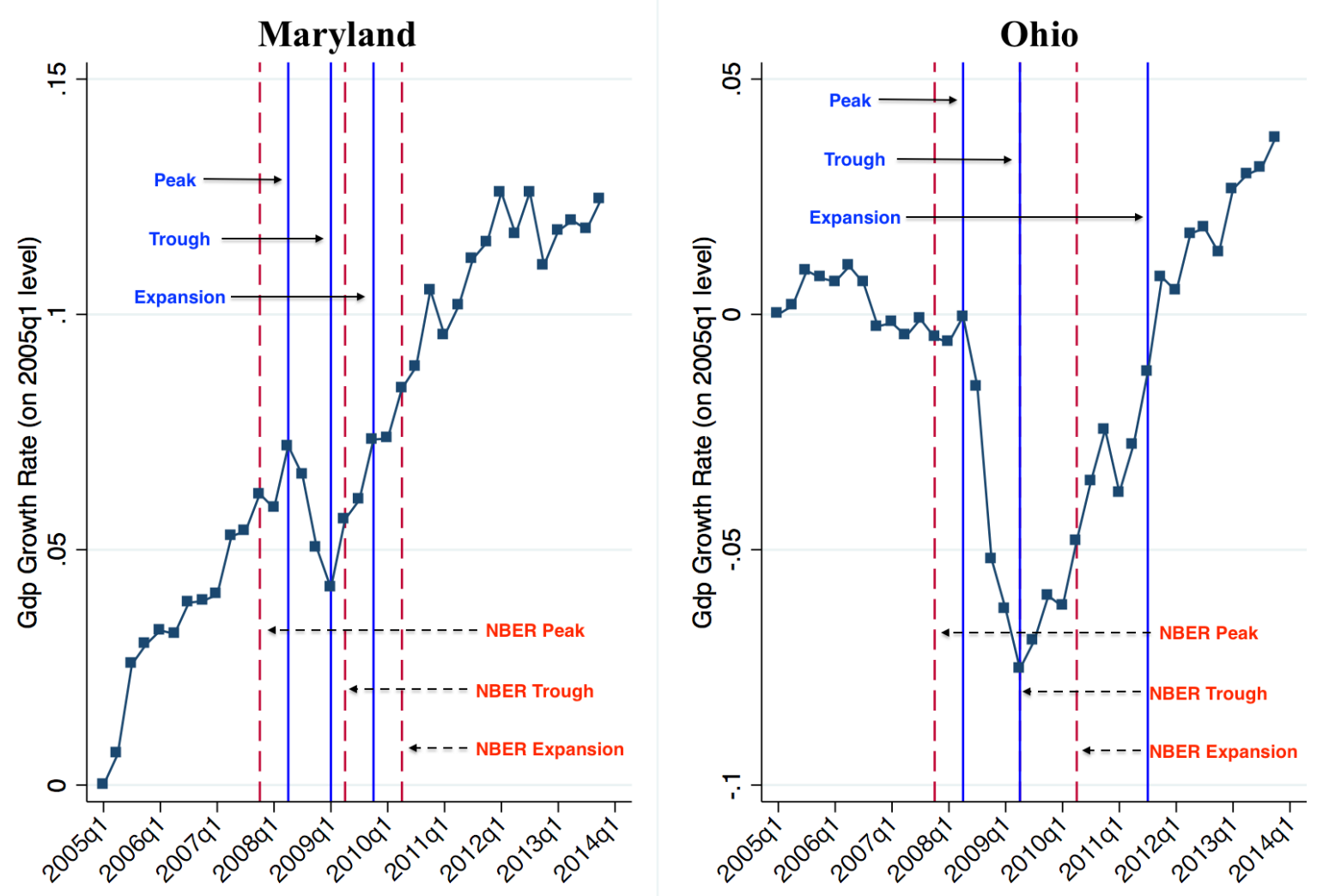

Note: This figure plots the Gdp Growth rate (relative to 2005q1) for Maryland (left-panel) and Ohio (right panel). In both sub-graphs, NBER peak and trough dates are in dashed red, whereas the state-specific peak and trough are in solid blue. Data is at quarterly frequency.

peak date and followed by at least two quarters of fall in GDP and (ii) the trough of Gdp closest in time to the NBER trough date and followed by an increase in Gdp in the following quarters. Recoveries are instead defined as the time window necessary for Gdp to go back to pre-recession level. In order to better grasp the time discrepancy between national and State-level cycles and how the algorithms define the turning points of each cycle, consider the examples reported in Figure A.14 for the State of Maryland and Ohio. For the State of Maryland, the peak of Gpd was not in 2007q4 -as defined by the NBER- but in 2008q1; the state-level trough occurred in $2009 \mathrm{q} 1$ and anticipated the national one by one quarter (2009q2); the beginning of the expansion started in 2009q4, while it occurred only in 2010q2 at national level. Differently, for the State of Ohio, the peak occurred in 2008q1, the trough occurred in 2009q2 and coincided with the NBER definition, while the state-level expansion started only in 2011q3. The same methodology is used for all other states with only one 
exception: North Dakota. In fact, there is no clear downturn for this State. In this case, I use the same business cycle dates as defined by the NBER.

Taking care of these discrepancies allows to better use state-level data and infer more precisely the evolution of employment through different economic phases in accordance with the state-level evolution of GDP.

Cyclical Polarization at State Level In Section 5.3, I use a simple measure of polarization capturing the degree to which the local market destroyed more routine jobs relative to non-routine ones during the Great Recession, i.e. how the ratio between non-routine and routine employment changed in local labor markets between the peak and trough of the business cycle. Consider

$$
\text { Polarization }_{s, G R_{s}}=\bigwedge_{G R_{s}}\left(\frac{\text { Employment }_{s}^{\urcorner R}}{\text { Employment }_{s}^{R}}\right)
$$

where $G R_{s}$ indicates that the change in the ratio of non-Routine to routine employment is evaluated between the beginning and the end of the Great Recession in state $s$.

Figure A.15 plots the measure of polarization by quintile across the US. The index is always positive, indicating that the structure of labor markets shifted in favor of non-routine occupations in all States during the Great Recession, with Washington D.C and Vermont at the upper and lower bound respectively.

Fig. A.15. State-level Polarization

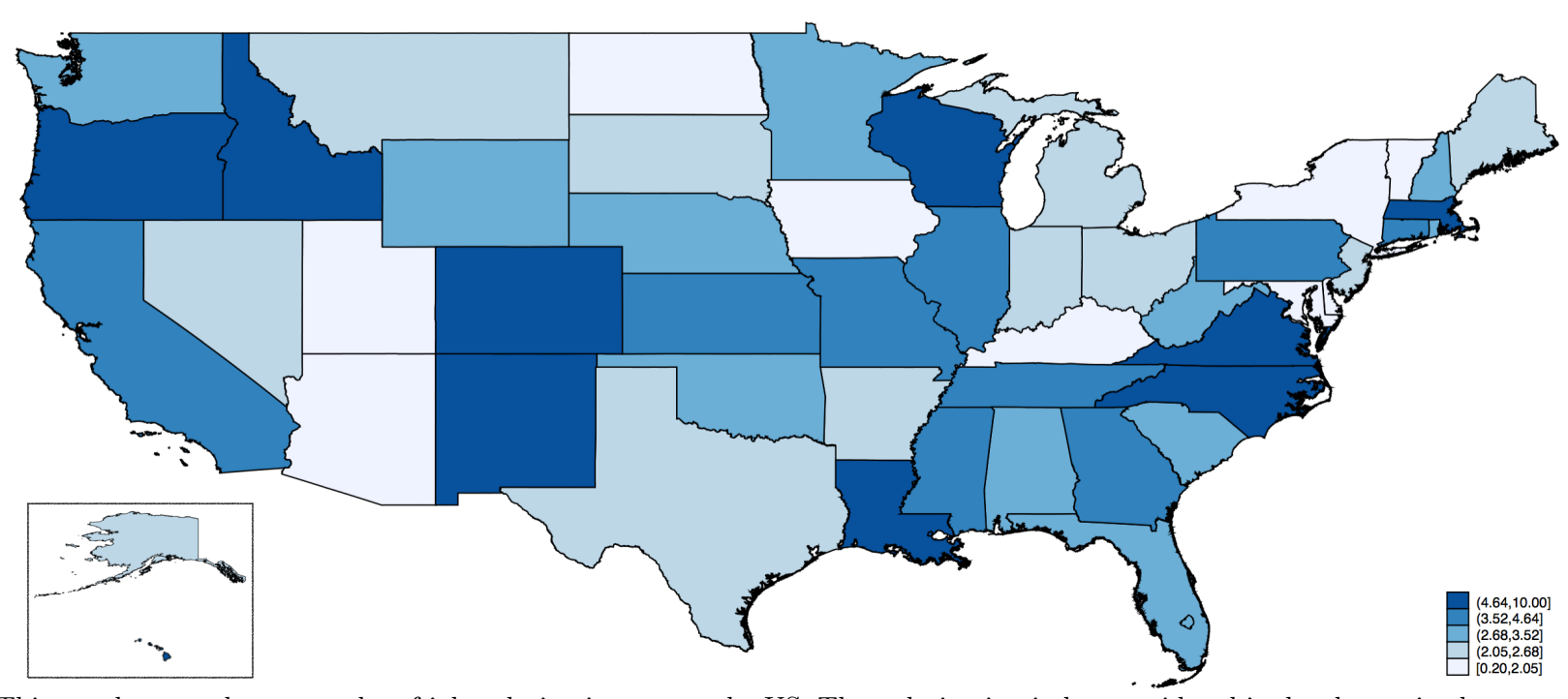

Note: This graph maps the geography of job polarization across the US. The polarization index considered is the change in the ratio of non-routine employment and routine employment. Such a change is evaluated between the peak and trough according to state-specific business cycle dates. 